\title{
Temporal Translation:
}

Exploring the perspectives of East and West

Selina Leung Sze Yu, B.A.S.

\author{
A thesis submitted to \\ The Faculty of Graudate Studies and Research \\ In partial fulfillment of the requirements \\ for the degree of \\ Master of Architecture \\ (M.Arch Professional)
}

Carleton Univeristy School of Architecture

Ottawa, Ontario, Canada

(c) 2008, Selina Leung Sze Yu 
Library and

Archives Canada

Published Heritage

Branch

395 Wellington Street Ottawa ON K1A ON4

Canada
Bibliothèque et

Archives Canada

Direction du

Patrimoine de l'édition

395 , rue Wellington Ottawa ON K1A ON4

Canada
978-0-494-40621-2

Your file Votre référence ISBN:

Our file Notre reterence ISBN:
NOTICE:

The author has granted a nonexclusive license allowing Library and Archives Canada to reproduce, publish, archive, preserve, conserve, communicate to the public by telecommunication or on the Internet, loan, distribute and sell theses worldwide, for commercial or noncommercial purposes, in microform, paper, electronic and/or any other formats.

The author retains copyright ownership and moral rights in this thesis. Neither the thesis nor substantial extracts from it may be printed or otherwise reproduced without the author's permission.
AVIS:

L'auteur a accordé une licence non exclusive permettant à la Bibliothèque et Archives Canada de reproduire, publier, archiver, sauvegarder, conserver, transmettre au public par télécommunication ou par l'Internet, prêter, distribuer et vendre des thèses partout dans le monde, à des fins commerciales ou autres, sur support microforme, papier, électronique et/ou autres formats.

L'auteur conserve la propriété du droit d'auteur et des droits moraux qui protège cette thèse. $\mathrm{Ni}$ la thèse ni des extraits substantiels de celle-ci ne doivent être imprimés ou autrement reproduits sans son autorisation.
In compliance with the Canadian Privacy Act some supporting forms may have been removed from this thesis.

While these forms may be included in the document page count, their removal does not represent any loss of content from the thesis.
Conformément à la loi canadienne sur la protection de la vie privée, quelques formulaires secondaires ont été enlevés de cette thèse.

Bien que ces formulaires

aient inclus dans la pagination, il n'y aura aucun contenu manquant.

\section{Canada}




\section{ABSTRACT:}

Technology has united our understanding of distance, time and space. It is this phenomenon that has caused the collision of Eastern and Western cultures. This thesis will explore the distinct views of the East and West perspectives, through a number of studies on perception.

Understanding the divergence between the east and west will show that their differences lie in their similarities. The two cultures are two halves of a whole, attracted together through the tension in their diversity.

In order to coexist the East and the West, this thesis proposes a host and guest relationship between Canadian and Chinese immigrants. In a transitional housing complex designed to emphasize hostility, the inhabitants will have to work together to arrive at hospitality. It is an architecture where hostility becomes hospitality, where the guest becomes the host. Thus, the divergence of the East and West will be resolved. 
Thanks to all those I love ... for giving me their hearts to endure this process with me

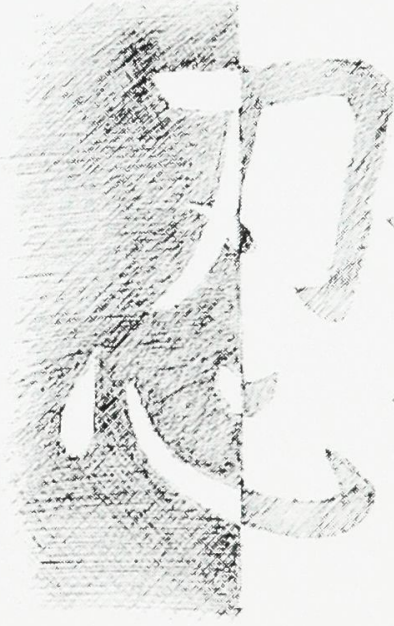


Special thanks to ... Marco Frascari, for all the wonderful stories you've told ... 'Grazie mille'!!! Steve Fai, for all the help and smiles

... Tom Dubicanic, for all the lessons in life drawing 
Notes:

This thesis requires the use of numerous Chinese words to explain its ideas. In order to merge Chinese vocabulary into the English text, all ideas are first introduced through an English translation, then the Chinese character and after in bracket the pronunciation of the character using hanyu pinyin. Better known as pinyin, it is the most common standard Mandarin romanization system in use. Example: east is 東 (pinyin: dong). The pronunciation system of pinyin is the standard used in the entire body of texts, but the second system of Wade-Giles can be found whenever quotes by Needham are used. This is to ensure the proper quoting of the source. 


\section{TABLE OF CONTENTS:}

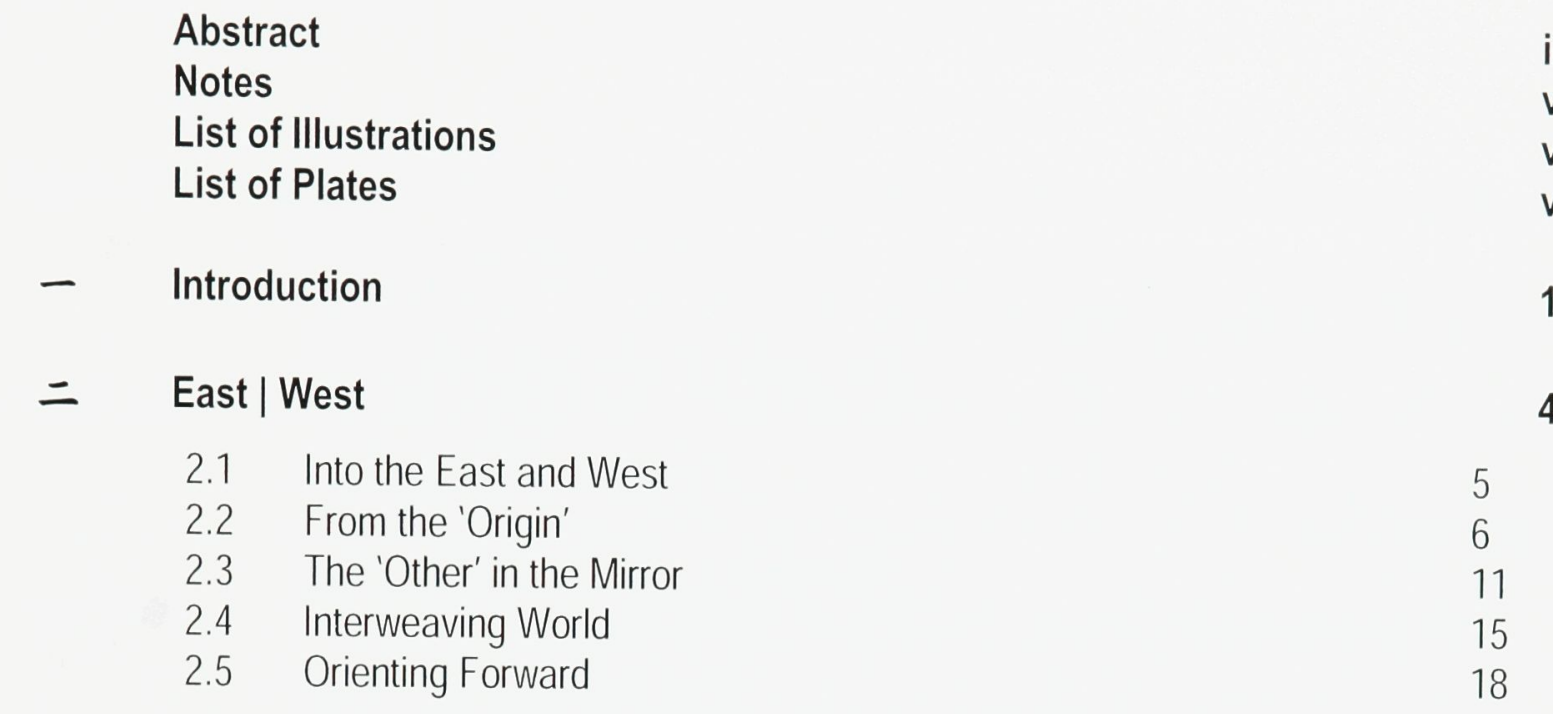

三 Anatomy | Landscape

3.1 Diagnosing the Body 21

3.2 The Anatomical 'Eye' 23

$\begin{array}{lll}3.3 & \text { The Art of 'Muscle' Training } & 27\end{array}$

3.4 Place in the 'Inner Atlas' 31

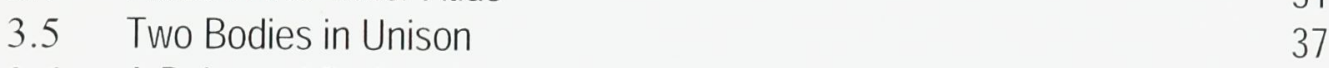

$\begin{array}{lll}3.6 & \text { A Balanced Body } & 40\end{array}$

四 Distance | Tension 42

4.1 Distance Check 43

4.2 Diverging Perspectives on Distance 44

4.3 Proxemic Sensory on Distance 49

4.4 The 'Tensions' of Alterity 51

4.5 Employing Tension Against Distance 53

4.6 In Between Near and Far $\quad 55$

4.7 Perspective Altered 66

$\begin{array}{lll}\text { 五 Conclusion } & 68\end{array}$

$\begin{array}{ll}\text { 六 Appendix } & 70\end{array}$

$\begin{array}{lll}\text { A } & \text { History of the Chinese Language } & 71\end{array}$

B Definition of culture from Mirror for Man: 73

C Drawings and Figures from Chapter III: Anatomy | Landscape 74

D Drawings and Figures from Chapter IV: Distance | Tension 81

$\begin{array}{lll}\text { 七 } & \text { Bibliography } & 94\end{array}$ 


\section{LIST OF ILLUSTRATIONS:}

(all images are copyright of the author unless noted otherwise)

Figure 2.1 The Chinese character of east 東 (dong) in its ancient forms of oracle bones, bronze script and seal script.

"東". 说文解字注. 2008, Gg-Art.Com NET TECH CO.LTD. < http://www.ggart.com/imgbook/index. php?bookid $=53$ >

Figure 2.2 The Chinese character of west 西 $(x)$ in its ancient forms of oracle bones, bronze script and seal script.

"西". 说文解字注. 2008, Gg-Art.Com NET TECH CO.LTD. < http://www.ggart.com/imgbooklindex. php?bookid $=53$ >

Figure 2.3 The Chinese character of Asia 亞 (ya) in its ancient forms of oracle bones, bronze script and seal script.

"亞". 说文解字注. 2008, Gg-Art.Com NET TECH CO.LTD. < http:/hwww.ggart.com/imgbook/index.php?bookid=53 >

Figure 3.1 內經圖 (Neijing tu): This is a drawing found in the Baiyunguan temple in Beijing. Kuriyama, Shigehisa (2001) "The Case of Chinese Views of the Viscera". The Imagination of the Body and the History of Bodily Experience. Japan: International Research Center for Japanese Studies. Pg 22.

Figure 3.2a 內景圖 - Neijing Tu (Chinese Drawing) Lu, Gwei-Djen, and Needham, Joseph (1980) Celestial Lancets: A History and Rationale of Acupuncture and Moxa. New York: Cambridge University Press. Pg. 19

Figure 3.2b 內景圖 - Neijing Tu (Japanese Drawing) Kuriyama, Shigehisa (2001) "The Case of Chinese Views of the Viscera". The Imagination of the Body and the History of Bodily Experience. Japan: International Research Center for Japanese Studies. Pg 17.

Figure 4.1 Aerial Image of Site. Google Maps. 2008, TerraMetrics, Map data @ NAVTEQ. $<$ http://maps.google.ca/maps?hl=en\&tab=wl> 


\section{LIST OF PLATES:}

(all images are copyright of the author unless noted otherwise)

Plate 3.1 Greek 'Anatomy' versus Chinese 'Mo.

Graphite and colour pencil on vellum. 34" x 30"

Plate $3.2 \quad$ Hermaphrodite.

Conceptual Drawing. Graphite and colour pencil on vellum, assembled on black and white board. $34^{\prime \prime} \times 40 "$

Plate $3.3 \quad$ Life Drawing (var.1)

Conte and pastels on Mayfair drawing paper. 60" x 60"

Plate 3.4 Life Drawing (var.2)

Conte and pastels on Mayfair drawing paper. 60" x 60"

Plate $3.5 \quad$ Life Drawing (var.6)

Conte and pastels on Mayfair drawing paper. 60" x 60"

Plate 3.6 Life Drawing (var.10)

Conte and pastels on Mayfair drawing paper. 60" x 60"

Plate 3.7a Complete Life Drawing (Male Orientation)

Conte and pastels on Mayfair drawing paper. $60^{\prime \prime} \times 60^{\prime \prime}$

Plate 3.7b Complete Life Drawing (Female Orientation)

Conte and pastels on Mayfair drawing paper. 60" x 60"

Plate 3.8 Demonstration of lines extrapolated from Life Drawing

Digital Manipulation

Plate $3.9 \quad$ Horizontal Landscape Painting

Chinese ink on rice paper. $18^{\prime \prime} \times 54^{\prime \prime}$

Plate 3.10 Demonstration of lines extrapolated from Life Drawing

Digital Manipulation

Plate 3.11 Vertical Landscape Painting

Chinese ink on rice paper. 54" x 18"

Plate 4.1 Horizontal Landscape Painting

Chinese ink on rice paper. $18^{\prime \prime} \times 54^{\prime \prime}$ 
Plate $4.2 \quad$ Axonometric Drawing

Graphite on vellum, with Canson coloured paper layered behind, 28" x 24"

Plate 4.3 Perspective Drawing

Chinese ink on rice paper, $32^{\prime \prime}$ x $24^{\prime \prime}$

Plate 4.4 Ground Floor Plan

Main Program: Entrances and Public Gardens

Plate 4.5 North Elevation

Plate 4.6 East Elevation

Plate 4.7 Longitudinal Section (Cut through north and south)

Plate $4.8 \quad$ Basement Floor Plan

Main Program: Market Place and Public Gardens

Plate 4.9 Second Floor Plan

Main Program: Restaurant

Plate 4.10 Third Floor Plan

Main Program: Language Resource Centre and Residential Apartments

Plate 4.11 Third Floor Plan

Main Program: Language Resource Centre and Residential Apartments

Plate 4.12 Residential Cluster Detail Plan

Communal courtyard and kitchen space versus Private intimate living space

Plate $4.13 \quad$ Fifth Floor Plan

Main Program: Roof-top Gardens (private)

Plate 4.14 Detail

Tension in Walls

Plate $4.15 \quad$ Detail

Physical path versus visual path

Plate 4.16 Detail

Altering Near and Far Perceptions

Plate 4.17 Detail

Canadians and Immigrants as a pair 


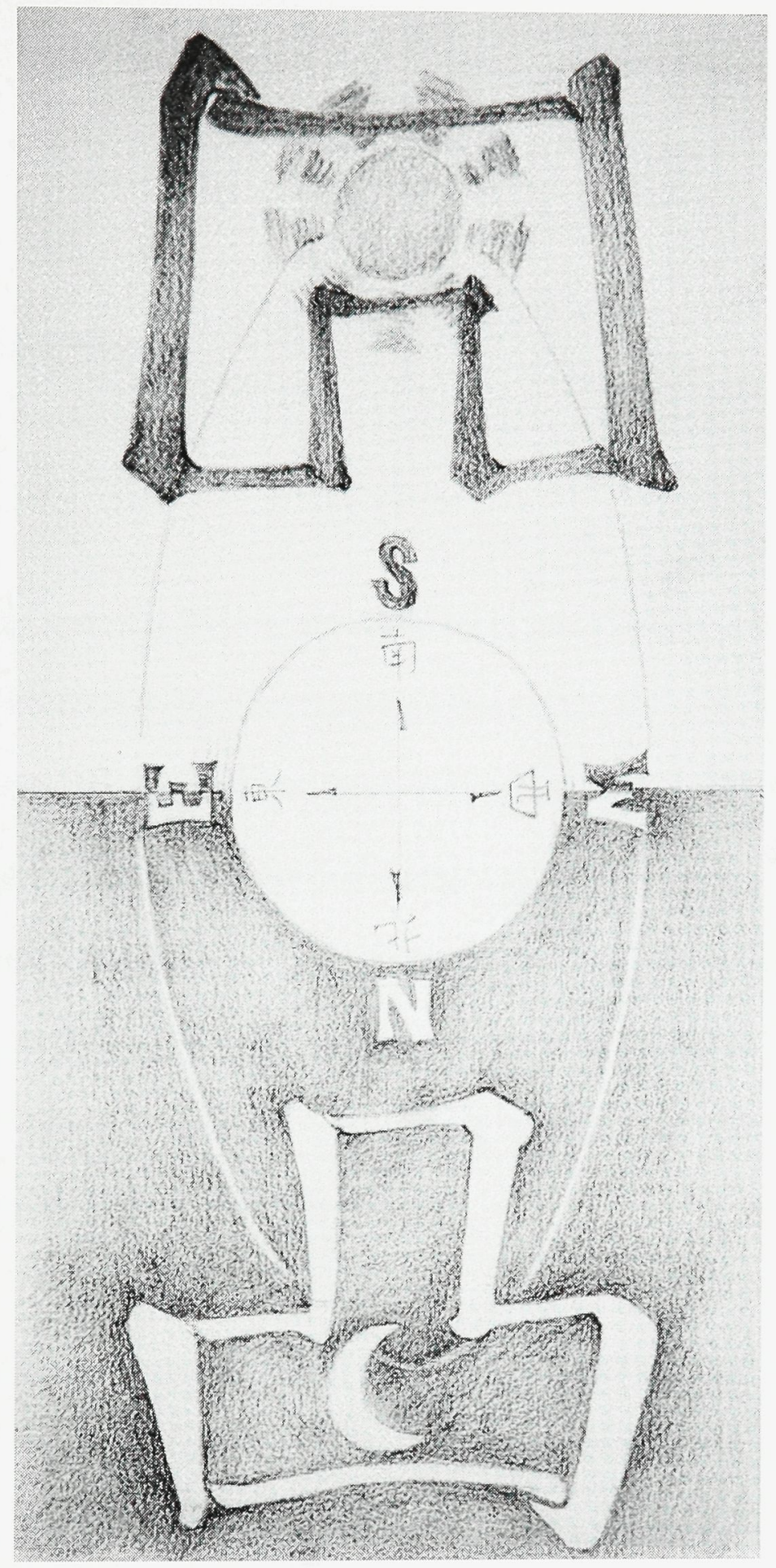

TEMPORAL TRANSLATION:

Exploring the perspectives of East and West

Selina Leung Sze Yu, B.A.S. 


\section{- INTRODUCTION:}

A compass is a tool used to define direction, noted for its consistency in pointing in one 'true' direction. Yet the western compass has an arrow that always points north, while the Chinese compass, on the other hand, is called the "point south needle" 指南針 (zhi nan zhen) because it always points south. It is clear from the start that the East and the West have divergent views and often opposing beliefs. But in the end, their compasses can be used in the same way to navigate in the same direction; it is only a matter of perspective. The compass relies on where you stand, and how you orientate yourself to observe the rest of the world. The divergence of perception between the East and the West is the subject of this thesis.

Consider the image of a conceptual drawing below. The composition of the drawing surrounds the compass image in the centre. It does not have a set orientation and is free to rotate in any direction. It is up to viewer to decide which perspective they wish to take.

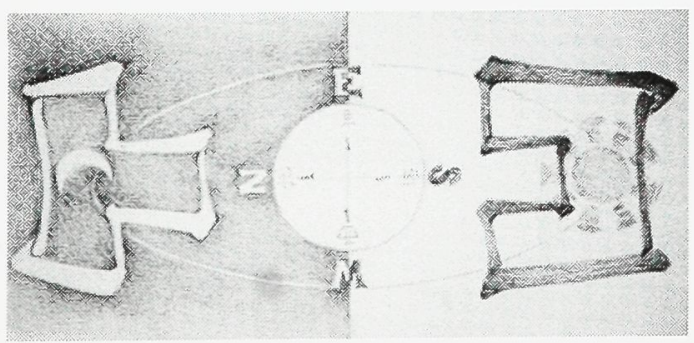


The perspectives of the East and the West are analogous to the two halves of the drawing. The sun and the moon work together to complete the cycle of the day. Similarly, the two Chinese characters in the drawing, 'indentation' Ш (ao or wa) and 'protrusion' Ц (tu), join together to form a box. The East and the West each have their strengths and weaknesses. Uniting the two perspectives will complete the 'emptiness' of the other. The following chapters look at their diverging perceptions and the ways in which they can be unified. Drawings will be used to test out intuitive ways of unifying the perceptions.

The first studies of perception use etymology to study the history of the words 'east' and 'west'. It will explore how both Europeans and Asians attempted to identify their own culture. It will also show that to define the 'self' required the defining of the 'other'. To co-exist the cultures of the East and the West is to realize what their differences and their similarities are. It is all a matter of perception.

The third chapter will look at the Western and Eastern perceptions of the body through Greek and Chinese medicine. The human body is the ideal subject in the study of cultural relationships. The beating pulse motivated the ancient Greeks to peer into the interior of the body; through the methods of dissection they created the anatomical body. In contrast, the Chinese used their senses to observe the exterior of the body and translated their knowledge of the body as a landscape. The two perspectives of the body are different yet they are the same, for both methods describe the same human body. Investigative drawings will be used to test the intuition that two 
perspectives of the body can co-exist. The investigations will be a companion to the understanding that a unification of the two perceptions will create a stronger, more definitive view of the body. Once again, it is about unifying different perceptions.

The fourth chapter looks at another example of the differences between the East and West through the perception of distance in art. In Western art, linear perspective is used to differentiate between depths in space. In Chinese art, vertical positioning is used to make the distinction between objects that are near from those that are far. Again, both methods achieve the same goal of portraying distance on a two-dimensional medium, but in different ways.

The second half of the fourth chapter will show that perception of spatial distance is a learnt behaviour, and that its alteration can be used to make possible a co-existence of the diverging views of the East and West. The chapter will specifically show how this co-existence of differences can be achieved in architecture through engaging bodily movements. The Western linear perspective and the Eastern oblique perspective are the 'two halves' of spatial perception that will be used together to create an architectural 'whole'. The architectural proposition utilizes this understanding to set up a host-and-guest dialogue between Canadians and new Chinese immigrants. Through the concept of a transitional housing complex, the hosts and guests will work together to combat the hostile environment purposefully created by the architecture. Only after the perceptions of the inhabitants have been altered will hostility become hospitality. Then, the host and guest will be joined in a unified perceptual world. 


\section{= EAST |WEST}




\subsection{INTO THE EAST AND WEST:}

"Each age and society re-creates it's 'other'." - Said (1979, p 332)

Speaking of east and west was once as simple as speaking of left and right, up and down. So why did the two well-used words, once used to simply denote direction, become overwhelmed with heavy social, cultural and political connotations? The answer can be found in the history of the two words' transformations, in their maturity from simple 'east' and 'west' to the burden-filled forms of 'East' and 'West'.' Therefore, the quest to discover the reasons for the changes in their connotations lies in their etymology.

This chapter uses a philosophical approach to study the history of the East and the West (or as identified today as Europe and Asia) to discover how each society defines themselves. Identifying how the East and West define themselves will help us to understand their differences, as well as improving our understandings of their cultures. For the same reason, we will also look at anthropology, which tells us that to construct an identity is to define a culture. Yet it will not be easy, as the construction of one's identity requires the construction of the 'other'; as to define the East is to define the West and vice versa.

\footnotetext{
1 We move from using lowercase that denotes geographic meanings to using uppercase for cultural representations.
} 
Learning how to perceive the 'other' will enable us to create a co-existence between the East and the West. In the end, both philology and anthropology will show us that the East and West are interrelated and co-dependent in more than just their identities.

As the modern world is transforming our historical definitions of everything from time and space to East and West, it is also redefining their co-existence. By borrowing from Orientalism and Occidentalism, we can put all these ideas into a contemporary context to see how Eastern and Western cultures have collided.

\subsection{FROM THE 'ORIGIN'}

The sun rises in the east. This is a perceptual truth witnessed everyday. This perception has remained consistent throughout the history of mankind. Ever since man has been able to record his observations, the sun has always been involved in the definition of 'east'. Whether in Europe or Asia, this has always remained the same. The evidence of such reality lies in the semiotics of their languages.

In Asia, the Chinese language of ideograms represents one of the earliest graphic records of man. Each Chinese character is thus unique in its form. ${ }^{2}$ In Chinese, the written form of east is 東 (the

${ }^{2}$ See Appendix A for a history of the Chinese language. 
pronunciation: dong). According to the Shuowen Jiezi ${ }^{3}$, east is where the sun rises from behind the tree. ${ }^{4}$ Below is a dissection of the character 東, into its root forms:

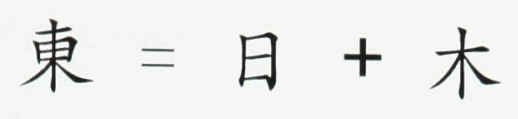

日 $(r i)$ is the pictograph of the sun, and 木 $(m u)$ is the trunk and its branches growing out of the ground depicting a tree. Together with a little imagination, it gives rise to the ideogram 東 (dong). (Refer to Figure 2.1) As well, in Europe, the definition of 'east' has always been a direction towards where the sun rises. In numerous European languages, the direction of 'east' is analogous to the word 'to rise/rising' - in French, Levant ('rising') is a term used to define the Middle East; in Hebrew, 'mizrahi' ('sunrise') referred to Jews from the eastern part of the country. Similarly, Europeans commonly referred to Japan as 'the land of the rising sun'. As can be seen, in both Europe and Asia, 'east' was defined by the start of the day.

FIGURE 2.1:

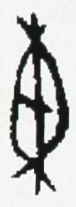

東 (dong) from oracle bones (Refer to Appendix A)

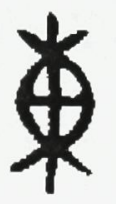

東 (dong) from bronze script

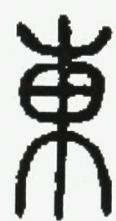

東 (dong) from seal script

In the same way, the end of the day signified the west; as the sun rising in the east was the beginning, its setting in the west signified the end. The Chinese ideogram for west is 西 $(x i)$. The interpretation of this character is a little harder to imagine. From Shuowen Jiezi, it is a bird in its

\footnotetext{
${ }^{3}$ Shuowen Jiezi, 說文解字 is the oldest Chinese dictionary to have analysed the structure of the characters and give a rationale to its graphic form. It was written in the $2^{\text {nd }}$ century $C E$, in the Han Dynasty.

4 東、也從木官溥說從日在木中、凡東之屬皆從東。“東”. 说文解字注. 2008, Gg-Art.Com NET TECH CO.LTD. < http://www.gg-art.com/imgbook/index.php?bookid=53 >
} 
nest, suggesting sunset and the direction thereof a bird's roosting. ${ }^{5}$ As birds return to their nest at sunset, the image of 西 (xI) (and therefore the word 'west' for the Chinese) is related to the image of the end of the day. The ancient seal scripts of 西 $(x i)$ more clearly renders this definition. (Refer to Figure 2.2)

FIGURE 2.2:

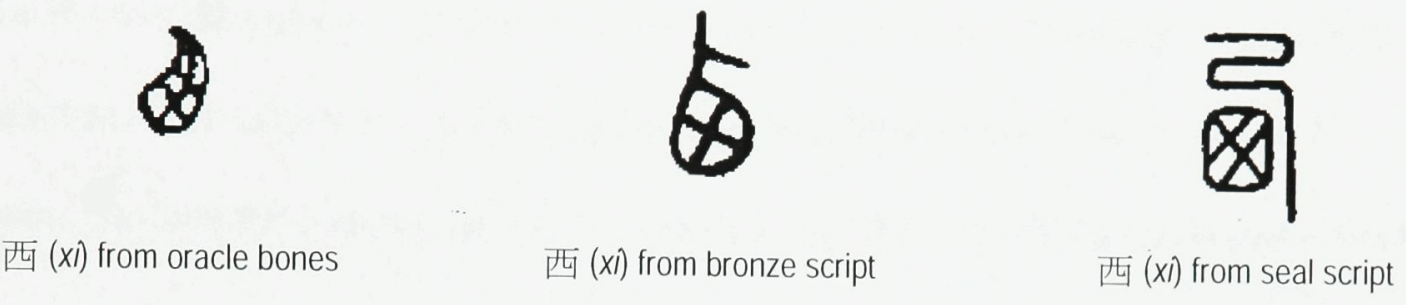

The Chinese also defined 'west' as a final resting place, either day's end or life's end. The darker connotation of the end of life, or death, fit well with the negative attributes they associated with the word 'west'. As Alastair Bonnet writes,

the West [as] the place where the sun goes down ensured its most ancient and enduring connotation: the west is the place of death. ${ }^{6}$

Bonnett meant that the connotation, 'dreading of the west' came from ancient Chinese and African cultures. He suggests this by showing that the colour white is the traditional colour of death in those cultures. The dreadful conquerors coming from the west were white in skin colour, and thus produced a fearful image associated with death.

\footnotetext{
5 西、鳥在巢上、形像日在西方而鳥棲故、因以爲東西之西、凡西之屬皆從西。“西”、说文解字注、 2008, Gg-Art.Com NET TECH CO.LTD. < http://www.gg-art.com/imgbook/index.php?bookid=53 > ${ }^{6}$ Bonnett, Alastair (2004) The Idea of the West: Culture, Politics and History. New York: Palgrave Macmillan. Pg 4.
} 
This Eastern fear of the west was mirrored in its counterpart, the Westerners' fear of the East. The Japanese writer Junichiro Tanizaki, in his essay In Praise of Shadows, writes about how the beauty of shadows was admired by the Japanese yet detested by the Westerners. For Tanizaki, it is no wonder that " 'The Mysterious Orient' of which Westerners speak probably refers to the uncanny silence of these dark places". Further on in the essay he writes that Westerner's "quest for a brighter light never ceases, he spares no pains to eradicate even the minutest shadow."7

Therefore, for both the East and the West, the uncharted 'other' was a place of mystery they feared. It was not until explorers ventured into those 'other' lands that ideas of the East and West began to expand.

We return to the words 'east' and 'west', and consider their Latin roots, oriri and occidere. The former is also the root of the word for Orient ${ }^{8}$, while the latter for Occident. This clarifies the association between the word Orient toward ideas of the East, and the word Occident toward ideas of the West. It also explains why Orientalism is the study of the East, and Occidentalism is the study of the West. The man who has redefined the term Orientalism is Edward Said. He states:

The first definition for Orientalism is an academic one... [It is] anyone who teaches, writes about, or researches the Orient ...

\footnotetext{
7 Tanizaki, Junichiro (1977) In Praise of Shadows. London: St. Edmundsbury Press. Pg 20 and Pg 31

8 'Origin' is another word with the Latin root, oriri. An interesting thought to ponder is whether or not Europe acknowledged Asia as its origin when it assigned 'Orient' to the East? It is not the goal to discuss this here.
} 
either its specific or its general aspects, is an Orientalist, and what he or she does is Orientalism. ${ }^{9}$

This is the first of three definitions for Orientalism defined by Said. It is perhaps the most general and objective one, without the burden of social, cultural or political context. It considers Orientalism as a pure object. In this manner, it is too broad and the reason why this use of the word has mostly been abandoned in academia. The second of Said's definitions is more widely accepted and most commonly used.

Orientalism is a style of thought based upon an ontological and epistemological distinction made between 'the Orient' and 'the Occident'. Thus a very large mass of writers ... [has] accepted the basic distinction between East and West as the starting point for elaborate theories ... concerning the Orient. ${ }^{10}$

Even Said admits himself that this is the position most researchers studying the East and West prefer to take on Orientalism. To objectively study their differences, it is necessary to keep their divisions clear. But for Said, to begin the study of Orientalism is to cross over the boundaries distancing the East and the West. This is the suggestive meaning in Said's third definition.

\footnotetext{
${ }_{9}^{9}$ Said, Edward (1979) Orientalism. New York: Vintage Books. Pg 2.

10 Said, Edward (1979) Orientalism. New York: Vintage Books. Pg 2
} 
Orientalism as a Western style for dominating, restructuring, and having authority over the Orient. ${ }^{11}$

\subsection{THE ‘OTHER’ IN THE MIRROR}

We showed how the West defined the East in terms of the sun-this association can also be seen in the word 'Asia'. But did the West really define this word? Most assume the following, that " 'Asia' is reported to have derived from a Babylonian term referring to the rising of the sun 'asu' (to rise)."12 But this assumption, that the West was solely responsible for naming the East, is no longer the only theory. As "the modern reader whose thinking has been influenced by Edward Said's concept of Orientalism, tends to seize upon proof of Western dominance wherever she or he looks"13, he becomes aware that the same Western dominance exists in etymology. Used to this, it then becomes natural to assume that the roots of most words are Western-based-which is often a false assumption. This can be seen with the word 'Asia', whose roots are most likely not Westernbased but rather Chinese.

Bonnet's recent studies describe how Italian Renaissance map maker Matteo Ricci, who was responsible for charting of the maps, was not responsible for labelling them.

\footnotetext{
11 Ibid, Pg 3

12 Bonnett, Alastair (2004) The Idea of the West: Culture, Politics and History. New York: Palgrave Macmillan. Pg 97.

13 Ibid, pg 102
} 
Indeed, as an admirer of the East he is unlikely to have been responsible for the Chinese characters for Asia, which are written as 'inferior - trifling - interior'. The Chinese translation makes it clear that Asia was considered to be a marginal place, an area that surrounded but did not include China. ${ }^{14}$

What he is trying to say is that the West did not create the word 'Asia', but the East did themselves. In the text by Bonnett, there was only a pinyin for the Chinese characters he spoke about - yaxiya. Due to the nature of the Chinese language, one sound can have dozens of applicable characters. Through the pairing of sounds and meanings, there is only one character possible for $y a$, and that is 亞. The closest character resembling 'trifling as well as having the sound $x i$ is 細. There is some doubt as to whether or not 細 $(x i)$ is the right character, because although its English translation can mean 'tiny', in Chinese it is more often used to refer to 'sensitivity' and 'attention to detail'. Trifling, on the other hand, relates much more to the idea of inferiority, being small and therefore unimportant. In addition, the character for west 西 also bears the same sound $x i$. Whichever the case is, the primary focus should be on the word 亞 (ya), since it has been placed both before and after $x i$.

FIGURE 2.3:

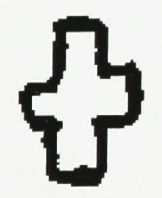

亞 (ya) from oracle bones

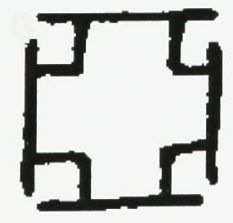

亞 (ya) from bronze script

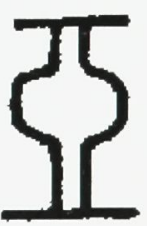

亞 (ya) from seal script

\footnotetext{
14 Ibid, pg 103
} 
In Chinese, the character 亞 (ya) is known today to mean Asia, and 亞洲 (ya zhou) is the Asian continent. In Shuowen Jiezi, 亞 (ya) is the remnant, or the figure of a deformed back of a person. ${ }^{15}$ It takes the definition of 'the inferior', either as the remaining of something or a disabled person. (Refer to Figure 2.3) This is indeed an appropriate description of how China compared itself to what lay beyond its lands. China labelled itself with 中國 (zhongguo); the literal translation is 'middle kingdom'. The first character 中 (zhong) is literally a line bisecting an enclosure ${ }^{16}$ :

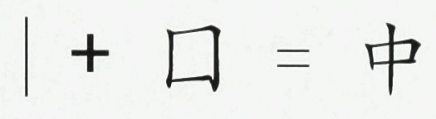

This signifies the importance of the centre position - the heart of all lands - in the mind of the Chinese. If 亞 (ya) is inferior, then 中 (zhong) is superior. Looking at the character carefully, something very interesting is revealed:
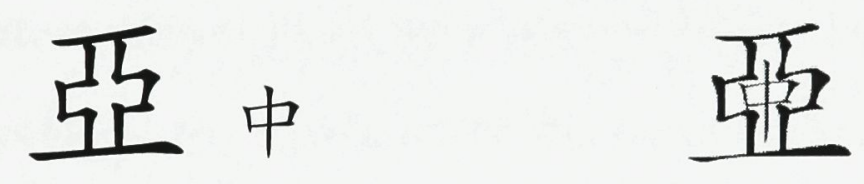

Enlarging the character 亞 (ya) allows the 中 (zhong) to fit perfectly in the centre. Therefore, if China - 中 國 (zhongguo) - is the middle kingdom, then 亞 (ya) is the territory that surrounds it. To return to the word Asia (yaxiya) and conclude about its origins, there is no doubt that the Chinese had most likely developed the term. But the importance in finding out the origin of the

\footnotetext{
15亞、醜也象人局背之形賈侍中說以爲次弟也凡亞之屬皆從亞。“亞”. 说文解字注. 2008, Gg-Art.Com NET TECH CO.LTD. < hitp://www.gg-art.com/imgbook/index.php?bookid=53> 16 中、和也從口｜上下通。“中". 说文解字注. 2008, Gg-Art.Com NET TECH CO.LTD. < http://wwww.ggart.com/imgbook/index.php?bookid $=53>$
} 
word is not to discover who invented it, but rather why. The reason for China is clear; it was to define the other.

"Each age and society re-creates its 'other'."17 For the East, the West is the other. Said explains that society creates the other in order to construct its own identity. We cannot define ourselves, alone, without the other. This is the same reason why we use a mirror's reflection to identify ourselves; it is amazing how we can only see reflections of our appearances while 'others' can see our true selves.

A society never defines its own culture; it is acknowledged as a common understanding. ${ }^{18}$ There is no need to describe what is commonly shared. The need only arises with the discovery of the other. The other can at once recognize all the habits and behaviours that are new to their understanding. These observations become a culture's reflection. Simple and often just surface images, these observations are defined as stereotypes. Although stereotypes are often associated with negative opinions and biases, they are still plain statements of observations that hold some truth within them. Just as our reflections define ourselves, stereotypes define cultures. But how accurate an observation reflects the truth depends on perception.

\footnotetext{
17 Said, Edward (1979) Orientalism. New York: Vintage Books. Pg 332.

18 See Appendix B for Geertz's summary of Clyde Kluckhohn's definition of culture.
} 


\subsection{INTERWEAVING WORLD}

Said's third definition of Orientalism provides reasons for the existence of stereotypes and the clashing of cultures in our modern world. He saw

Orientalism as a Western style for dominating, restructuring, and having authority over the Orient. ${ }^{19}$

Said saw Orientalism and its collection of Western stereotypes as the West's attempt to once again control the East. In the past, the West were the ones crossing over into the East, through colonialism and imperialism; their invading influences can still be seen in the global spread of capitalism and the westernization of the developing world. But now the East is expanding into the West-through immigration and globalization. We have reached an age where the physical boundaries of nations are redundant in the unlimited virtual realm. Cultures are colliding and overlapping in manners never seen or experienced before:

Our non-Western contemporaries have grasped the fact that, in consequence of the recent unification of the world, our past history has become a vital part of theirs ... we mentally still-

19 Said, Edward (1979) Orientalism. New York: Vintage Books. Pg 3. 
slumbering Westerners have now to realise ... our neighbours' past is going to become a vital part of our own Western future. ${ }^{20}$

The rise of Occidentalism is a sign of the East's retaliation against Orientalism. The westernization of the East perpetuated a force that has grown exponentially and which has become large enough to counter the force of their counterparts, making them equal in the war of cultural infiltration-and in the war of stereotypes.

It appears that both the East and West are now fighting neck to neck in the war - Orientalism against Occidentalism. It is exactly this that Said and lan Buruma have been trying to avoid. In 2004, Ian Buruma and Avishai Margalit published Occidentalism: In the eyes of its enemies to bring forth the issues with the current war against terrorism.

Prejudices are part of the human condition. But when the idea of others as less than human gathers revolutionary force, it leads to the destruction of human beings. ${ }^{21}$

Buruma spells out a warning not just for the East or the West to see, but for the entire world. The power of prejudice is frightening and must be fought. Said offers a possibility:

20 Toynbee, as quoted by Bonnett in: Bonnett, Alastair (2004) The Idea of the West: Culture, Politics and History. New York: Palgrave Macmillan. Pg 8.

21 Buruma, Ian, and Margalit, Avishai (2004) Occidentalism: The West in the Eyes of its Enemies. New York: Penguin Press. Pg 11. 
Rather than the manufactured clash of civilizations, we need to concentrate on the slow working together of cultures that overlap, borrow from each other, and live together in far more interesting ways than any abridged or inauthentic mode of understanding can allow. ${ }^{22}$

Prejudices are part of the human condition and can never be eliminated. Rather, it is wiser to work together to understand these prejudices and value each 'other'. The goals of both Orientalism and Occidentalism are to exemplify the richness of cultural diversity, in the multicultural unification of the globe. Just as the East and West can never have any clear distinct boundaries or definitions, neither can their cultures, which overlap. The idea of borrowing from each other to enrich each culture is what the practice of anthropology tries to achieve. As Geertz describes in The Interpretation of Cultures,

The aim of anthropology is the enlargement of the universe of human discourse ... culture is not a power ... it is a context, something within which they can be intelligibly - that is, thickly described ... Understanding a people's culture, exposes their normalness without reducing their particularity. ${ }^{23}$

\footnotetext{
22 Said, Edward (1979) Orientalism. New York: Vintage Books. Pg xxix.

${ }^{23}$ Geertz,Clifford (1973) The Interpretation of Cultures. New York: Harper Collins/Basic Books. Pg 14
} 
For Geertz, there is no power within culture; it is meant to distinguish groups. But how do we define without prejudice's destructive powers? To look at culture as context, is once again to make observations. Not any stereotypical observations, but intelligibly sensitive observations that depend on perception. To perceive as oppose to simply observe, is to not only see with our eyes, but to also understand what we see. The study of cultures is to perceive the other while at the same time seeing the other's perception of us.

To study the East and West as opposing forces, where co-existence seems impossible is an attitude caused by our lack of understanding of what culture is about, of how identity is defined and the importance of the other. We must view the meeting of cultures as an opportunity for alteration to our perception.

\subsection{ORIENTING FORWARD:}

"The object of study is one thing and the study of it another." (Geertz, pg.15)

Let us now return to the very objective of this thesis, which is to orient us in between the East and the West. ${ }^{24}$ It is to stand back and acknowledge the existence of the 'other' and understand the differences in their perception. The study of anthropology keeps the object and the study of it in ${ }^{24}$ Using 'Orient' as a transitive verb. To orient, is to face, to determine position or acquaint with the existing situation. 
clear distinction. Anthropologists study human interaction from a third person point of view without studying the object itself. The object in their study is the body of man. The study of the body is not anthropology, but medicine. For over two millennia, the Greeks and the Chinese both scrutinized the body to perfect in their own ways the study of medicine. It is through a medical analysis of the 'universal body' that the next chapter will reveal how perceptions of the East and West differ, and how understanding these differences will define cross-cultural architecture. 


\section{三 $\quad$ ANATOMY | LANDSCAPE}




\subsection{DIAGNOSING THE BODY:}

To understand the cultural differences between the East and the West is our aim. Using comparative cross-examination as a method of analysis will pose subjective and biased conclusions. Instead by examining each of their perceptions on a universal entity will ensure an objective and unbiased study. The human body is thus an ideal object for our study of cultural relationships. In both the East and the West, the study of the human body is part of the study of medicine.

The West's study of medicine began with the ancient Greeks. They strived to capture the pulse by touch, and trained the eye to see the dead anatomical body. In contrast, the Chinese never studied the body as 'dead' matter, nor did they regard dissection as a method used to develop medicine. Rather they used their senses to interpret the body as a landscape.

The most elaborate contrast of ancient Greek and Chinese medicine is analysed in Shigehisa Kuriyama's The Expressiveness of the Body and the Divergence of Greek and Chinese Medicine:

Two people can place their fingers on the 'same' place and yet feel entirely different things. Where Greek doctors latched onto the pulse, Chinese doctors interrogated the mo. The divergence was as much a matter of experience as it was of theory. Greek 
and Chinese doctors knew the body differently because they felt it differently. ${ }^{1}$

For both the Greek and Chinese physicians, there were two ways to know the body - by seeing and touching it. But the way they each saw and felt were different, therefore the ways of recording and representing the body also differed. The image below compares a classical Greek-style interpretation of the human body with a traditional Chinese-style:

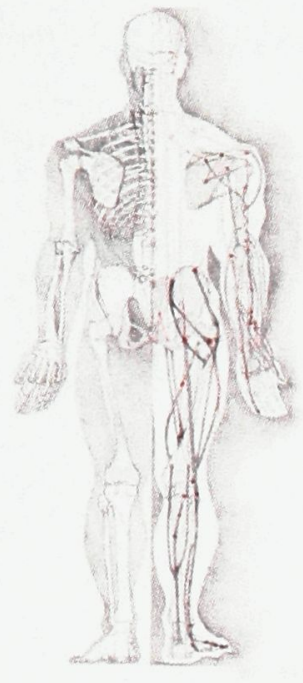

Greek 'anatomy'

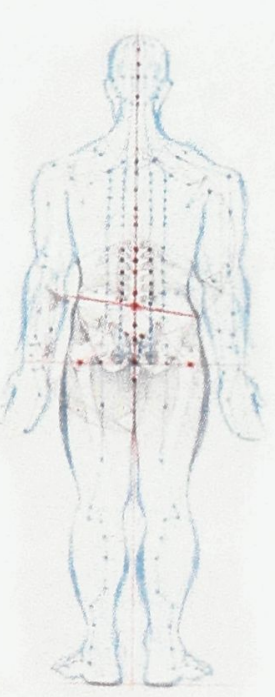

Chinese 'mo'
Plate 3.1: Graphite and colour pencil on vellum, (Refer to Appendix $\mathrm{C}$ for an enlargement of the drawing)

The left image embodies the Greek's anatomical understanding of the body. It depicts a body as a skeletal structure, controlled by muscles and the tendons joining them. In contrast, the image on the right displays the Chinese interpretation of the body, with twelve conduits interconnected to allow for the ' $m o^{\prime} 2$ to circulate. It is possible to reconcile these two divergent interpretations by first analysing their origins. Understanding the logic behind each view will teach us a pattern of

\footnotetext{
1 Kuriyama, Shigehisa (1999) The Expressiveness of the Body and the Divergence of Greek and Chinese Medicine. New York: Zone Books. Pg 55.

2 ' $M o^{\prime}$ ' is the pinyin for the Chinese character: 脈. There is no proper English translation of the word 'mo'. For purposes of understanding here, the 'mo' is something that flows through twelve conduits inside the body. It is not blood, nor the pulse. These ideas will be explained further on in the essay.
} 
conciliation (between the East and West) that we can then apply to grander schemes. As well, the following drawing studies will help to illustrate both our analysis and understanding of the differences between the Eastern and Western perceptions of the body.

We will begin by exploring the West's image of the body and how it influenced the study of anatomy. Then, we shall investigate the contrasting opinions of the East, in particular their view of the body as a landscape. Finally, we will show how a unification of the two creates a stronger, more definitive view of the body.

\subsection{THE ANATOMICAL 'EYE'}

The modern image of the skeletal or the muscular body was developed by western medicine, which originated in Greece with Hippocrates of Cos II (ca. 460 BC - ca. 370 BC) ${ }^{3}$. However, the Greek's interest in anatomy developed much later, as well as their theories on the pulse.

The 'pulse' is an indicator of life in the body. Both the Greeks and the Chinese knew to place their fingers on the wrist to feel the signs of life. The Hippocratic physicians were not aware of what they felt; they knew the pulse as sphygmos ${ }^{4}$ and that it throbbed in vessels connected to the heart.

\footnotetext{
${ }^{3}$ Hippocrates of Cos II is the founder of the Hippocratic School of Medicine in Greece. He wrote the 'Hippocratic Oath' that prescribed the practice of medicine for physicians to come.

${ }^{4}$ Kuriyama, Shigehisa (1999) pg 30-31, quoting Aristotle, On Respiration 480a: "All the vessels throb (sphyzousin), and throb simultaneously with each other, because they are connected with the heart."
} 
Their idea of these vessels included arteries, veins and nerves, which are different, as we know today. This confusion was not resolved until Herophilus (335-280 BC) made the distinction that "the pulse exists only in the arteries and heart, whereas palpitation, spasm, and tremor appear in the muscles and nerves." ${ }^{15}$ It was only after this distinction was made that Galen (AD 129 - ca. 200 or 216) was able to develop the idea of the pulse.

He insisted that the pulse could be physically perceived not only though the sense of touch, but also through the sense of sight ${ }^{6}$, as he had seen through dissection, kindling a new fascination for anatomy. This new interest in dissection, once prohibited by law, was purely medical. Celsus (ca. $25 \mathrm{BC}-$ ca. 50), one of the first investigators in the art, wrote:

Since pains and various kinds of diseases arise in the interior parts ... no one can apply remedies for them who is ignorant of the parts themselves. Therefore, it is necessary to cut into the bodies of the dead, and examine their viscera and intestines. ${ }^{7}$

This continuous search into the body's interior became the study of anatomy - the backbone of Western medicine. Yet there was also a purer interest in dissection beyond the medical one:

\footnotetext{
5 Kuriyama, Shigehisa (1999) pg 32, quoting Daremberg and Ruelle, 221.

6 Kuriyama, Shigehisa (1999) pg 34-35, and to add to that: "For Galen taught that a single pulse comprised of four parts: the diastole, the rest following diastole and preceding systole, the systole, and the rest following systole and preceding diastole." pg 36, quoting from Galen Peri diagnoseos sphygmon 1.3 (K.8.500) 7 ibid, pg 12. Quoting from Celsus, De Medicina, "Prooemium," paras. $23 \mathrm{ff}$.
} 
For the dissector, the viscera are truths buried in and under dense

flesh, and fat, and bone; they are secrets that have to be

uncovered. 8

The Greeks were determined to seek the invisible, to make it visible to the naked eye. As Kuriyama summarizes, "one had to see, and yet not see; see the form, but not the matter. See what, ultimately, can't be seen."9

It is clear that the secret knowledge sought for by anatomists was not the visible shape of organs, the forms of the muscles or structures of the bones. The invisible matter was something that simply could not be seen. It is this unobtainable knowledge that propels western medicine to never give up searching. It framed the body as Nature's encyclopaedia of knowledge, a book they had to thoroughly dissect to understand.

The following image is a drawing that has dissected the human body. It attempts to merge a male and female body (a metaphor for East and West) in search of the knowledge lying in between the East and the West. The united body is a 'hermaphrodite', a term from the Greeks for an individual possessing male and female physical traits:

\footnotetext{
8 Kuriyama, Shigehisa (2001) "The Case of Chinese Views of the Viscera". The Imagination of the Body and the History of Bodily Experience. Japan: International Research Center for Japanese Studies. Pg 18.

${ }^{9}$ Kuriyama, Shigehisa (1999) pg 128
} 


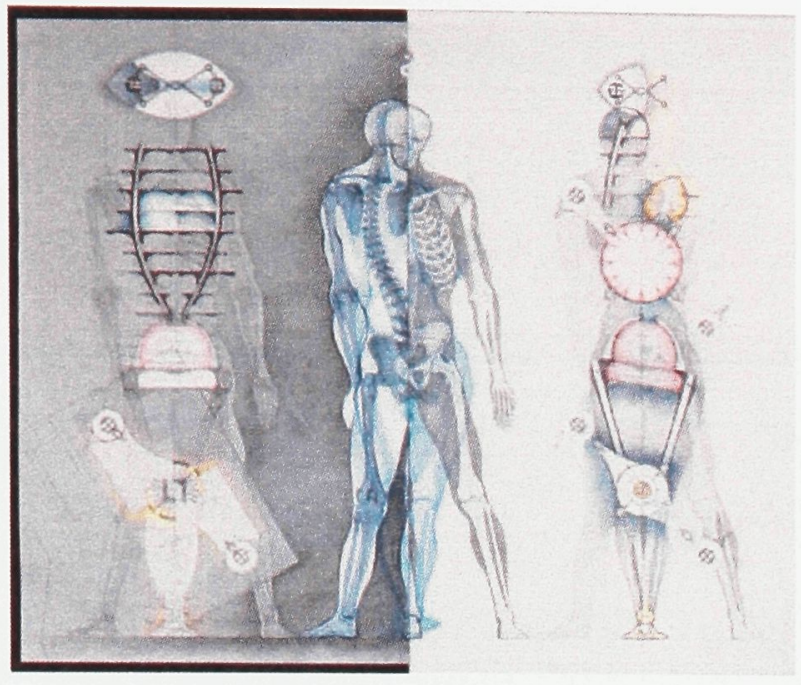

Plate 3.2: Hermaphrodite Graphite and colour pencil on vellum, assembled on black and white board

(Refer to Appendix C for an enlargement of the drawing)

In the middle is the anatomical structure of a united male and female form. On the left and right are attempts to translate the anatomy into structures of architecture. This was done through a series of horizontal and vertical section drawings imaginatively translated from the hermaphrodite. This translation is analogous to Kuriyama's understanding of Western anatomy, as it only reveals structure and fails to address what connects them. The invisible matter missing in the drawing is the reason why the image portrays a dead architecture. The structural bones of the building are there, but it lacks the pulsating relationship that connects it all together. The practice of anatomy, so focused on recording observations of the eye, was never able to grasp the invisible half of the body. Instead, anatomists made it a priority to train the eye into seeing the muscles in anatomy. 


\subsection{THE ART OF 'MUSCLE' TRAINING}

The anatomist's determination to know the truth caused Western physicians to read the body in the same manner. Even Western art was bound to this knowledge of the body through anatomy. This can be seen in ancient Greek sculptures, whose focus on musculature has roots in anatomy. Kuriyama explains:

$$
\begin{aligned}
& \text { Envisioning musculature is an acquired skill ... students must } \\
& \text { learn anatomy ... the trained gaze sees what the beginner's } \\
& \text { vague sight does not, because the anatomical eye knows exactly } \\
& \text { what it is supposed to perceive. }{ }^{10}
\end{aligned}
$$

The art of anatomically seeing required training and practice, and one needed to learn to see actual muscles and not just undulating skin. But Kuriyama warns that this training poses a danger for artistic, anatomical representation and musculature in art.

What was seen from the outside was inseparable from what was imagined, anatomically, beneath the skin ... there was thus the constant danger of slipping from seeing toward projecting. ${ }^{11}$

\footnotetext{
10 ibid, pg 112, quoting A. Hyatt Major, Artists and Anatomists (New York: Artists Limited Edition, 1984), 10. In addition, this quote parallels Kuriyama's later note on dissection: "The dissector must learn to discern order, through repeated Spractice, guided by teachers and texts. Without training and long experience, Galen insists, one sees nothing at all." pg 127.

11 ibid, pg 115
} 
Kuriyama is explaining a difficulty in art - representing exactly what the eye sees onto any twodimensional medium. It is impossible to isolate what the eye sees and what the eye imagines; because an interpretation always has to happen, therefore, it is a projection.

The following life drawing studies repeats the attempt to unify the male and female bodies on a canvas. This drawing differs from the previous in that it avoids dealing with architecture. It is purely an artistic study of the muscular body.

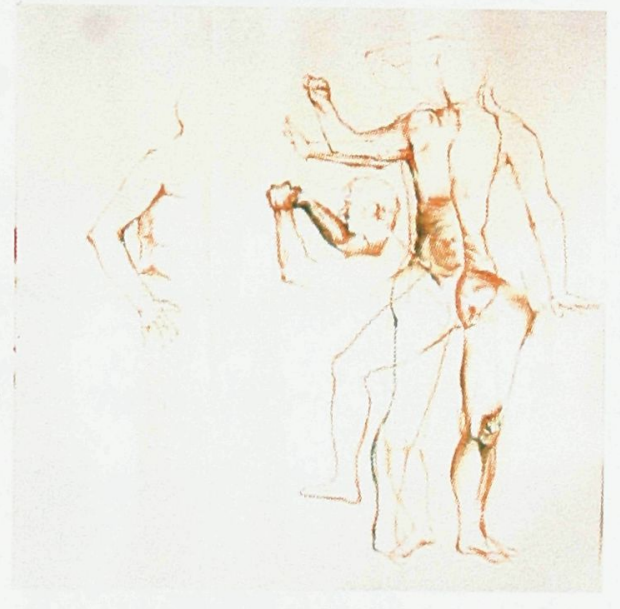

Plate 3.3: Life drawing Var.1 (session one) The first session with a male model is captured in the image above on the left. In these two-hour sessions, the model strikes various poses lasting 5 minutes to 20 minutes in length.

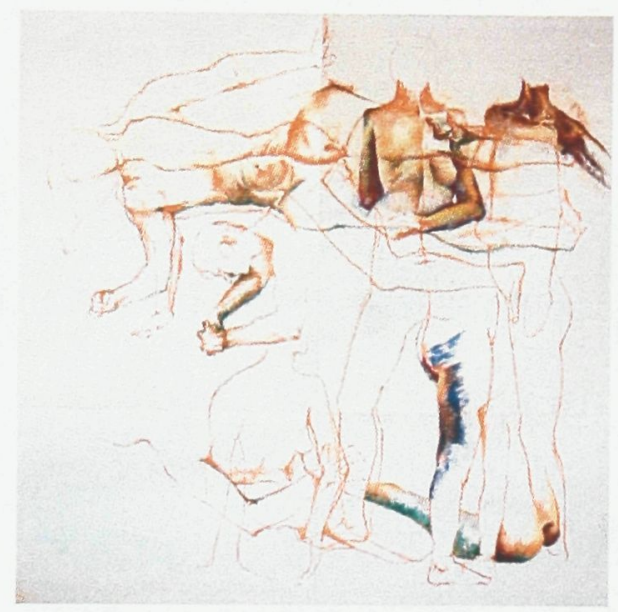

Plate 3.4: Life drawing Var.2 (session two) The second session was with a female model, and the image on the upper right has been rotated 90-degrees counter clockwise to accommodate the female body.

The work was meant to evolve slowly over successive sessions of life drawing with a male or female model. The mediums used are conte and pastels (hard and soft) on six Mayfair drawing papers, combining to the size of $5^{\prime}$ by $5^{\prime}$. There were a variety of models, and in order to keep consistency through the drawing, male and female figures were always kept in perpendicular orientations to each other. 


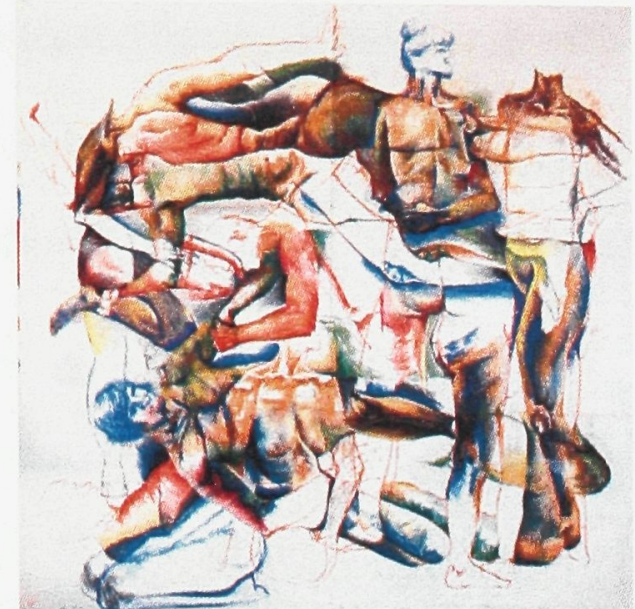

Plate 3.5: Life drawing Var.6 (session six) After multiple repeated sessions, spatial relationships between the male and female bodies begin to form.

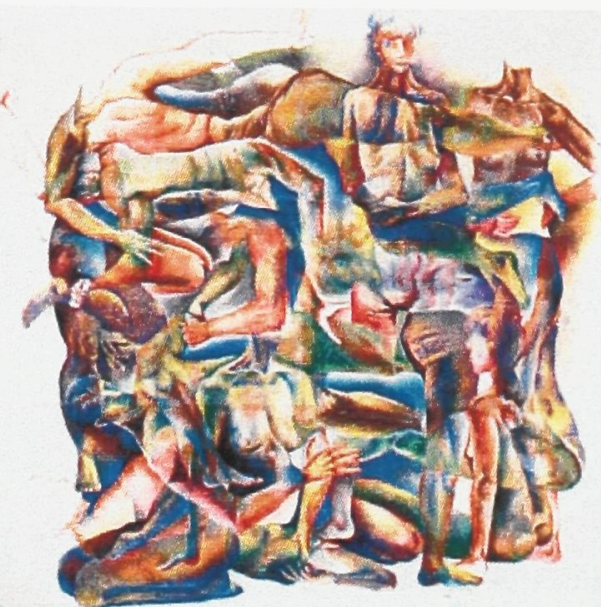

Plate 3.6: Life drawing Var.10 (session ten)

As the number of sessions increased, the number of overlaps and spatial arrangements also

increased. In order to accommodate for the various poses and to develop a sense of space, decisions were made to co-exist both forms.

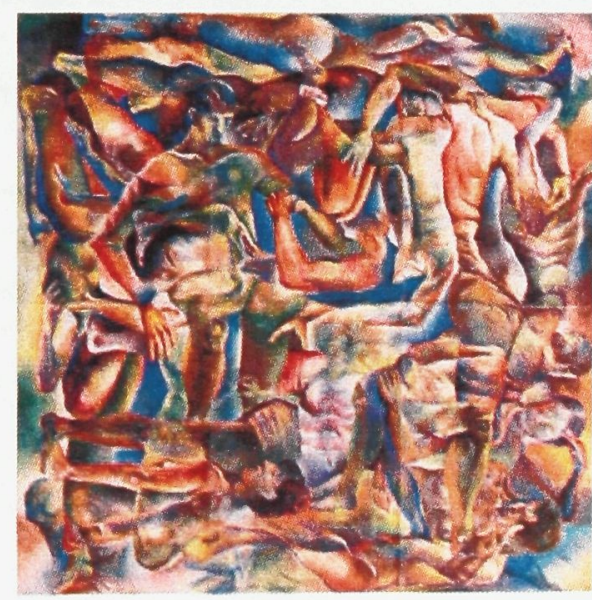

Plate 3.7a: Completed Life drawing

(Male orientation)

(Refer to Appendix C for an enlargement of the drawing)

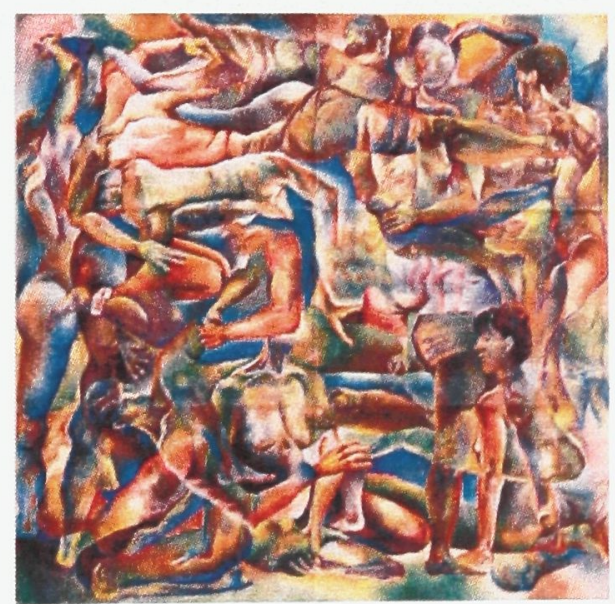

Plate 3.7b: Completed Life drawing (Female orientation) 
Life drawing has always been a method of artistic training; it is a method that teaches the eye to see musculature. This particular drawing helped to not only shape the anatomical eye, but also clarified the art of 'inner seeing' that Kuriyama describes:

Western anatomy [has] stressed how even the most 'realistic' anatomical gaze is shaped by the imagination ... it is often impossible sharply to isolate what we see from what we imagine; and analyses of the imagination, in turn, regularly suppose a kind of inner seeing. 12

The life drawing can be described as a realistic rendering of what the eye saw. But because of the poses and movements of the models, the portrayed reality owes it to imagination. It is imagination that allowed the mind to process a horizontal line already drawn on the canvas from previous sessions, and interpret it with the drawing of new lines of a vertical model. The perpendicular translation happened constantly while re-orienting the canvas between the male and female models. This translation of the eye to the hand, which occurs instantly in a trained artist, is what Kuriyama identifies as 'a kind of inner seeing'. Thus knowing that envisioning muscles requires an inner seeing - imagination - presents us with a possibility to steer away from anatomically seeing to an alternative imagination. ${ }^{13}$ One where the ' $m 0^{\prime}$ flows through the body like water does over 'the blood and breath of the earth'. ${ }^{14}$

\footnotetext{
12 Kuriyama, Shigehisa (2001) pg 22, quoting Mary Warnock's Imagination.

13 "The obsessions with muscles reflected the birth of a new experience of embodied life and an altered perception of persons." Kuriyama, Shigehisa (1999) pg 149

${ }^{14}$ Kuriyama, Shigehisa (1999) pg 50, it is quoting from Guanzi, chap. 39: "Shuidi," juan 14, 1a.
} 


\section{4 'PLACE' IN THE INNER ATLAS}

With the Western image of anatomy so vivid in our memory, it is difficult to see an alternative; how can there exist another way of 'seeing' the body without musculature training or the practice of dissection?

The Chinese provided an alternative method of imagining the body. A tenet of Chinese Taoism is to not seek knowledge that ultimately cannot be obtained..$^{15}$ Instead of diving deep into the inner parts of the body to find knowledge of the invisible, the Chinese searched for clues on the skin. It is the exterior of the body that fascinated the Chinese physicians. They realized that a close relationship must exist between the interior and the exterior of the body in order for it to function as a whole. On the surface, what was visible to the eyes was 色 (se), and what the fingers felt was 脈 $(m o)$. The Chinese studied the exterior with their senses:

Shape mattered far less than place ... the solution of Chinese doctors was to gaze upon the surface ... the skin shone as the site of privileged revelations. For there, at the surface, doctors contemplated a person's se - as in wuse, the five colours. ${ }^{16}$

\footnotetext{
${ }^{15}$ A translated verse from Taoism: "The Tao, belongs neither to knowing nor to not knowing. Knowing is false understanding; not knowing is blind ignorance. If you really understand the Tao beyond doubt, its like the empty sky. Why drag in right and wrong?" Watts, Alan, and Al Chung-liang Huang. Tao: The Watercourse Way. New York: Pantheon Books, 1977. Pg 38, a translation from Wu-men Kuan.

${ }^{16}$ Kuriyama, Shigehisa (1999) pg 166. The Chinese characters for five colours is: 五色 (wuse)
} 
The five colours corresponded directly to the five elements (五行, wuxing) in the Chinese understanding of the greater macrocosm. The five elements (wood, fire, earth, metal and water) are linked together in a balance of generative and destructive cycles. In the same way, the five colours (五色, wuse) - green, red, yellow, white, and black - flourished and faded on the surface of the skin in the same manner as the cosmic cycle. ${ }^{17}$ Seeing the colours was only the first part of diagnosis for Chinese physicians.

The illness can first be seen in the face (se), even though it may not appear in the body. It seems to be there, but not there; it seems to exist, yet not exist; it seems to be visible, and yet invisible ... as an illness becomes more serious, its corresponding colour intensifies. If the colour fades 'like clouds completely dispersing,' the illness will soon pass. One observes whether the colour is superficial or sunken to know the depth of the illness, whether the colour is dispersed or concentrated to know the proximity of crises. ${ }^{18}$

A proper knowledge of the body cannot be obtained without knowing the mo. ${ }^{19}$ Seeing the 'se' and feeling the 'mo' became the two primary methods of diagnosis in Chinese medicine, for they were

\footnotetext{
${ }^{17}$ Kuriyama, Shigehisa (1999), pg 168

${ }^{18}$ Kuriyama, Shigehisa (1999), pg 179

19 ibid, pg 170, quoting from Suwen 13/ 41-42.
} 
inseparable to 'knowing' the inner body. The technique of feeling the mo is 切脈 (Qiemo) performed by placing three fingers on the patient's wrist.

The finger placed lightly on the right wrist, at the cun position, diagnosed the large intestines, while the finger next to it discerned the state of the stomach. Pressing harder, these two fingers probed, respectively, the flourishing or decline of the lungs and spleen. 20

The cun is a point on the wrist where the mo is felt. It is also called the cun opening, for it is believed that each cycle of the mo begins here. Therefore, it is this point the Chinese inspected to gain their knowledge of the inner body. The mo was felt in order to know the state of all the inner organs. Here lays the difference between the Greek's dilating and contracting artery and the Chinese palpating mo. They were not the same at all.

If the mo was the language of life, its grammar was topological ... this is perhaps the most salient characteristic of palpation in China: the belief in the significance of place. ${ }^{21}$

The concept of the mo is difficult for Western medicine to grasp because the mo is not the pulse, nor the circulation of blood. It did not beat according to the heart. The mo flowed throughout the

\footnotetext{
${ }^{20}$ Kuriyama, Shigehisa (1999), pg 25

${ }^{21}$ Kuriyama, Shigehisa (1999), pg 40
} 
body to all places, in a continuous cycle. This is analogous to the cycle of water as it travels through all places on earth. The Chinese were not interested in the shape of organs that fascinated the Greeks. What mattered more was the place of each organ in relation to the other organs within the body, and how they functioned as a whole. That is why the mo was not the pulse, because it described internal relationships rather than one organ. This topographic method of perceiving the body was described metaphorically; the Chinese translated bodily relationships into a landscape. To see an example of this visual language, we must look into the Taoist 22 drawing, 內經圖 (Neijing tu):

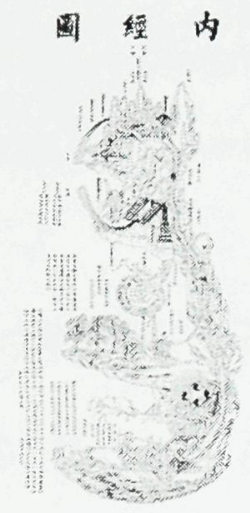

\section{FIGURE 3.1: 內經圖 (Neijing tu)}

This is a drawing found in the Baiyunguan temple in Beijing. "It is arguable the most artistically finished image of the body's interior in Chinese history; it is, at the same time, almost unrecognizable as an image of the body's interior."23

(Refer to Appendix $\mathrm{C}$ for an enlargement of the drawing)

It is a figurative landscape, with anatomical organs and nerves replaced by misty mountains woven with streaming rapids. At first, it may be hard to imagine, but, when compared to the images below, the Taoist principles begin to make sense.

\footnotetext{
22 "To appreciate medical habits of seeing, I urge, we must look more carefully at Taoist practices of imagining." Kuriyama, Shigehisa (2001) pg 22

${ }^{23}$ ibid, pg 22
} 


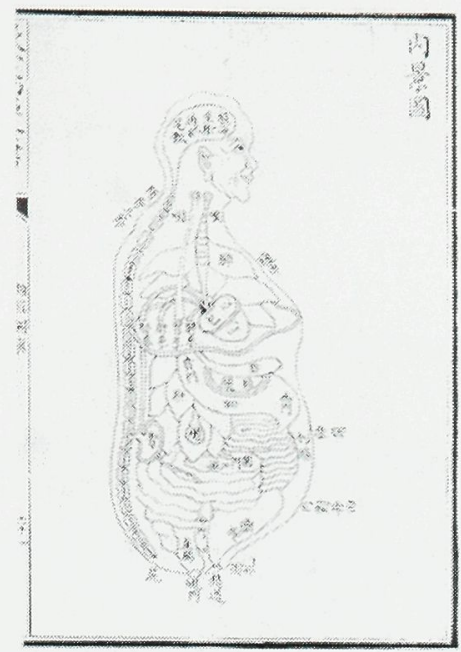

FIGURE 3.2a: 內景圖 - Neijing Tu (Chinese Drawing)

Lu, Gwei-Djen, and Needham, Joseph (1980) Celestial Lancets: A History and Rationale of Acupuncture and Moxa. New York: Cambridge University Press. Pg. 19

(Refer to Appendix C for an enlargement of the drawing)

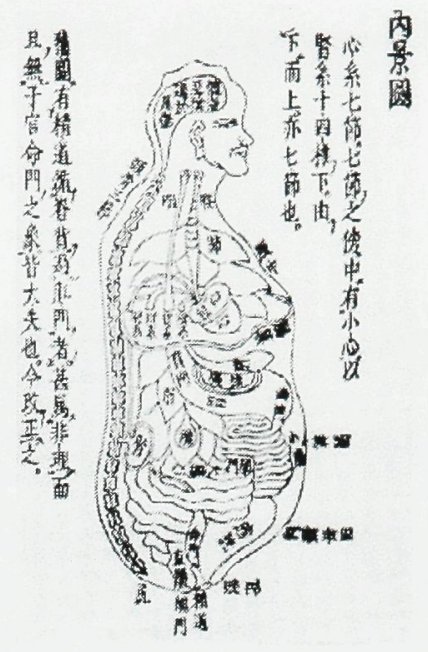

FIGURE 3.2b: 內景圖 - Neijing Tu (Japanese Drawing)

Kuriyama, Shigehisa (2001) "The Case of Chinese Views of the Viscera". The Imagination of the Body and the History of Bodily Experience. Japan: International Research Center for Japanese Studies. $\mathrm{Pg} 17$.

The title of these drawings 內景圖 (Neijing Tu) can be translated as the 'inner landscape'24. It is similar to depiction of the anatomical body only because there is an outline of the body. Other than the exterior form, the rest of the interior greater resembles the previous Taoist landscape. The arrangement of the organs and parts was governed by something besides their shape and form.

Kuriyama suggests that the Chinese charted the viscera in the same way geographical maps charted the earth, and that "the depiction of the body in Chinese medicine was shaped above all by

\footnotetext{
${ }^{24}$ Neijing tu is the same pinyin for 內經圖 and 內景圖. The difference is in the Chinese character for Jing $=$ 經 / 景. The first jing 經 means classic text (canons) or rules. The second jing 景 means scenery or view. Both are interchangeable in the context of Neijing tu, the drawing is both a set of rules and a view for the inner body.
} 
the logic of cartography."25 Along this line, we could consider 內景圖 (Neijing Tu) as not just 'inner landscapes', but as an 'inner atlas', ${ }^{26}$

The Chinese emperor 'Yü the great' was known for his knowledge in hydraulics. He applied soil science and hydraulic engineering to the oldest geographical documents. In the same manner, the Chinese physicians applied the same language to the practice of acupuncture, creating the language of Qiemo. The language of acupuncture analogs the great rivers of China. The rivers that flow through the body in acupuncture are called 'tracts' or 'meridians' 經絡 (Ching 10). There are twelve tracts in total, and they have the same symbolic correlation to the twelve great rivers in China. ${ }^{27}$ In addition to meridians, there are also 'acu-points' 穴 (xue). These mark the places along each meridian for acupuncture treatment. Specific names were given to each acu-point to indicate their importance as place markers. The names chosen were none other than names referring to bodies of water like 'seas' 海 (hai) and 'ponds' 池 (chi), and topographical features like 'mountains' 山 (shan) and 'valleys'谷 (gu).28 All of these terminologies lead us to imagine a vividly moving landscape, a topographical imagination of the body.

\footnotetext{
25 Kuriyama, Shigehisa (2001) pg 26

26 圖: two descriptions from Needham, Joseph (1971) Science and Civilisation in China (series). London: Cambridge University Press: "Bone and bronze forms of the character which came to mean 'map' (圖, thu) actually show a map." Vol 3 Cartography, Geography, pg 498. "The word thu has always retained an ambiguity, being applied equally to maps and charts and to drawings and paintings." Vol 4 Civil Engineering, Building, pg. 112

27 This analogy is being described in Kuriyama, Shigehisa (2001), pg. 50-51 and Lu, Gwei-Djen, and Needham, Joseph (1980) Celestial Lancets: A History and Rationale of Acupuncture and Moxa. New York: Cambridge University Press. Pg. $22-23$

28 Kuriyama, Shigehisa (1999), pg 285
} 


\subsection{TWO BODIES IN UNISON:}

The images below show two studies imagining the body as geographic atlas. The cartography was laid over the previously demonstrated life drawing studies:
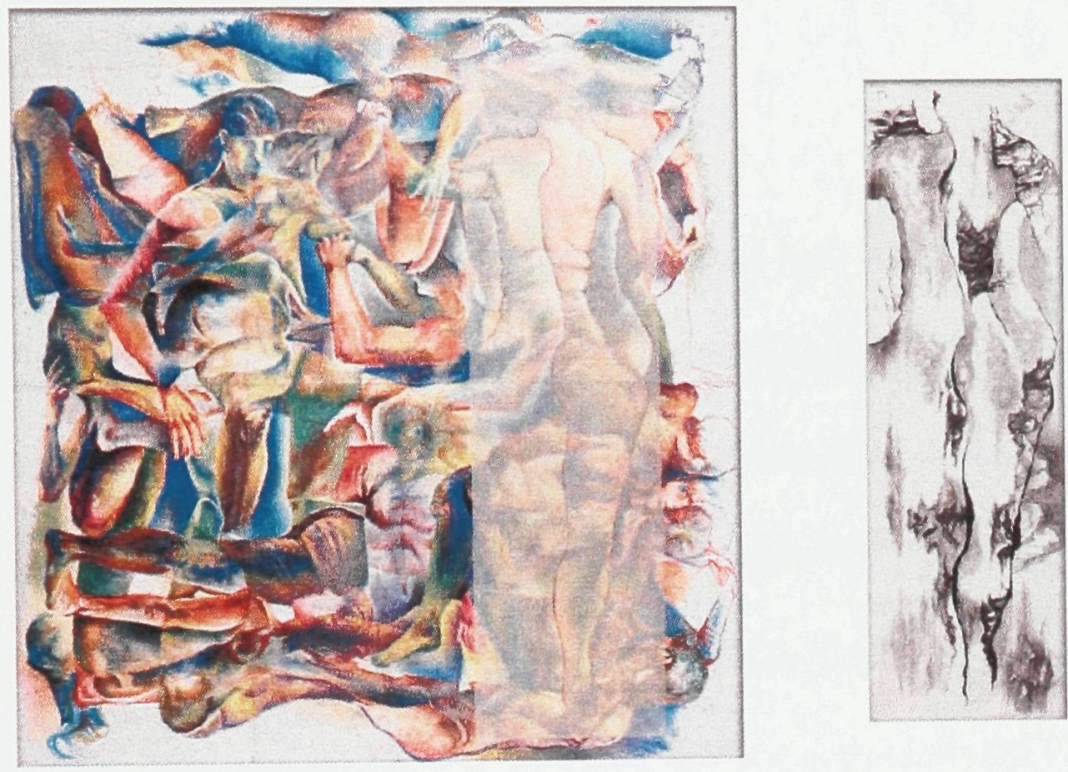

Plate 3.8: Demonstration of how lines were extrapolated onto tracing paper from the life drawing, and then of how the extracted lines were translated over to the Chinese painting on the right.

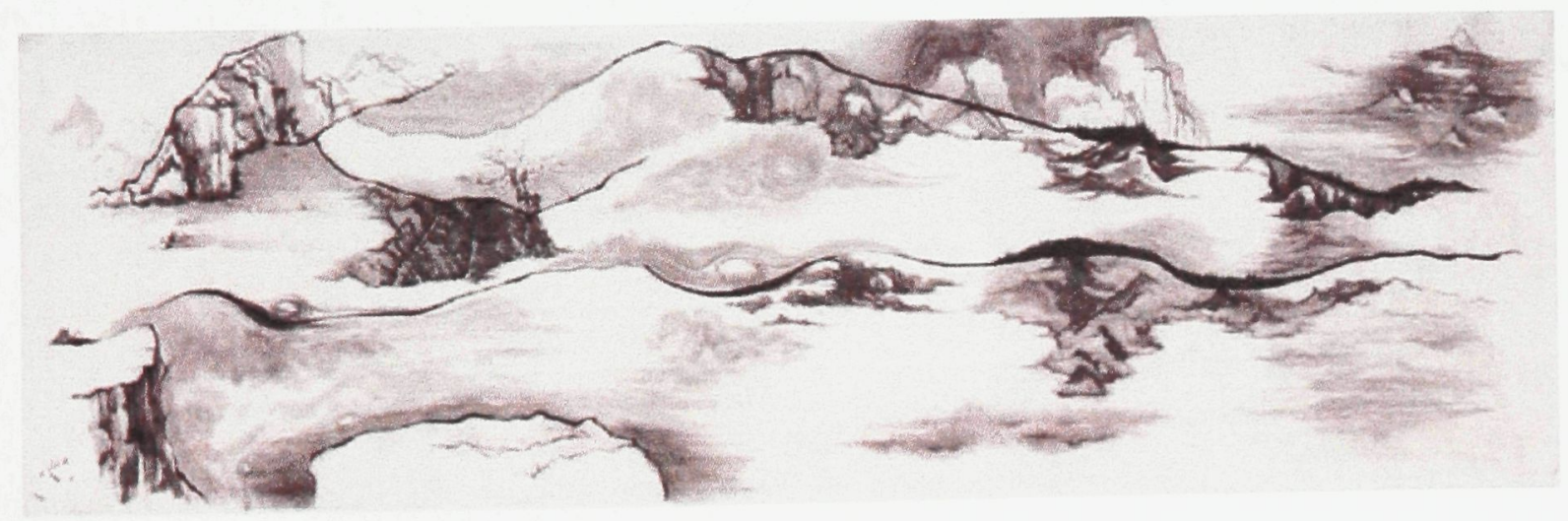

Plate 3.9: Horizontal landscape painting

(Refer to Appendic C for an enlargement of the drawing) 
In this first study (in the male orientation), the vertical contours of the male body were highlighted using tracing paper. These lines were then transferred using Chinese ink onto a scroll of rice paper. In its vertical orientation, it was difficult to imagine an alternative reading of the lines. But when the entire scroll was rotated 90-degrees counter-clockwise, the lines immediately turned into rolling hills and flowing rivers. Thus, a vertical section of the body, rotated, became a Chinese horizontal landscape painting.

The process of creating these Chinese paintings demonstrates how a different perception of the same body can be represented. The first representation of the body, the life drawing, captures the Western anatomical muscles. The second representation of the body, the landscape paintings, captures the Eastern topological landscapes. The Western anatomical drawings convey the body's visible structure and form, while the Eastern landscape drawings depict the invisible relationship of life and breathe. Each representation tells a different tale in the story of the body. Therefore, combining these two representations will enable a complete understanding of the body. 

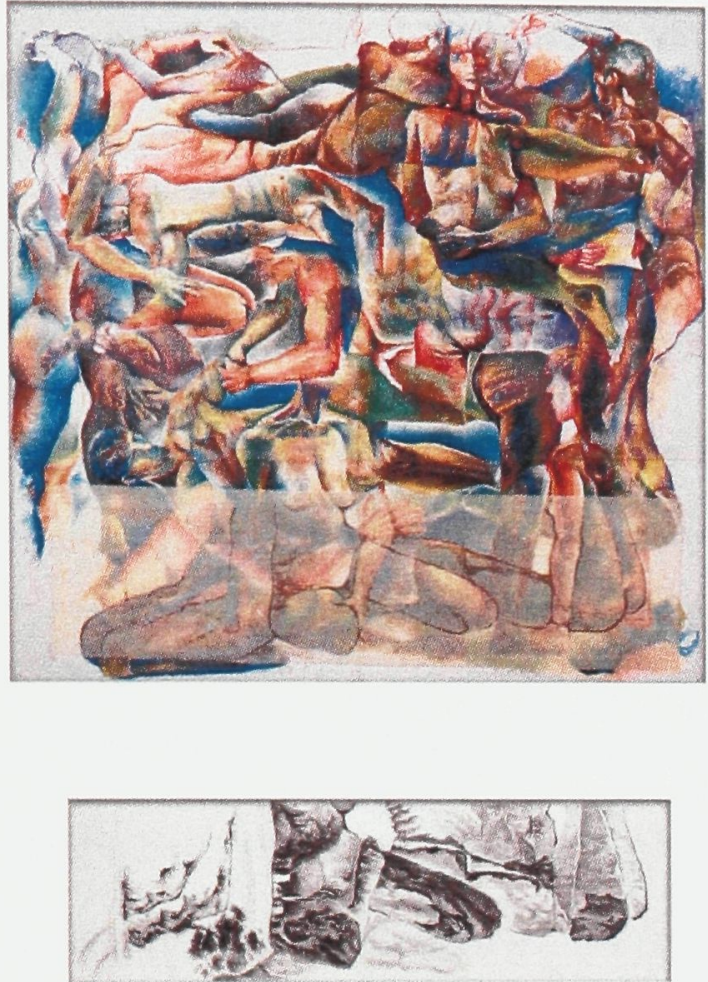

Plate 3.10: Demonstration of how lines were extrapolated onto tracing paper from the life drawing and then of how the extracted lines were translated to the Chinese painting on the right.

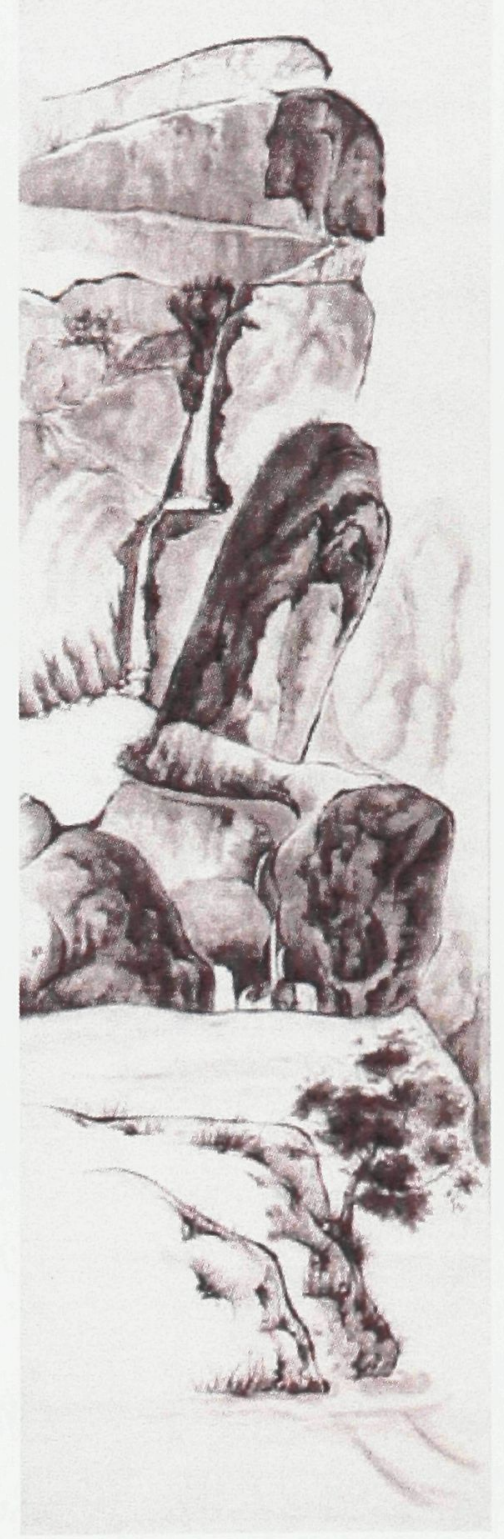

Plate 3.11: Vertical landscape painting Similarly, a repeated attempt was done over the female body (horizontally, in the female orientation). This time, the horizontal section was rotated 90 -degrees vertically to become a Chinese vertical landscape painting.

(Refer to Appendix C for an enlargement of the drawing) 


\subsection{A BALANCED BODY:}

Let us take a step back and analyse how all of this fits into our study of the East and West. Isolating the object of the body from the study of human interactions (anthropology) has removed the 'cultural' connotations of East and West. It became an objective study of Chinese and Greek medicine. The divergence of the two distinct medical arts allows us to perceive what the other 'sees', in order to reflect upon our own perception:

The puzzling contrast between envisioning muscularity and gazing at se [can never be solved by the Greeks or the Chinese themselves]. For the puzzle is only partially about contrasting ideas of anatomy and physiology. It also involves diverging perceptions of persons, disparities in how people see and experience their own being. ${ }^{29}$

The differences in perception exist even without issues of East and West, for two people can never see and experience in the same manner. This is observed through the artistic representations of the body. Two points of view on any matter bring more clarity than one. The knowledge of the body was thus enhanced when both perceptions were united. "Western medicine excelled in anatomy, Chinese medicine excelled in palpation. The future of medicine lay in their

\footnotetext{
${ }^{29}$ Kuriyama, Shigehisa (2001), pg 192
} 
combination." 30 The East and the West both have their strengths and weaknesses. Combining the strengths of each society will help to eradicate their weaknesses and ease the tensions that exist between the two. The strategy to co-exist the East and the West is to use the strengths of one to counteract the weaknesses of the other in order to achieve a balance.

In the representations of the body, we have learned that the cultural differences between the East and the West exist because of perception. However, the real problem of representing what is observed in our world is the perception of distance. The difficulty is in capturing the sense of depth and space of a three-dimensional world on a two-dimensional medium. The next chapter explores the Eastern and Western perceptions of distance and their respective methods of projecting space. By combining these two techniques of understanding distance, a united architectural spatial arrangement that co-exists the East and the West can be achieved.

\footnotetext{
${ }^{30}$ Kuriyama, Shigehisa (2001), pg 38. Quoting Quan Hansheng, "Qingmo xiyang yixue chuanru shi guoren suo chi de taidu," Shihuo 3.12 (1936): 50.
} 
四 Distance | Tension 


\subsection{DISTANCE CHECK:}

"One of the great mistakes of beginners was said to be "not distinguishing between the near and the far' (yuan chin pu fen) - Needham (1971, pg 112)

The division that exists between the East and the West is also grounded in 'distance', based first on their geographic segregation, on a physical distance. The 'other' was easily avoided due to this distance, and therefore any tension that may have existed was minor. Yet as technology diminished this physical distance, a new form of separation took its place, a cultural and historical distance that is accumulated over time as westernization embraces the goals of imperialism. Now, as physical distance no longer exists between the East and West, it eliminates the physical boundaries containing historical distance creating tension that must be dealt with. As historical distance builds over time, it can also be resolved through time. Distance is a matter of perception, and as long as it is possible to alter one's perception, then distance can be overcome. To understand how the East and the West perceive physical and historical distances, we have to look into the world of art. The knowledge will facilitate the translation of distance into a space that enables the altering of one's perceptual world. 


\subsection{DIVERGING PERSPECTIVES ON DISTANCE}

In art, the act of drawing and painting are both processes of translating a three-dimensional physical space onto a two-dimensional surface. Artists have to learn how to address the loss of one dimension, which is the projection of distance experienced in space onto a medium that is planar and without distance. In other words, artists are required to differentiate between objects that are near from those that are far away. In the West, artists, under the influence of optics and Euclidean geometry, developed the 'Laws of Perspectives'. Conversely, in the East, science and mathematics were not used to explain distance; yet depth was achieved otherwise.

The West's perception of distance in art was well governed. The "laws of perspectives" were discovered in the Renaissance to express three-dimensional space as a function of linear perspective. ${ }^{1}$ Linear perspective is the most common form of perspective used by artists in the Western world. It forces parallel lines to converge at a vanishing point in the distant horizon. Railroad tracks and highways appear to converge at a single point; it is what our eye 'sees' and the science of optics. ${ }^{2}$ In this manner, planes parallel to the horizon line and perpendicular to the perspective lines increase in size as they move away from the vanishing point. At the horizon, we have the background plane. Objects in this plane are the smallest. The plane closest to the spectator is the foreground plane and objects here are the largest. Therefore under linear perspective, spatial distance is achieved using size to differentiate objects in space.

\footnotetext{
1 Hall, Edward T (1990) The Hidden Dimension. New York: Anchor Books. Pg 86

2 Hall (1990), pg 191(Appendix).
} 
The East's perspective of distance was governed by height. Joseph Needham states:

[l]n Chinese drawing distance had always been represented by

height, so that one object standing behind another had been

drawn above it, and not necessarily smaller. This has the result

of giving to many Chinese pictures the character of bird's-eye

views. Everything is seen as if from a height. ${ }^{3}$

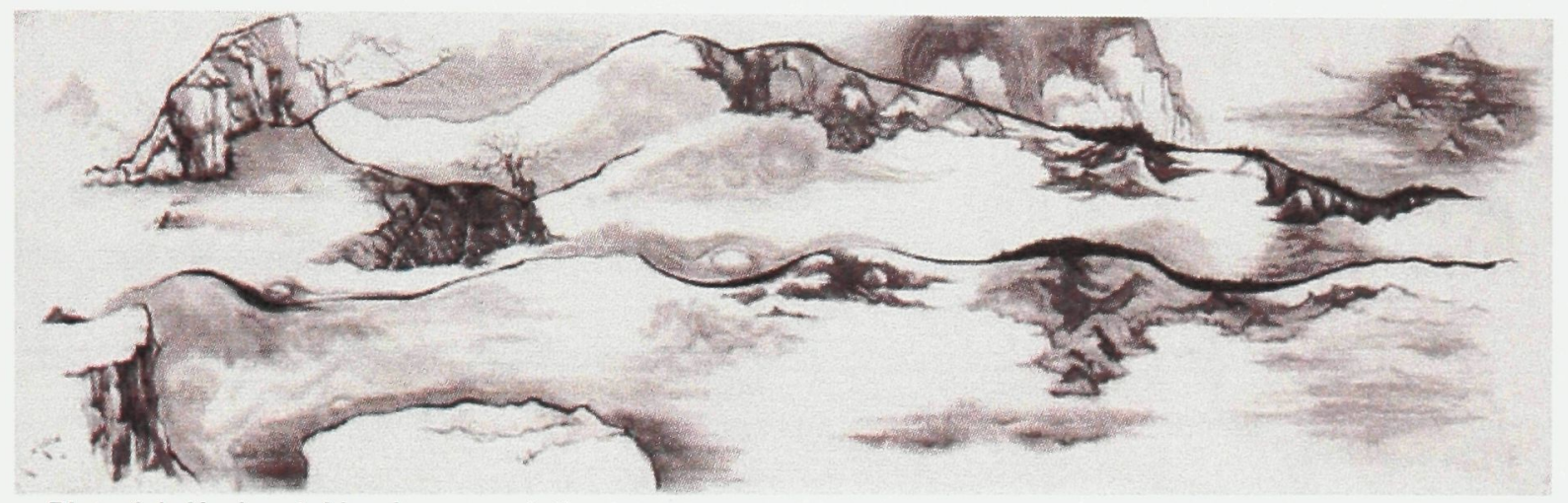

Plate 4.1: Horizontal landscape painting

Chinese ink on rice paper, 18" x 54"

The painting in plate 4.1 is considered Chinese in style not because they were done using Chinese brush, ink and paper, but because of its method of projecting distance onto a vertical scale. In plate 4.1, the rock cliff's positioning at the bottom of the painting is based on its proximity (being the closest) to the viewer in reality. The river flowing behind is placed above the rock cliff. The mountains beyond the river - being the furthest away - are placed at the top of the painting. Indeed, the spectator's angle becomes a bird's eye view, hovering above the landscape. The use of height and size describes a spatial quality on a two-dimensional medium. In other words, both strategies achieve the same goal, but in different ways - using different perspectives. Needham quotes:

${ }_{3}$ Needham, Joseph (1971) Science and Civilisation in China (series). London: Cambridge University Press. pg 112 
Let it be accepted, ... that on the whole there is no true vanishing point in Chinese drawing, and no exact rules of foreshortening ... [W]hat they employed was 'parallel perspective', i.e. a system in which lines, which were parallel in fact, remained so in the drawing. The Chinese, who had little or no Euclidean geometry, remained faithful to the postulate that parallel lines never meet at all, even in pictures. ${ }^{4}$

The Chinese used a form of perspective, the oblique perspective; one based not on what the eye 'sees', but one that was true to nature, where parallel lines never meet.

The Chinese has used this method of height to demonstrate spatial distance since year one A.D ${ }^{5}$. They solved the problem of distance without the knowledge of optics that developed in the West. Despite the differences in their forms of perspective, both the East and West managed to convincingly depict a sense of distance in their art. Just as their etymologies are different but the same, so too are their unique abilities to translate distance. Linear perspective represents what the eye sees, while parallel perspective renders what the mind knows. Both methods are used today in architectural representation. Oblique and Parallel perspectives, or axonometric drawings are useful in architecture because they capture three-dimensional space without distortion to actual numerical dimensions (plate 4.2). Perspective drawings on the other hand render an impression of what has yet to be built, a projection of what the eye will see (plate 4.3).

${ }_{4}^{4}$ Needham, Joseph (1971) Science and Civilisation in China (series). London: Cambridge University Press, pg 113 ${ }^{5}$ Needham (1971), pg 112 
Plate 4.2: Axonometric Drawing Graphite on vellum, with Canson coloured paper layered behind, 28" x 24" (Refer to Appendix D for an enlargement of the drawing)

Plate 4.3: Perspective Drawing Chinese ink on rice paper, 32 " $\times 24$ "

(Refer to Appendix D for an enlargement of the drawing)
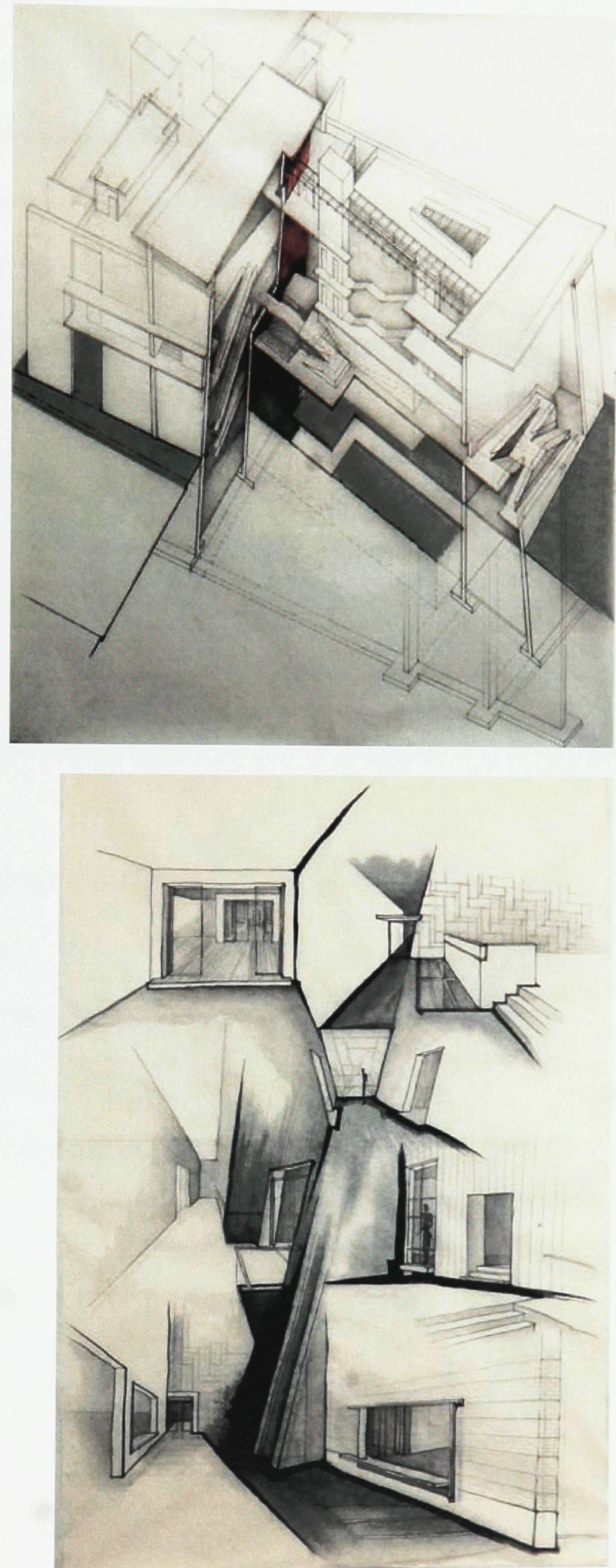
The axonometric drawing and the perspective drawing both depict the same space, yet there is something astonishingly different between them. The axonometric drawing aids in the understanding of the actual physical dimensions - size and scale - of spaces, while the perspective drawing aids in the understanding of the visual dimensions - light and materiality - of spaces.

Oriental art shifts the viewing point while maintaining the scene as constant. Much of Western art does just the opposite. In fact, a most significant difference between the East and the West although it is reflected in the art far transcends the field of art. Space itself is perceived entirely differently. ${ }^{6}$

The two drawings appear to be two entirely different views only because they were created within two perceptual worlds. Space contains more than just a three-dimensional physical distance; embedded within are cultural distances as well. Art allows us to understand how to perceive physical distances with the eye. It also illustrates that another form of distance exists. To understand how to perceive cultural distances in space we need to employ our other senses.

${ }^{6}$ Hall (1990), pg 74 


\title{
4.3 PROXEMIC SENSORY ON DISTANCE
}

We have yet to draw a similarity between the cultural division of the East and West and the physical distance that stands between them. To achieve this, we must consider distance in a social sense, in the sense of 'proxemics'. It is a term that Edward T. Hall has "coined for the interrelated observations and theories of man's use of space as a specialized elaboration of culture." ${ }^{.7}$ For Hall:

\begin{abstract}
Man's sense of space and distance is not static, that it has very little to do with the single-viewpoint linear perspective developed by the Renaissance artists ... Instead, man senses distance as other animals do. His perception of space is dynamic because it is related to action - what can be done in a given space - rather than what is seen by passive viewing. ${ }^{8}$
\end{abstract}

The study of proxemics deals with man's action within the changing space. Proximics tells us that the eye alone is not enough to experience our dynamic world. "[l]t is in the nature of animals, including man, to exhibit behaviour which we call territoriality. In so doing, they use the senses to distinguish between one space or distance and another."9 The senses discussed by Hall are the methods our body uses to interact within a space. We distinguish between distance by an abstract feeling of what is close and what is far. It is not a sense of touch, for you can never place your hand on distance, yet it can be felt. This feeling of distance is a matter of perception, influenced by

\footnotetext{
7 Hall (1990), pg 1

${ }^{8}$ Ibid, pg 114-115

${ }^{9}$ lbid, pg 128
} 
a territorial sense of comfort. A comfortable distance between two friends may be an offensive closeness to a different party. Hall continues:

The concept that no two people see exactly the same thing when actively using their eyes in a natural situation is shocking to some people because it implies that not all men relate to the world around them in the same way. ${ }^{10}$

This is the nature of man; we all have different perceptual worlds, and therefore different measures of distance. These differences exist even without culture. Yet the similarities in the perception of distance between the East and West lay in the universal human body. We once again return to use the body as an objective tool. The body is what one uses to detect distance. It is an object that functions in the same manner whether it is in the cultural context of the East or the West. Culture does have control over the establishing of one's perceptual world. Hall tells us that there is:

[s]ignificant evidence that people brought up in different cultures live in different perceptual worlds is to be found in their manner of orienting themselves in space, how they get around and move from one place to the next. ${ }^{11}$

10 Hall (1990), pg 69

${ }^{11}$ Hall (1990), pg 70 
Humans all have different perceptual worlds, and therefore different measures of distance. The study of proxemics tells us that humans orient themselves in space with the use of their body. It is by utilising the human body that we will unify the cultural distance between the East and the West. To use the body is to understand how it moves in space to detect distance. This knowledge enables the development of a strategy to translate spatial perceptions into an architectural space. It is a space that will co-exist the East and the West. The strategy for unification is to have one's perceptual world altered.

\subsection{THE 'TENSIONS' OF ALTERITY}

Actions in space are cultural. What we do in it, how we navigate through it, define the cultural distances of a space. Hall explains the differences in how the East and the West domesticate a space.

When Westerners think and talk about space, they mean the distance between objects. In the West, we are taught to perceive and to react to the arrangements of objects and to think of space as 'empty'. The meaning of this becomes clear only when it is contrasted with the Japanese, who are trained to give meaning to spaces - to perceive the shape and arrangement of spaces. ${ }^{12}$

\footnotetext{
12 Hall (1990), pg 153
} 
One way to interpret the statement is that the West considers space as emptiness, while the East attaches meaning to it. Another way to interpret the statement is that the West focuses on the arrangement of objects while the East focuses on the arrangement of the surrounding space. The former interpretation places the East and West in opposition to each other, where space is defined differently. The latter, on the other hand, positions East and West in attraction to each other, where they each define half of the problem, and together they complete the picture. Both interpretations have constantly existed in our understandings of perception; it is the tension between the East and West. This tension will exist for as long as there are different perceptual worlds. But because tension exists as both forces of attraction and repulsion, it is what we must use for translating a unified space.

The architectural space that will result from understanding physical and cultural distances requires the existence of tension. It is this tension that causes one to be constantly aware of his surroundings. "The regularity of distances observed for humans is the consequence of sensory shifts."13 Humans use their senses to make distance checks as they engage actively in dynamic spaces. Since space is not static and we are always moving in space, it is fair to say we are constantly re-positioning ourselves in space, constantly redefining distances. In familiar spaces, distance checks can be less frequent, but in new territories under new sensory shifts, new definitions of distances need to be established. All of this reinforces the notion that one's measure of distance is a learnt behaviour, and it is constantly redefined with exposure to sensory shifts. Therefore, it is proven that the perception of distance can than be altered and changed, allowing for a possible architecture that diminishes the distance between the East and the West.

\footnotetext{
13 Hall (1990), pg 113
} 
The architectural spaces must be designed with the following aims:

1. Activating the bodily sense through sensory shifts (constant versus moving)

2. Disengaging old perceptual worlds through the need to redefine measures of distance

3. Co-existing East and West through the use of tension to animate space

\subsection{EMPLOYING TENSION AGAINST DISTANCE}

All architecture requires a site. There is no better country than Canada that can address the tensions between the East and the West. Canada is known for its hospitality towards immigrants. It is no wonder that "the 2006 Census enumerated 6,186, 950 foreign-born people in Canada. They accounted for virtually one in five (19.8\%) of the total population, the highest proportion in 75 years." 14 In addition, it is the first time that an estimated number of 1,034,000 people reported one of the Chinese languages as their mother tongue. ${ }^{15}$ This "reaffirmed the position of the Chinese languages as Canada's third most common mother tongue group, behind English and French."16 Amongst recent immigrants, $58.3 \%$ were born in Asia. ${ }^{17}$ All of these statistics prove how culturally diverse Canada is, and how Asian immigrants - Chinese in particular - are influencing the

\footnotetext{
14 "2006 Census: Immigration, citizenship, language, mobility and migration". The Daily, 2007. Statistics Canada. $<$ http://www. statcan.ca/Daily/English/071204/d071204a.htm >

$15 \mathrm{lbid}$, "This was an increase of $18.5 \%$, or 162,000 , from 2001. In 2006, they accounted for $3.3 \%$ of the total population of Canada, up from $2.9 \%$ five years earlier."

16 lbid

${ }^{17} \mathrm{Ibid}$, "Recent immigrants born in Asia (including the Middle East) made up the largest proportion (58.3\%) of newcomers to Canada. This was virtually unchanged from $59.4 \%$ in 2001. In contrast, in 1971, only $12.1 \%$ of recent immigrants for this period were born in Asia."
} 
demographics of Canada. The recent statistics also show no signs of decline in the influx of Chinese immigrants. It is on this continuous force of arriving immigrants that, we can test the methods of diminishing distance between the East and West.

According to the same 2006 Census, in 2006 3.2\% of immigrants chose Ottawa-Gatineau to settle in. ${ }^{18}$ This is the fifth most popular city amongst immigrants. The city of Ottawa is the nation's political capital. Within the last five years, Ottawa's rapid growth has enabled it to become a census metropolitan area. In terms of population, Ottawa is placed fourth amongst the largest cities in Canada. ${ }^{19}$ Due to this popularity from immigrants and the city's importance to Canada, it makes Ottawa an ideal site for the architectural aims.

The thesis proposes a host and guest relationship between Canadians and Chinese immigrants in a transitional housing complex. The architecture will be united by the tension that exists between these two groups. There is a force of attraction between them that enables an interdependent relationship to exist. The host, the Canadians interested in going to the East, and the guest, the Chinese immigrants coming to the West, are the two halves that make up the whole of this architecture. There is always a tension and a degree of hostility between a host and its guest until both parties get to know one another; after that, hospitality is experienced. The same goes for a new and unfamiliar architectural space. The hostility of the uncharted space will require its guests to establish new measures of distance. Using the bodily senses to navigate through the

\footnotetext{
$18 \mathrm{Ibid}$, "In 2006, 5.2\% of newcomers chose to live in Calgary, 3.2\% chose Ottawa-Gatineau, 2.9\% chose Edmonton and $2.2 \%$ chose Winnipeg."

${ }^{19}$ City of Ottawa (2005) "Table 1: Population of Canada's Six Largest Metropolitan Areas". Annual Development Report. 2005. <http://www.ottawa.ca/city_services/statistics/dev_report_2005/pdf/table_1_to_30_en.pdf>
} 
architecture (the host), participants (the guests) will arrive at hospitality by interacting within the space. Placing both groups of people as guests against the architectural host creates an interconnecting bond between them, allowing them to work together to conquer the hostile spaces. Therefore, there is a double play in the host and guest relationships; one between the two groups of inhabitants, and the other between the architecture and its inhabitants. The architecture provides a place where hostility becomes hospitality, where the roles of host and guest are exchanged, and the diverging perspectives of the East and West are altered. In time, the guests will experience hospitality; it is then that the guest becomes the host, as new Canadians, and the host becomes a guest, as an emigrant to China. Both groups will understand the tensions and distance between the East and the West, for their perceptual worlds will be altered.

\subsection{IN BETWEEN NEAR AND FAR}

The chosen site is a lot near the west end of the downtown financial core of Ottawa. The site offers the convenience of being in the heart of Ottawa while its close proximity to apartments and houses creates the opportunity for a new urban community. The site has been chosen for its ability to remove some trivial barriers that most newly arrived immigrants face, and provides easy access to public transit and Chinatown. The public transport system in Ottawa has a rapid bus line - the Transitway. Through the downtown core, the Transitway uses two one-way streets, Albert Street 
to head west, and Slater Street to head east. The site is located in between these two streets and to the west of Lyon Street North.

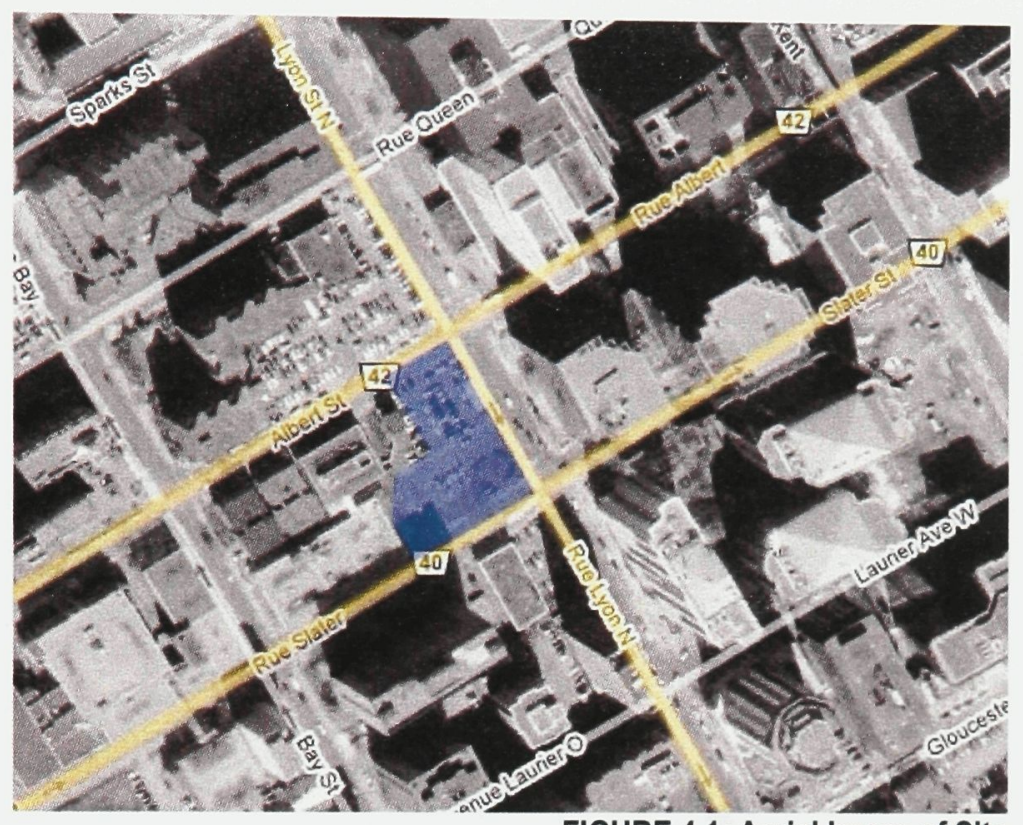

FIGURE 4.1: Aerial Image of Site Highlighted in blue is the site

Historically, Ottawa has not been a popular choice for Chinese immigrants. The first group of Chinese immigrants in Ottawa appeared after the Second World War. Unable to obtain jobs, they either opened or worked in restaurants, laundromats, and convenience stores mostly centred on the intersection of Banks Street and Albert Street. It wasn't until the 1980's that the number of Chinese immigrants greatly increased, and business settlements moved into the current Chinatown on Somerset Avenue. Now, on both sides of Somerset, from Lyon Street in the east to Preston Street in the west, are stores owned by Chinese Canadians. The chosen site is approximately a ten-minute walk from Chinatown. Having the Chinese community in close proximity would provide some hospitality amongst all the hostility experienced by the immigrants. 
The proposed transitional housing complex would contain private dwelling spaces for eating and resting and communal spaces for interaction and social activities. In addition, there would be spaces for community engagement, such as a language resource centre, a restaurant, a market place and various gardens. Below is a detailed listing of the program:

Main Entrances (2), each with:

Lobby

Information / Security Desk

Escalator / Elevator / Stairs

Restaurant:

Lobby / Reception / Waiting area

Kitchen (2)

Dining Hall

Private Room

Washrooms

Market:

Lobby / Entry / Cashier desk

Vending area

Storage area

Garden

Elevator and Loading area

Language School/Resource Center:

Lobby / Administration desk

Rooms of various sizes

Reading area / Library

Washrooms

Residential Apartments:

Security/Lobby

Mailroom

Greeting/Waiting Room

32 Units various sizes (max. 80 people occupancy)
正門 (兩個) 各自有:

大堂空間

詢問處

電梯 $/$ 樓梯

餐廳:

大堂|招待

廚房

大飯廳

私有室

洗手間

市場:

收銀處

販賣區

存貯 / 倉庫

公園

上/落貨區

語言學校/資源中心:

招待處

大小會議室

圖書間 / 閱讀間

洗手間

住宅公寓:

私有大堂

郵件室

等待間

三十二間, 不同大小的單位 (高達 八十人居住) 
Bachelors, One-Bedroom, Two-

Bedrooms, Barrier-free units

Courtyards

Gardens:

Greenhouses

Playground

Pavilions

Barbeque areas
單人套房, 一房一廳, 兩房一廳, 護理套房

庭院

庭園:
温室
游樂場
亭子/庭園
燒烤區

Arriving to the site one will either be welcomed by the open public spaces and gardens framed by the soft brick walls on Lyon Street or intercepted by the inhospitable, heavy concrete walls aligning Albert and Slater Streets. There are two public entrances: one entry for those coming from the North, or Albert Street, and another for access from the South, or Slater Street. (Plate 4.4)

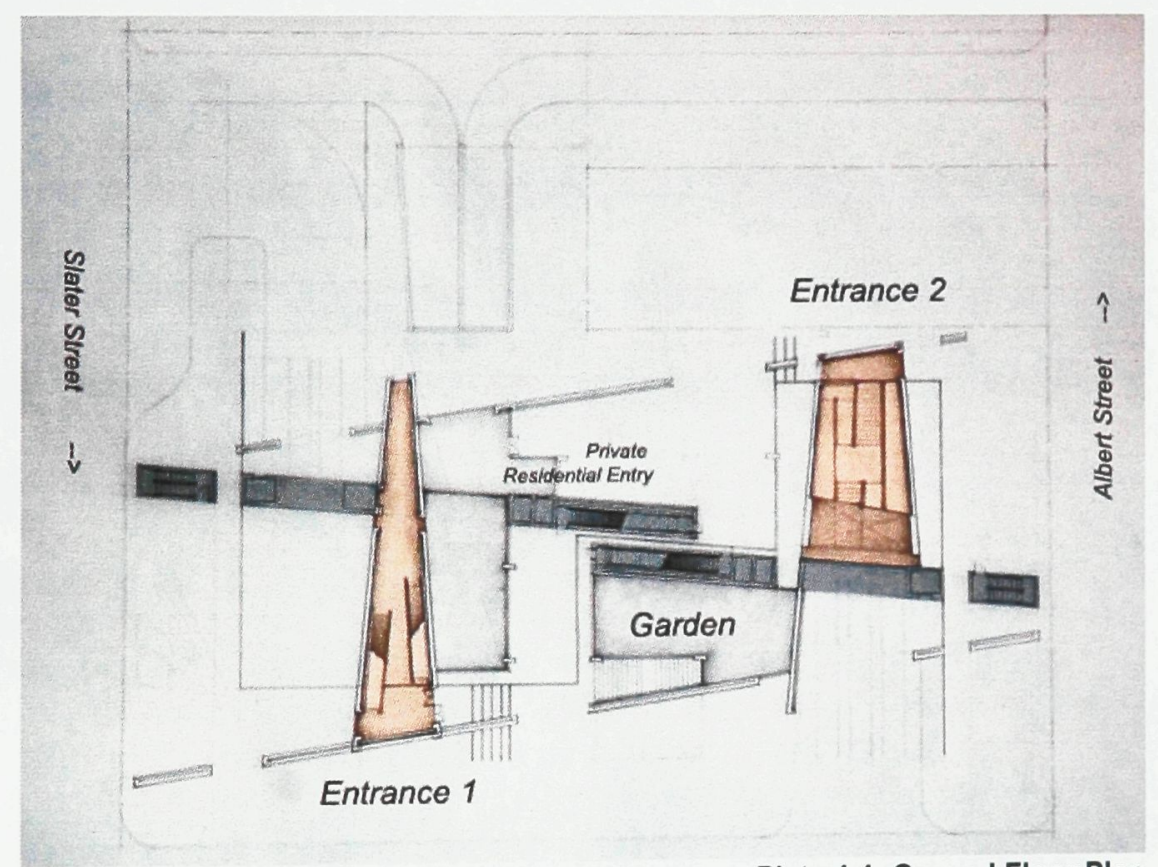

Plate 4.4: Ground Floor Plan Main Program: Entrances and Public Gardens (Refer to Appendix D for an enlargement of the drawing) 
From the North and South, the solid concrete walls are representative of the tension that exists between the architecture and its guests. The monolithic mass of the wall lacks any scale of humanness, echoing seclusion and hostility. (Plate 4.5) The few arranged openings, directs light to guide the eye into the soft, hospitable interior. Although the interior space is visible, one must use their senses to navigate through the hostile thresholds set up to physically conceal the entrances.

Plate 4.5: North Elevation

(Refer to Appendix D for an enlargement of the drawing, and other Elevations)

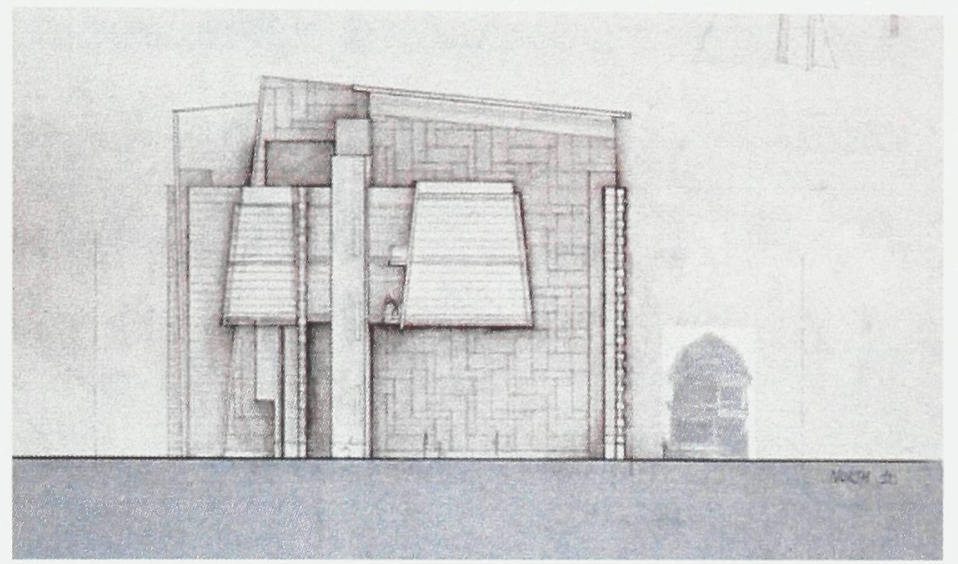

Having navigated past the North and South walls, one will find a friendlier East and West façade.

(Plate 4.6) The softness of the wood benches piercing the brick walls offers an opportunity to pause and engage into the public gardens. The change of materiality from concrete to brick returns to the architecture the warmth of a human scale. This hospitality continues to direct one into the two entrance lobbies.

Plate 4.6: East Elevation

(Refer to Appendix D for an enlargement of the drawing, and other Elevations)

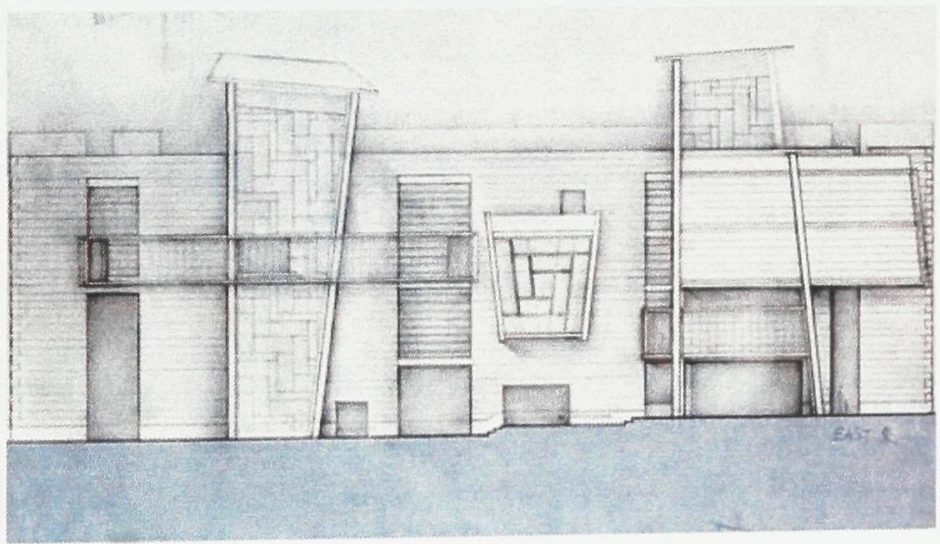


Upon stepping into the interior space, what appeared from the outside as hospitable immediately becomes hostile. It is in these two circulation lobbies that the general public can experience the greatest tensions with the architecture. These tensions are demonstrated in various drawings. In plan (plate 4.4), the space of one lobby converges while the other diverges as you venture into its depths. The walls not only shift in plan, but they do the same in section (plate 4.5). As one circulates vertically up the two spaces, in one the walls spread further apart, while in the other, the walls lean closer together. Being in these spaces, one is constantly forced to use their senses to establish new measures of distance in order to counteract the tension that exists.

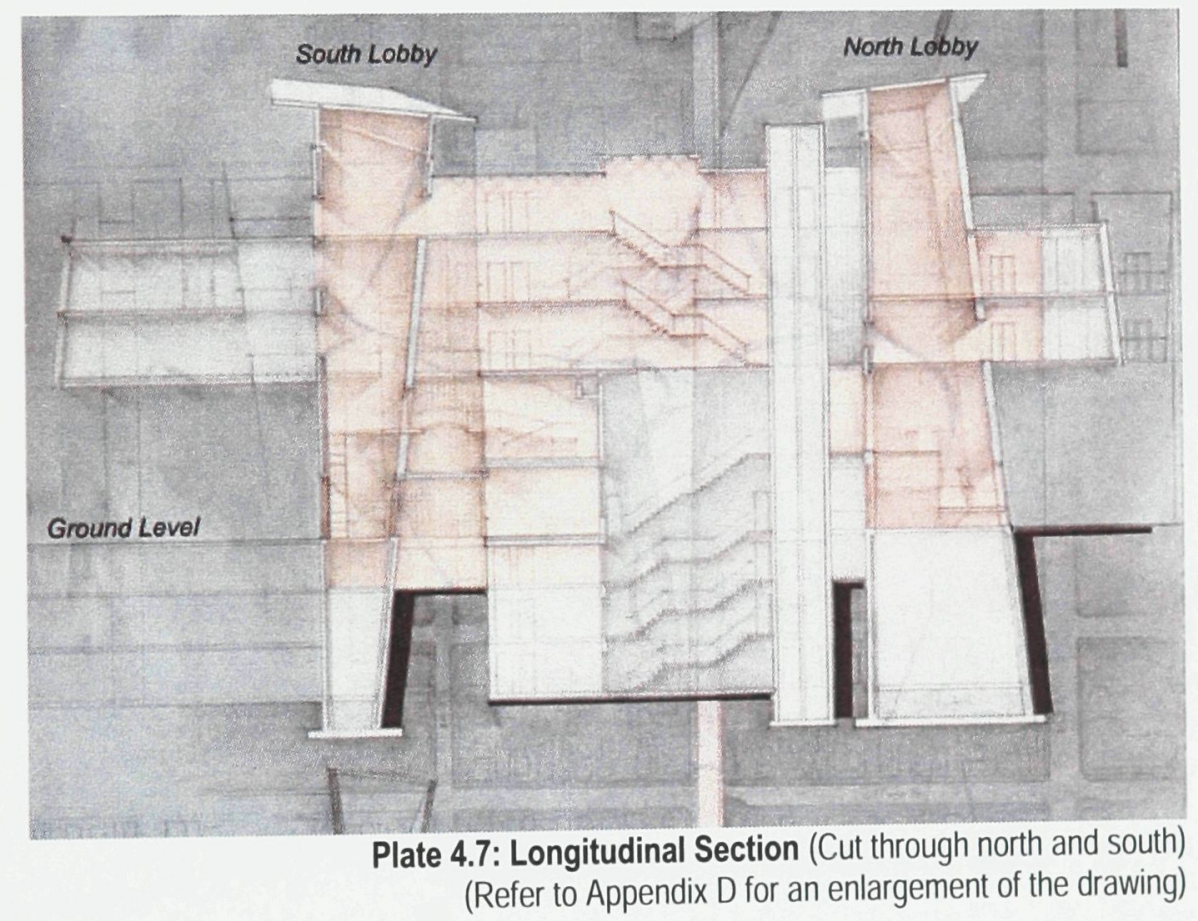

These lobbies are the circulation anchors for the building. From here one can have access to all six levels of the building, even the private spaces if they have been invited. The lobbies not only facilitate traffic to flow in and out of the site, they also perform as service shafts for ventilation, water and electrical circulation. All program spaces have physical connections to the circulation 
lobbies; sometimes these connections are only visual, meaning they allow for the eye to see into a space but not for the body to interact with.

The market place is a hospitable and inviting space. It is located in the basement level along with the open courtyard that is directly accessible from Lyon Street at ground level. (Plate 4.4 and 4.8) The sunken garden space invites the public into the heart of the site without entering into the interiors of the building. The lush landscaping provides warmth in the courtyard, while softening the roughness of the heavy walls. The market opens directly into the garden, blurring the boundaries between interior and exterior. This also allows for sunlight and natural ventilation to enter into its vending spaces.

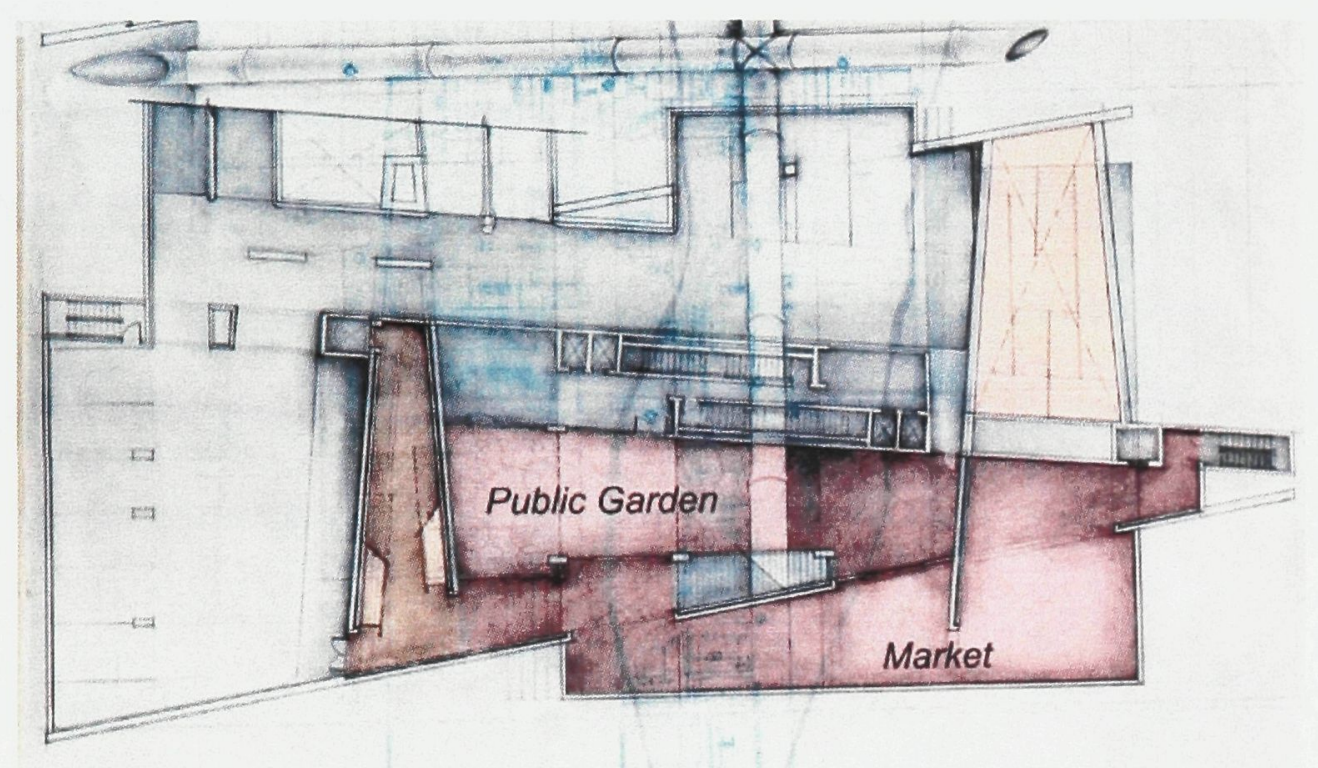

Plate 4.8: Basement Floor Plan Main Program: Market Place and Public Gardens (Refer to Appendix D for an enlargement of the drawing) 


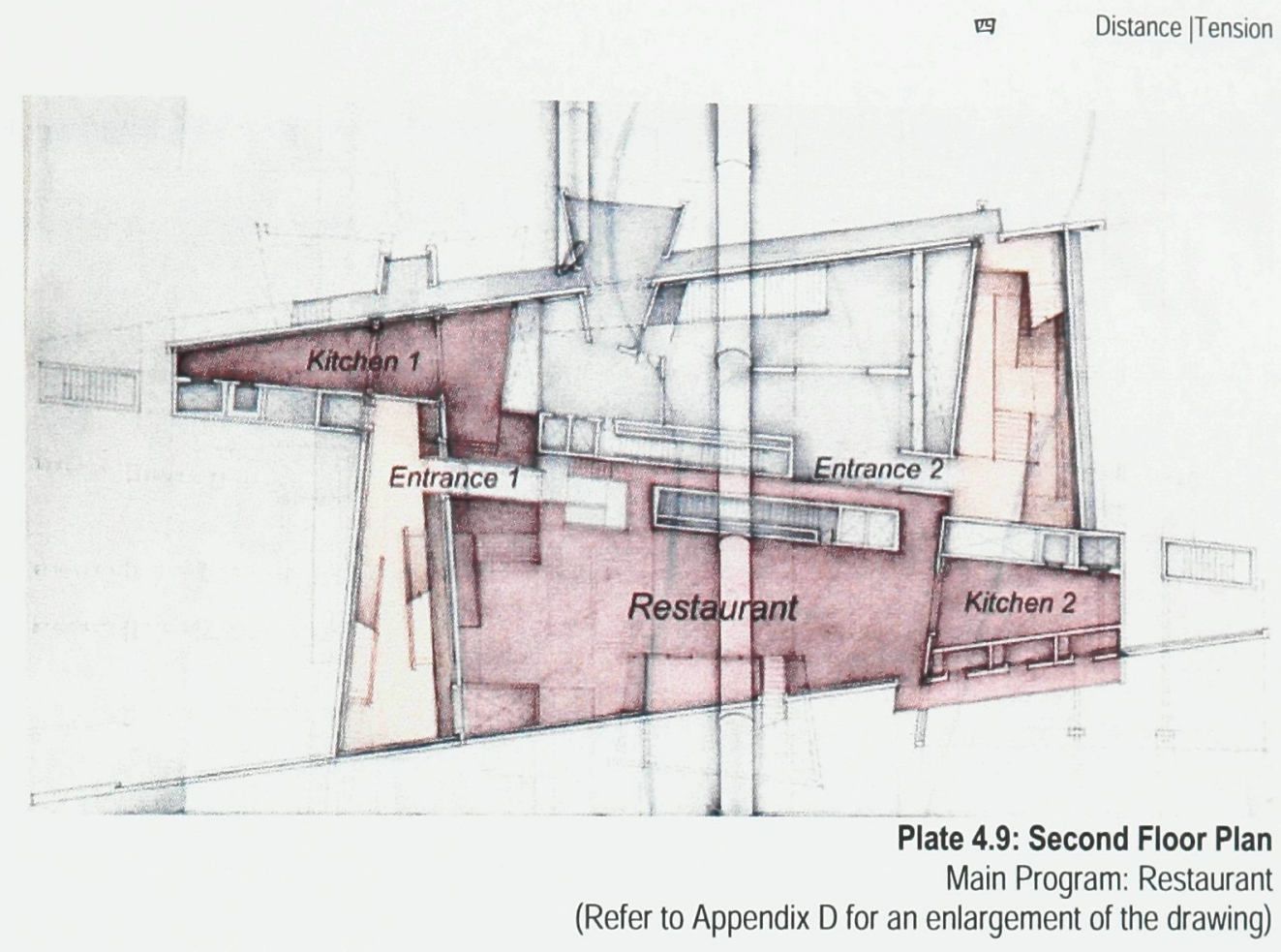

The restaurant is on the second level (plate 4.9), taking up a majority of the space on that level.

The restaurant has two entrances that lead into the same dining hall. Both entrances transition between the differences in light and materiality of two spaces. From a brightly lit, rough hostile lobby, to a dimmer, softer hospitable dining hall. At the dining table, a guest can order dishes prepared from both the Eastern and Western kitchens. Both kitchens are separate yet open themselves onto the unified dining space.

In addition, on the second level is a private, secure entrance into the apartments for the residences. This hidden entrance off the public courtyard leads into a warm gathering space used as the welcoming or waiting area. From here, residents can make their way up to the third floor - where the apartments are located - through elevators or staircases only accessible by the residents. This threshold space - like all threshold spaces in the building - bridges the change of light and materiality of two distinct spaces. The transition happens between materials of rough and smooth, 
hard and soft, or textured and plain. It is through the constant change in materials and transitioning between them that will enable the activating of bodily senses in order to navigate towards hospitality within a space.

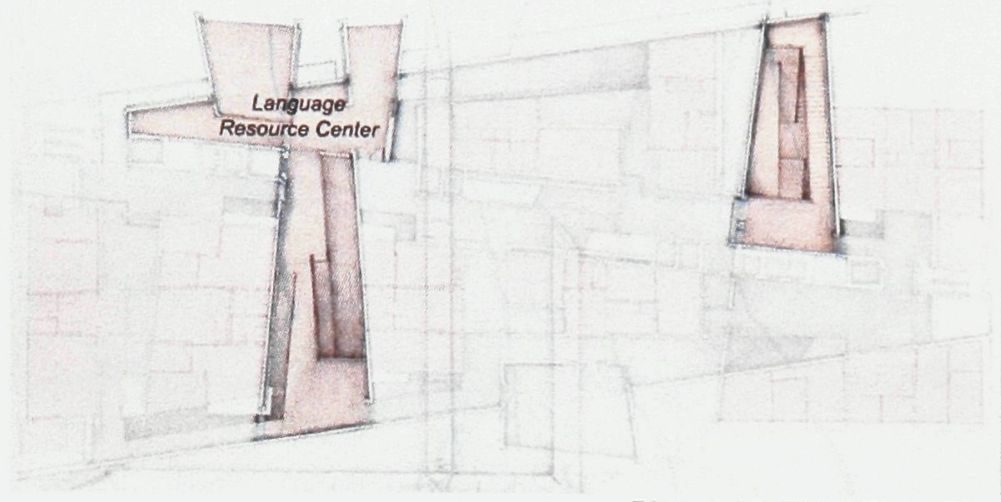

Plate 4.10: Third Floor Plan Main Program: Language Resource Centre and Residential Apartments ((Refer to Appendix D for an enlargement of the drawing)

The language resource centre is located on the third level (plate 4.10). It provides brightly lit rooms of various sizes for the purpose of learning languages. It is open during the day to the general public. There is a resource library containing materials that aid in the teaching and are made accessible to the residents at any time, even after public hours. This is made possible by having the resource centre located near the private realms.

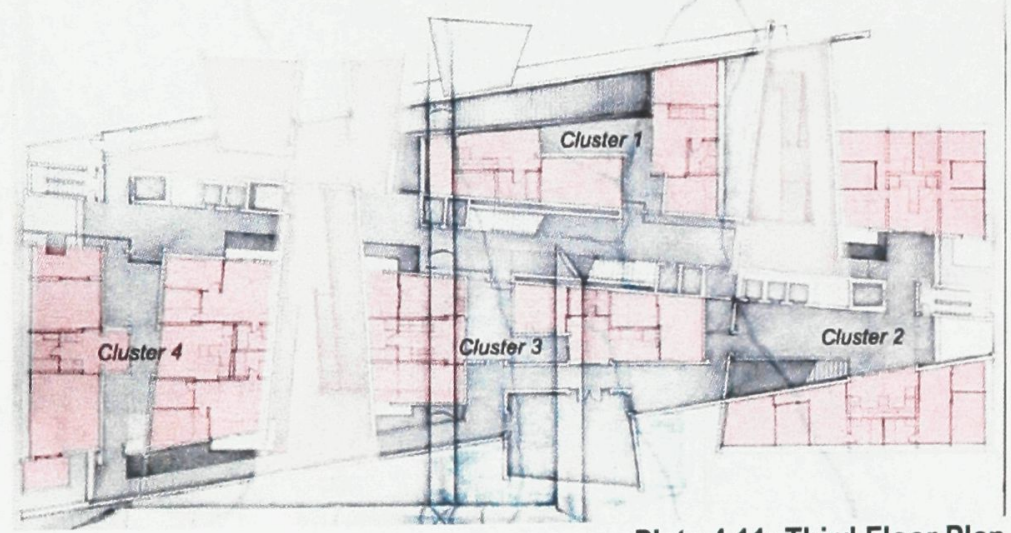

Plate 4.11: Third Floor Plan Main Program: Language Resource Centre and Residential Apartments (Refer to Appendix D for an enlargement of the drawing) 
The rest of the third level belongs to four clusters of apartments. (Plate 4.11) Each cluster contains two pairs of units, set up directly across from each other. Each pair of units houses Canadian(s) in one and immigrant(s) in the other. (Plate 4.12) They will engage their tension through a shared kitchen and dining area. Each communal area opens up to the opposite pair, forming a courtyard within the cluster. The courtyards and kitchens are brightly lit, warm and inviting spaces. It is designed to be the primary usable space for the inhabitants. In each pair of units, a structural stonewall separates the communal space from the private intimate space. The solid masonry wall provides privacy and detachment from all hostility when a retreat is needed. A sliding door within the masonry wall is used to regulate the connection between the communal and the intimate spaces. When the sliding door is open, the two spaces will flow into the other through the unity in materials joining them together. There are units of various sizes, designed to accommodate various groups of people, whether they are singles or a family of four, there will be a unit that is suitable.

Plate 4.12: Residential Cluster Detail Plan Communal courtyard and kitchen space Versus Private intimate living space

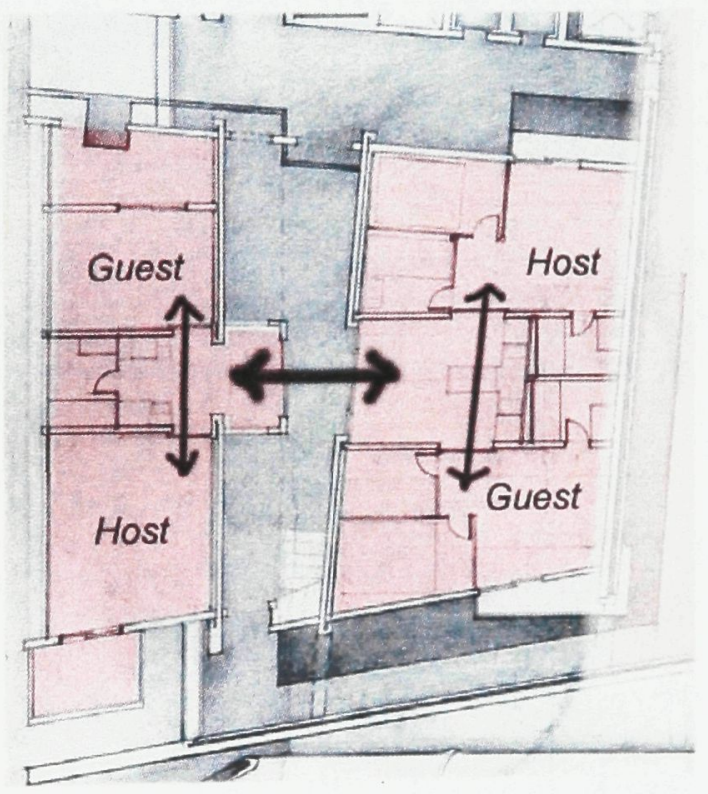


The fourth level is a second level of apartments. The same four clusters of units exist, in the same configurations. The two floors of residences are connected in the courtyard of each cluster forming a community. Therefore, a cluster of four in plan becomes a cluster of eight in section. The purpose of the courtyard is to allow the residents within the cluster to intermingle and work together. In section, stairs connect the residents from the courtyard up onto the roof top gardens. Sunlight and natural ventilation is used to enhance the courtyard space.

The rooftop gardens on the fifth level join all the clusters together (plate 4.13). The gardens can only be accessed by the residents and are meant for their private use. Even up on the rooftop, the tension does not stop. The various heights and materiality of the walls and shifting passageways control the arrangement of the gardens and the distances between them. The gardens are arranged to contrast one another, varying from sizes large and small to materials of rough stone and smooth landscaping. Many transitional thresholds are used connecting between the gardens, creating passages that change in elevation and levels of intimacy.

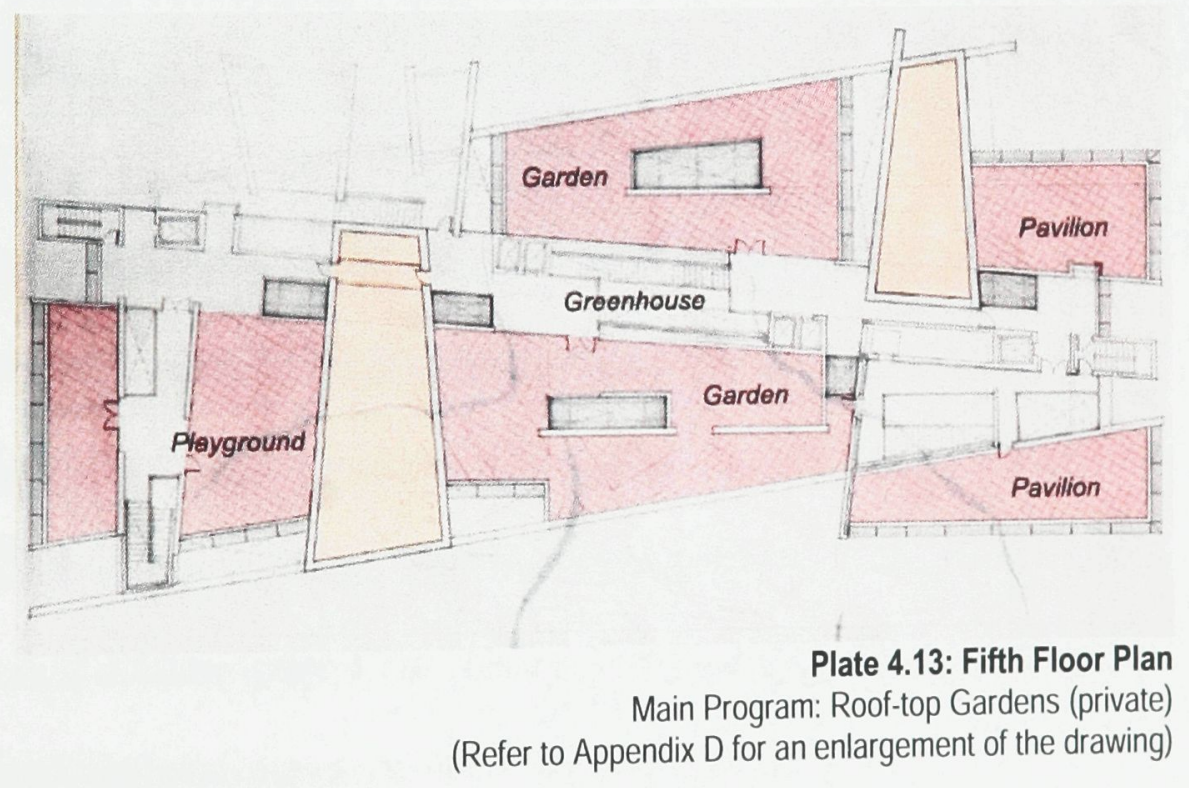


This spatial strategy is reflected in the 'maze' character of the entire building. One can never predict what is around the corner, due to the constant change in materials and qualities of light. The path is always twisting and turning, forcing one to change direction and search for an alternative path. The foot must pay attention to its every step. The hostile environment invites the hand to touch the walls to aid in navigation. The hospitality comes from a space that appears to be near visually, but since there is never a direct path, it is physically far and becomes hostile. In addition, there are always multiple pathways one can take to travel between two spaces. The instability and irregularity in the spatial planning creates the animated spaces required for the hostile building. It is an architecture that forces your bodily senses to constantly readjust. Tension will always exist within the spaces, yet eventually the body will come to an understanding and arrive at hospitality.

\subsection{PERSPECTIVE ALTERED:}

The transitional housing project proposed in this thesis has been designed based on the understandings of how the East and the West perceive physical and historical distances. The knowledge of distance has been translated into a number of spaces where tension constantly exists and the perception of distance is altered. By shifting the dimensions and angles of walls, it distorts the eye's measure of distance (plate 4.14). Setting up physical paths versus visual paths engages the body to constantly make changes to physically adapt (plate 4.15). 

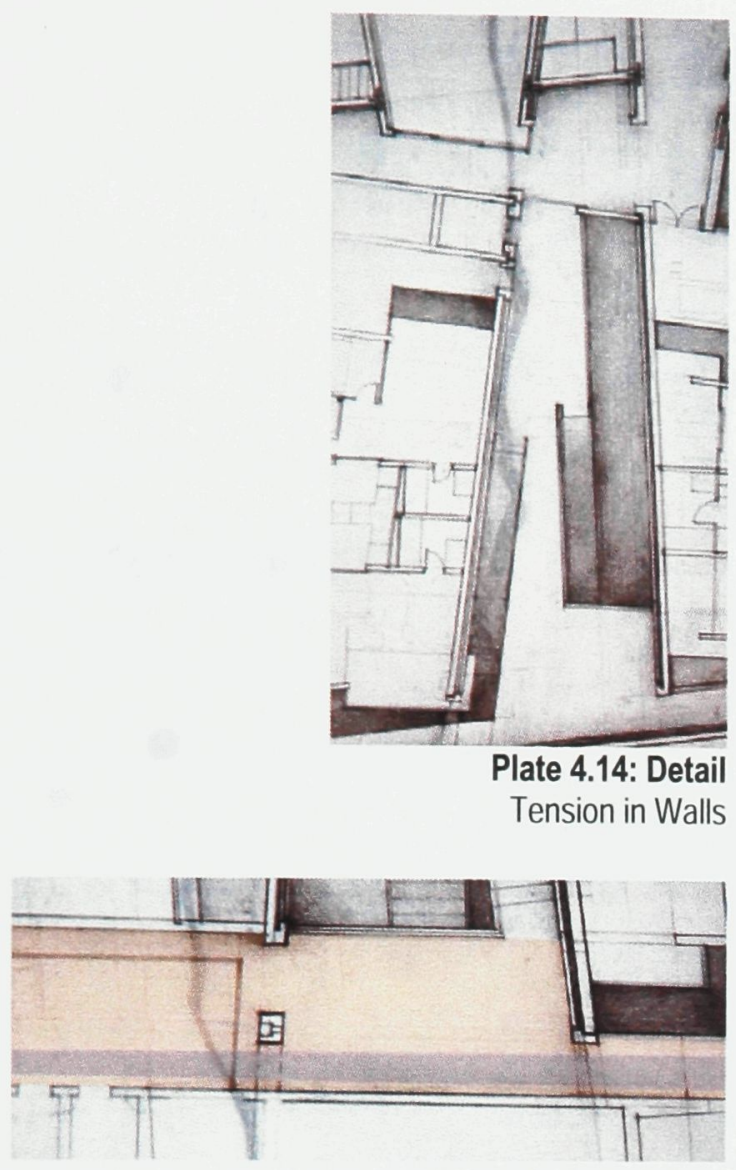

Plate 4.16: Detail Altering Near and Far Perceptions
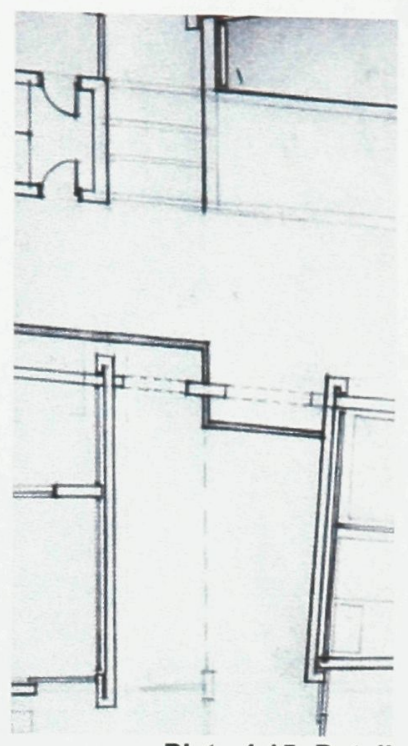

Plate 4.15: Detail Physical path versus visual path
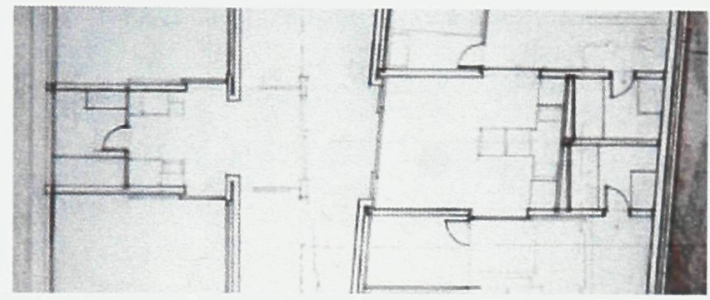

Plate 4.17: Detail Canadians and Immigrants as a pair

The optical illusions of the visual paths alter one's perception of near and far (plate 4.16). The constant change in elevations and material palette of the physical paths alters one's level of comfort. And lastly, tension is used to attract Canadians and immigrants together as a pair (plate 4.17), allowing them to work together in order to overcome the hostility within the architecture. Their perceptual worlds have been altered when they no longer find the building hostile. When the tension that once held them together has retreated behind the hospitality, then it is time for them to go their separate ways. The immigrant is now a full Canadian in the West, while the Canadian is ready to embark on a journey to the East. Their departure is not the end of a meaningful relationship, but a new beginning. 


\section{五 CONCLUSION:}

當局者迷, 旁觀者清
(dāng jú zhě mí ' páng guān zhě qīng)

"If one is personally involved in a matter, it is easy to blind oneself to the truth. However, if one is not involved the matter, it is possible to see things more clearly."1

This proverb is derived from a story of a host and its guest discussing the matters of perception.

The Chinese word for host is 主 (zhu) and for guest is 客 (ke). It is interesting to see how the

Chinese have used these two words to derive the 'subjective view' of the host, 主觀 (zhu guan),

and the 'objective view' of the guest, 客觀 (ke guan). In any situation, those involved can easily lose themselves behind the subjective situation, unable to resolve matters. But those standing on the side, because they are not involved, will have a clear objective view of both sides, and therefore the complete picture. Having both an objective and subjective view on any matter ensures a balance and wholeness. By uniting the divergent perspectives of both the East and the West, we gain a fuller, complete awareness of the world around us.

\footnotetext{
1“當局者迷, 旁觀者清”. Wiktionary, The Free Dictionary. 2007, Wikimedia Foundation, Inc. Apil 20, 2007. <http://en.wiktionary.org/wiki/\%E7\%95\%B6\%E5\%B1\%80\%E8\%80\%85\%E8\%BF\%B7\%EF\%BC\%8C\%E6\%97\%81\%E8 \%A7\%80\%E8\%80\%85\%E6\%B8\%85>
} 
Through etymology we learned that the words East and West were derived from a cultures attempt to define their identity. To define the 'self' is first to define the 'other'. In medicine, the Greeks examined the human body through dissection arriving at the study of anatomy. The Chinese studied the surface of the human body instead and represented the body as a landscape. The investigative drawings of anatomical muscles and the landscape body illustrate the co-existence of two different methods over the same body. In art, the West perceived distance through linear perspective, while the East perceived distance through vertical positioning. Again, both methods successfully achieve distance on a two-dimensional surface, in different ways. The East and the West offer two different perspectives on the same matter. Considering both views on any situation will enhance the solution. Therefore, the East and the West are analogous to the host and the guest in the proverb; they are two halves that complete the whole.

The host and the guest are always a pair; one cannot exist without the other. The transitional housing complex proposed requires both Canadians and immigrants to co-exist within. Without either party, neither can overcome the hostility within the architecture. It is only by working together that hospitality can be found. When hospitality has overcome hostility, then the pair will have had their perceptual worlds altered. The host is now the guest, and the guest is now the host. There is no longer a clear distinction, for the diverging perceptions of the East and the West are ultimately unified. 
六 APPENDIX 


\section{Appendix A: History of the Chinese Language}

To understand the structure of the Chinese written language, it is necessary to trace its etymology and development over the past 2,500 years. The Chinese are an ancient civilization tracing as far back as six millennia. The earliest forms of their language are etchings and engravings recorded on bones and bamboo. These etchings resemble symbols used by the Egyptians in their hieroglyphics. They were mostly representations of the observed surrounding or the record of an idea or action. These very early drawings of the Chinese language formed what is known as 'the oracle script'. A similar form found etched on bronze from the Zhou Dynasty form is now known as the 'bronze script'. It is from these random drawings that a systematic series of 'strokes' was developed, forming the 'seal script'. The Chinese written language is composed of seven basic strokes. These strokes form the basis of the Chinese language, in the same way the alphabet does for the English language. With these seven basic strokes, the oracle scripts were rationalized into 'characters'. Each character in Chinese is like a 'word' in English. While a word is composed of vowels and consonants, a character is composed of different variations of the seven strokes.

The very first characters produced were in a series known as 'pictograms'. These are graphic representations of nature as it is observed. When pictograms were developed, man was 
living much closer to nature, closer to the sun 日 ( $r$ ), the moon 月 (yue), and all the elements. Wood 木 $(m u)$ is the material of the tree, the pictograph of bare branches. Fire 火 (huo) is the flame burning from a pile of wood. Water 水 (shuil) is the substance flowing between the rocks in a creek. The Chinese language records the observed natural phenomenon in a pictographic form. These elements of nature combine to create the diversity of the world. Water, wood, fire, and sun are some of the basic building blocks of life. Thus the pictographic characters that represent nature's fundamental elements became the building blocks for the Chinese written language. 


\section{Appendix B: Definition of Culture from Mirror for Man}

Geertz's Summary of Clyde Kluckhohn's definition of culture from Mirror for Man:

1. The total way of life of a people

2. The social legacy the individual acquires from his group

3. A way of thinking, feeling, and believing

4. An abstraction from behaviour

5. A theory on the part of the anthropologist about the way in which a group of people in fact behave

6. A storehouse of pooled learning

7. A set of standardized orientations to re-current problems

8. Learned behaviour

9. A mechanism for the normative regulation of behaviour

10. A set of techniques for adjusting both to the external environment and to other men

11. A precipitate of history 


\section{Appendix C: Drawings And Figures From Chapter III: Anatomy | Landscape}
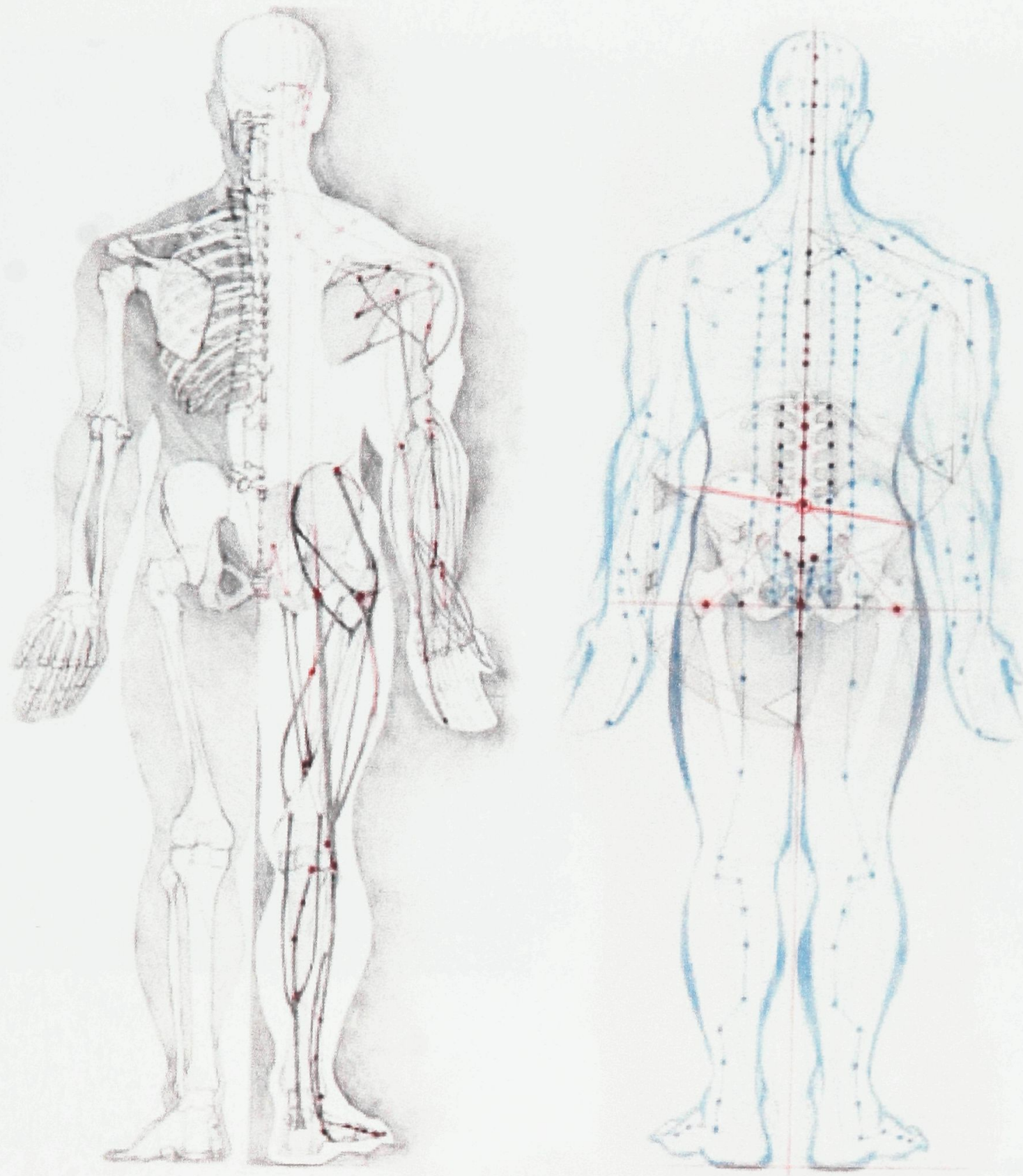

Plate 3.1: Greek 'Anatomy' versus Chinese 'Mo. Graphite and colour pencil on vellum. 34" x 30" 


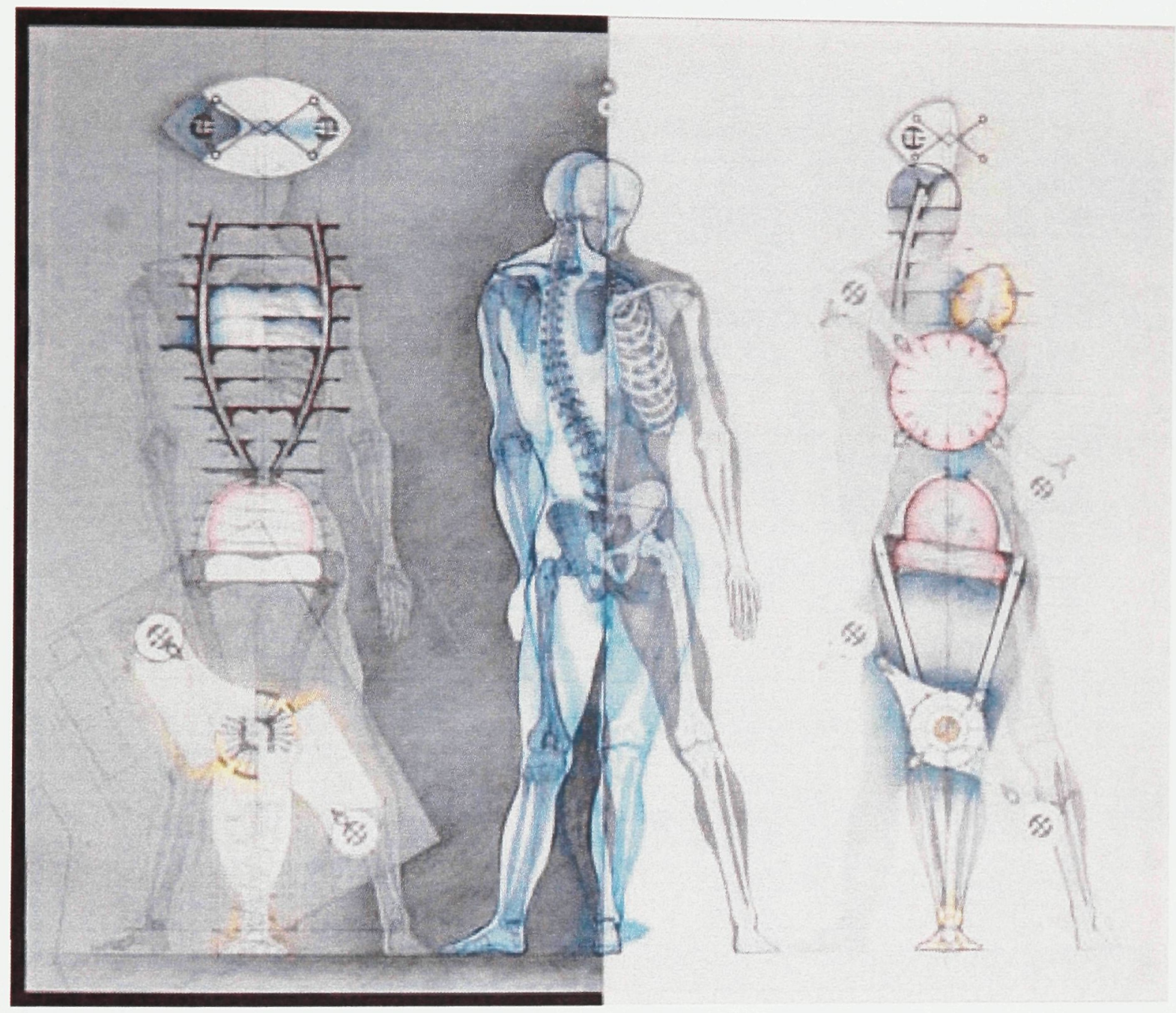

Plate 3.2: Hermaphrodite.

Conceptual Drawing. Graphite and colour pencil on vellum, assembled on black and white board. $34^{\prime \prime} \times 40 "$ 


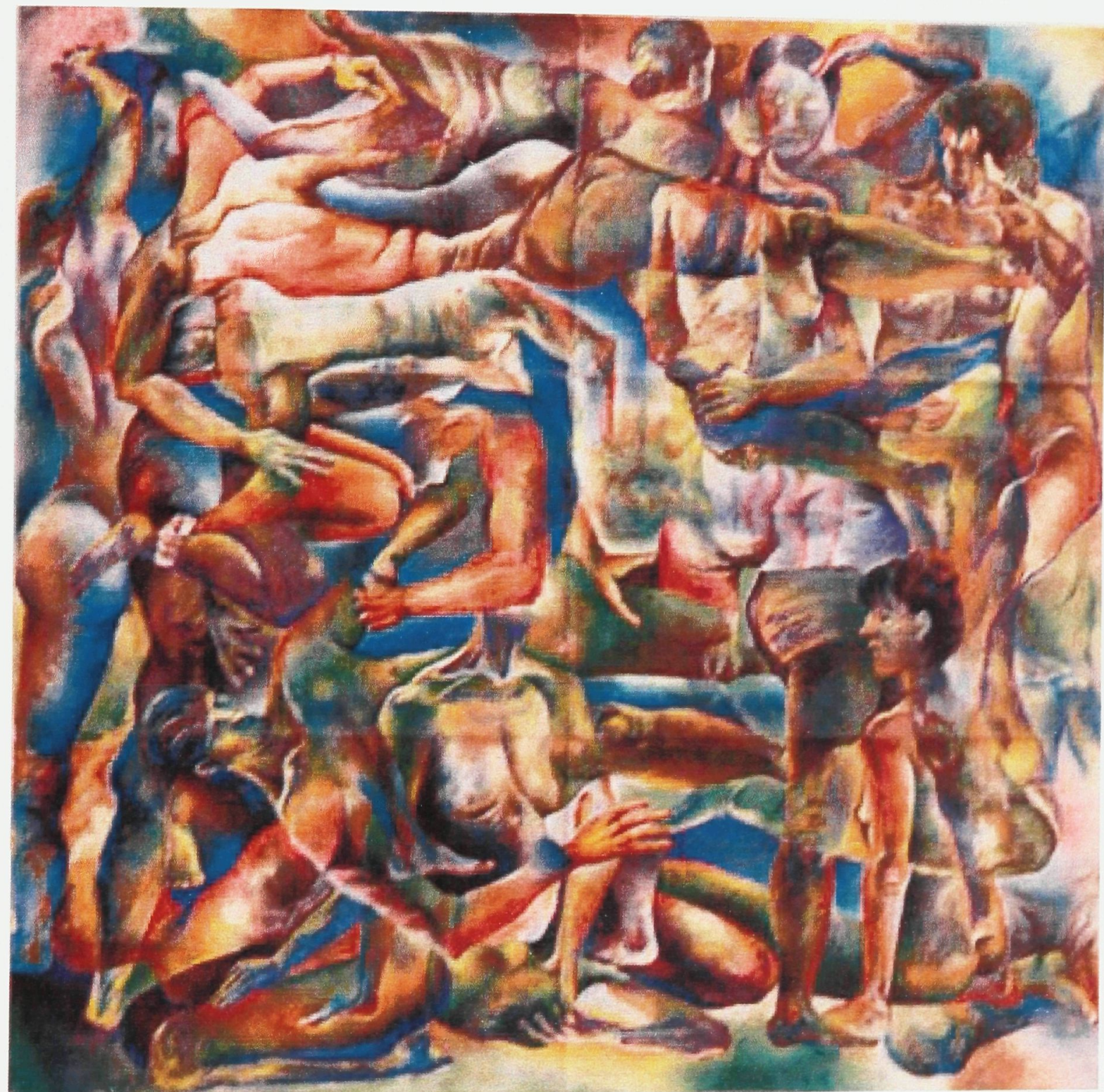

Plate 3.7b: Complete Life Drawing (Female Orientation) Conte and pastels on Mayfair drawing paper. $60^{\prime \prime} \times 60^{\prime \prime}$ 


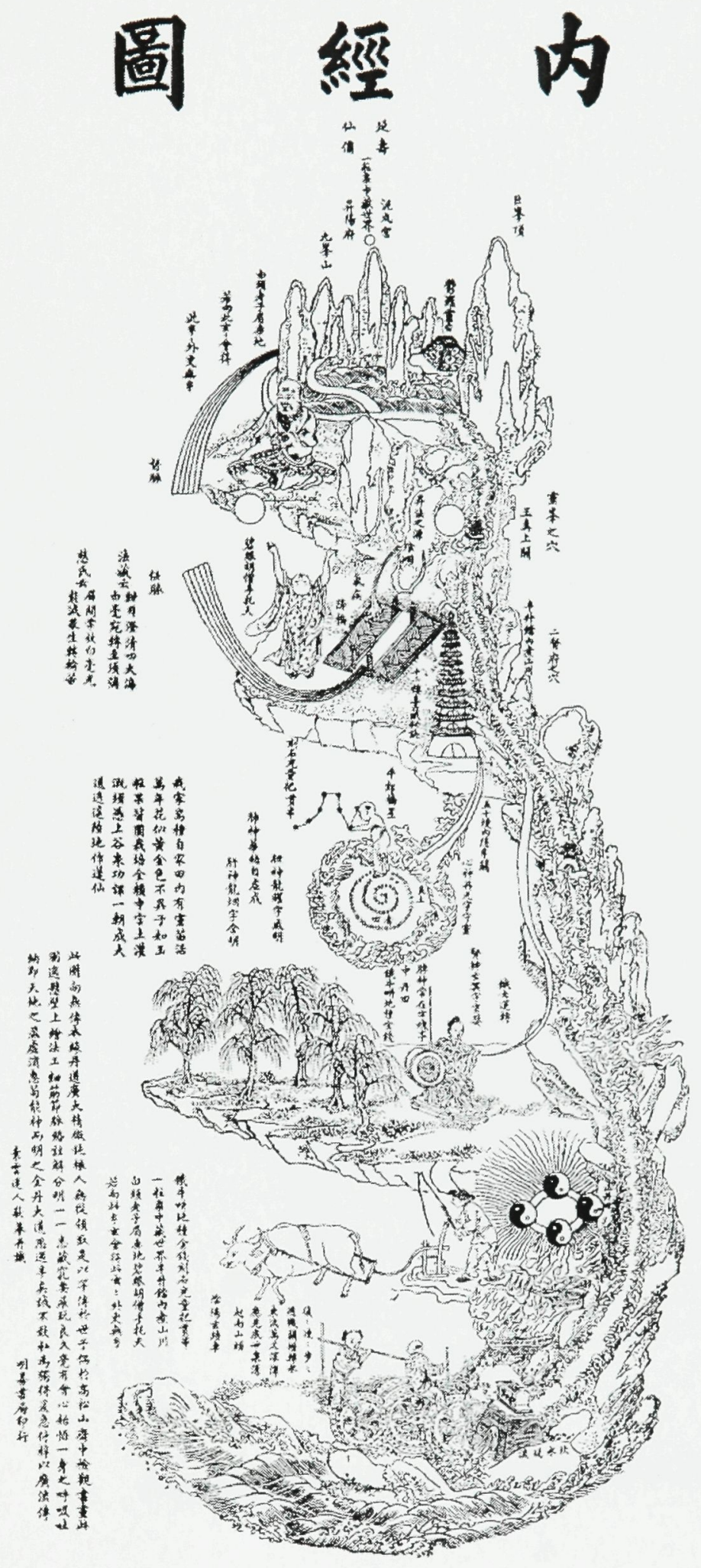

Figure 3.1: 內經圖 (Neijing tu) 


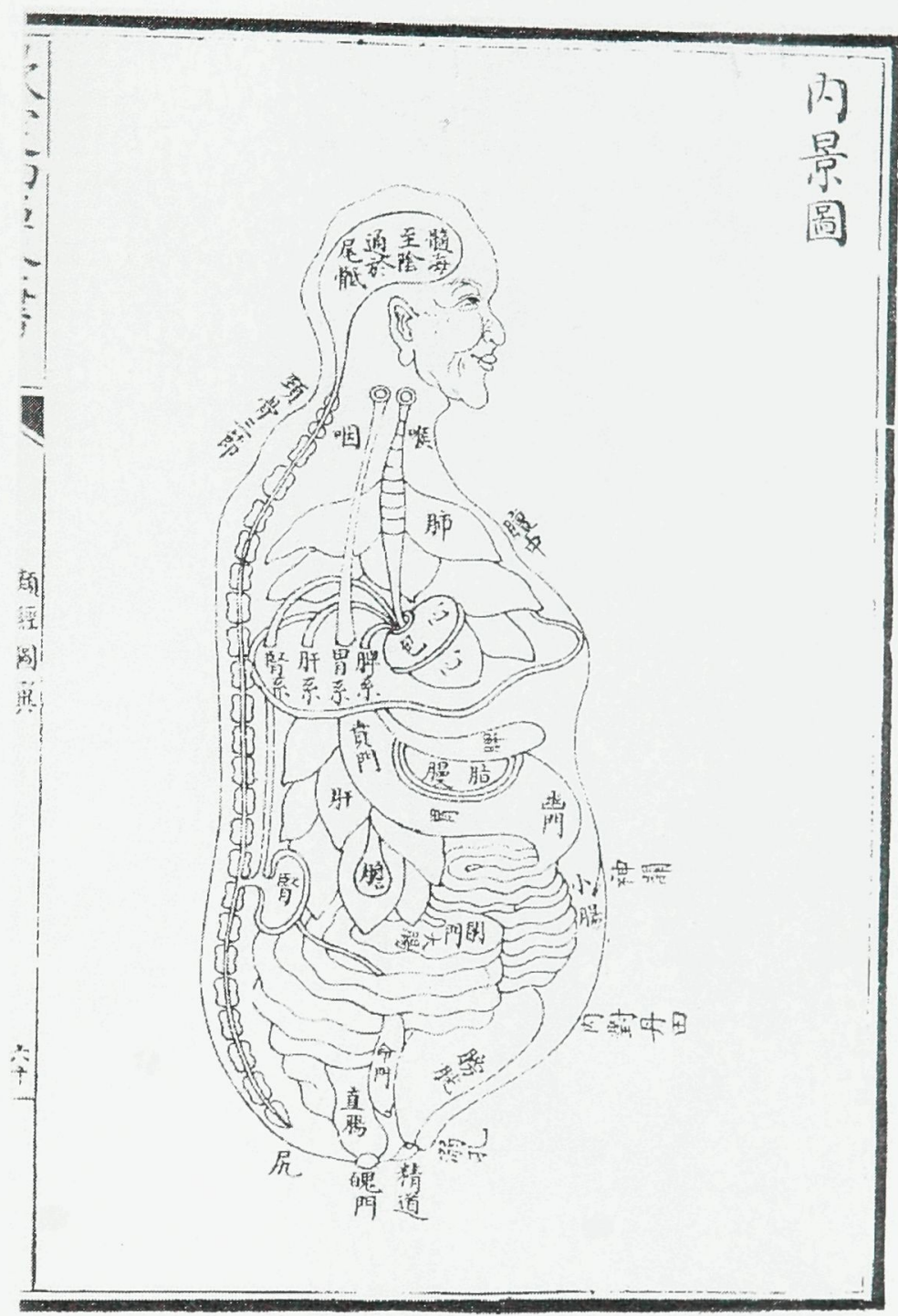

Figure 3.2a: 內景圖 - Neijing Tu (Chinese Drawing) 


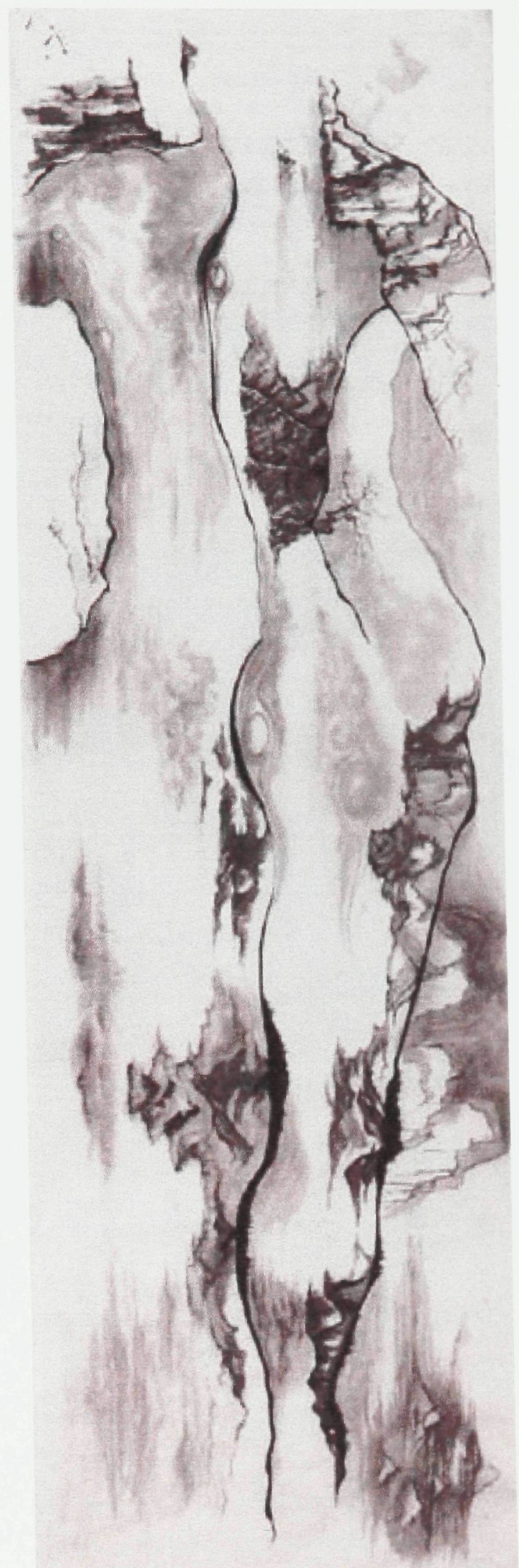

Plate 3.9: Horizontal Landscape Painting Chinese ink on rice paper. $18^{\prime \prime} \times 54 "$ 


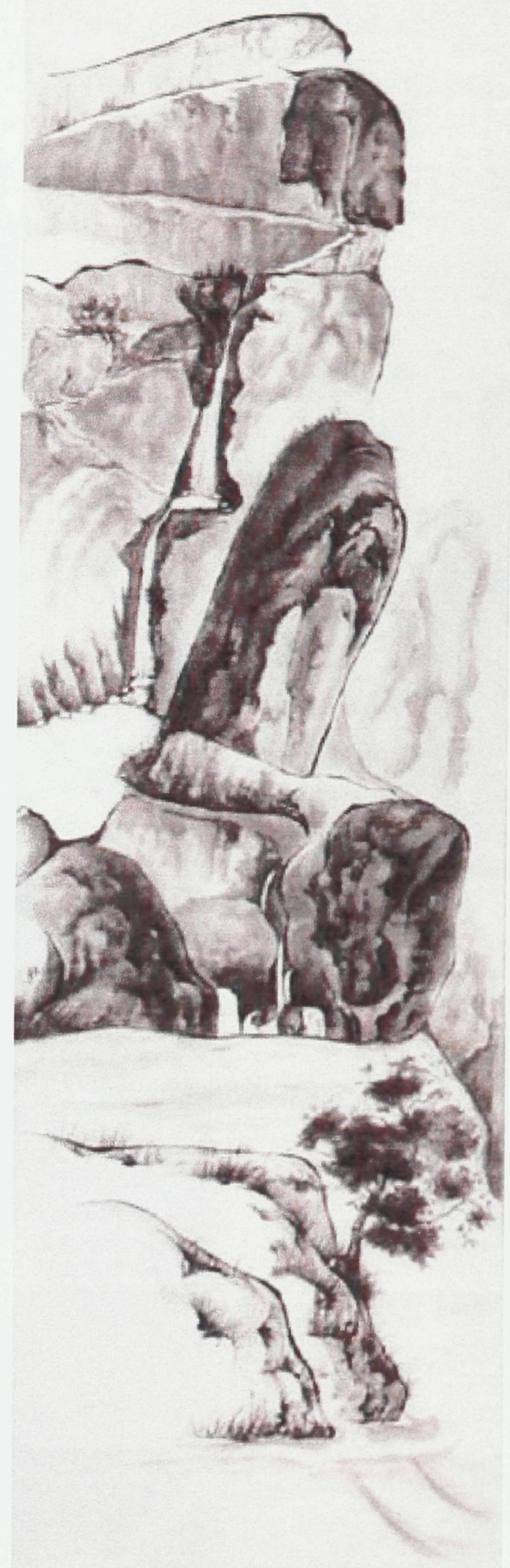

Plate 3.11: Vertical Landscape Painting Chinese ink on rice paper. $54^{\prime \prime} \times 18^{\prime \prime}$ 


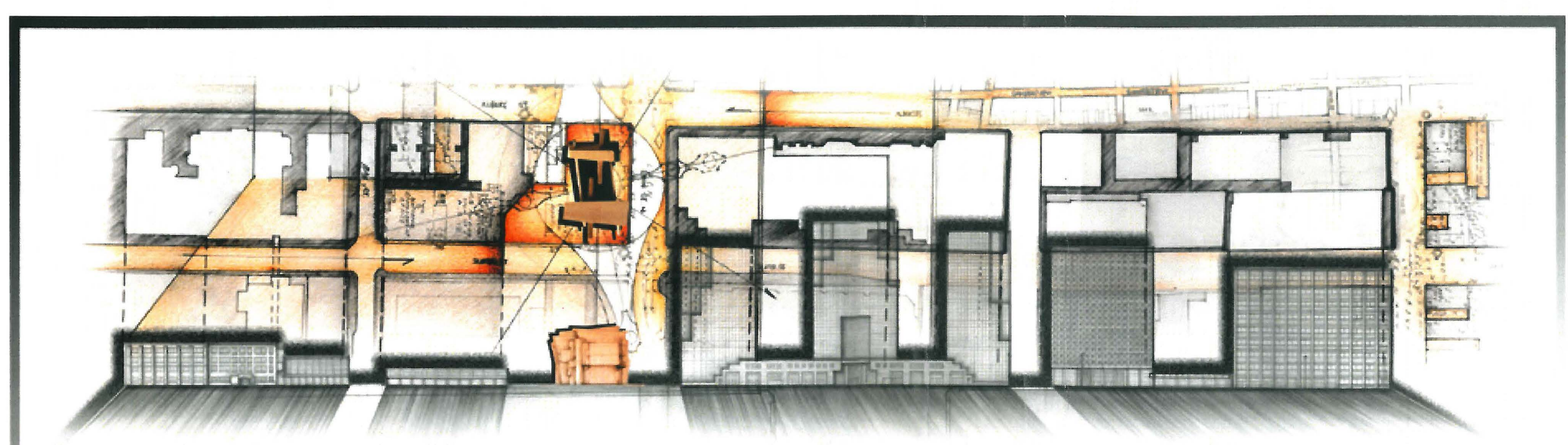

Site Collage (plan and cross section along Slater Street) Digitally Manipulated Image from original drawings at 1:1000. 9" x 30"

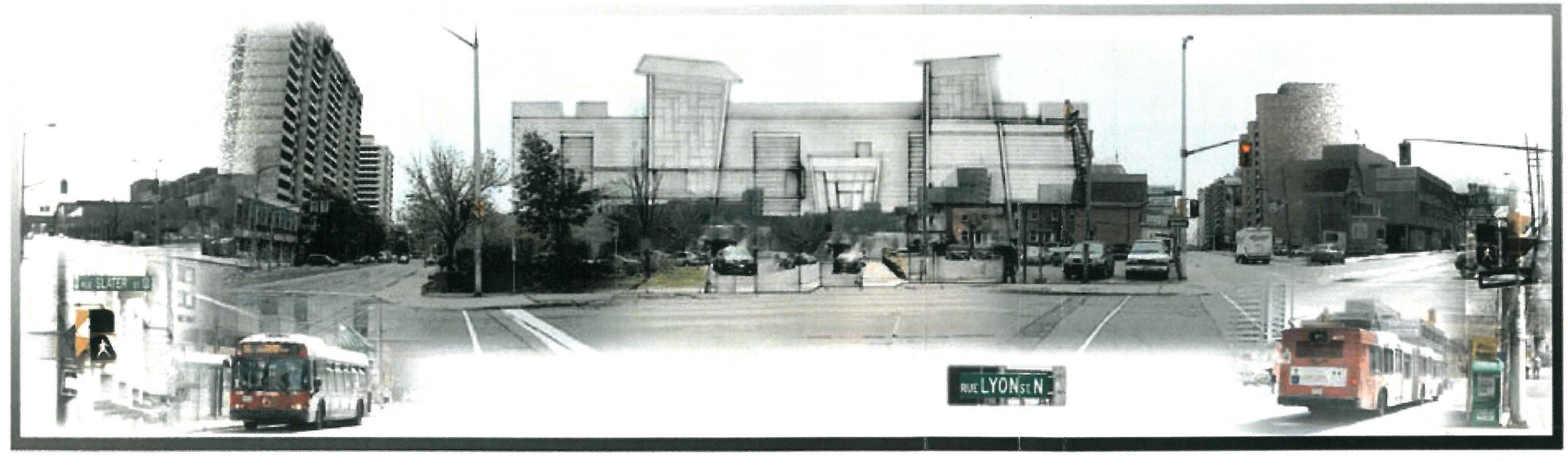

Site Image Collage (view from Lyon Street) Digitally Manipulated Image from site photographs and original drawings. $9^{\prime \prime}$ × $30^{\prime \prime}$

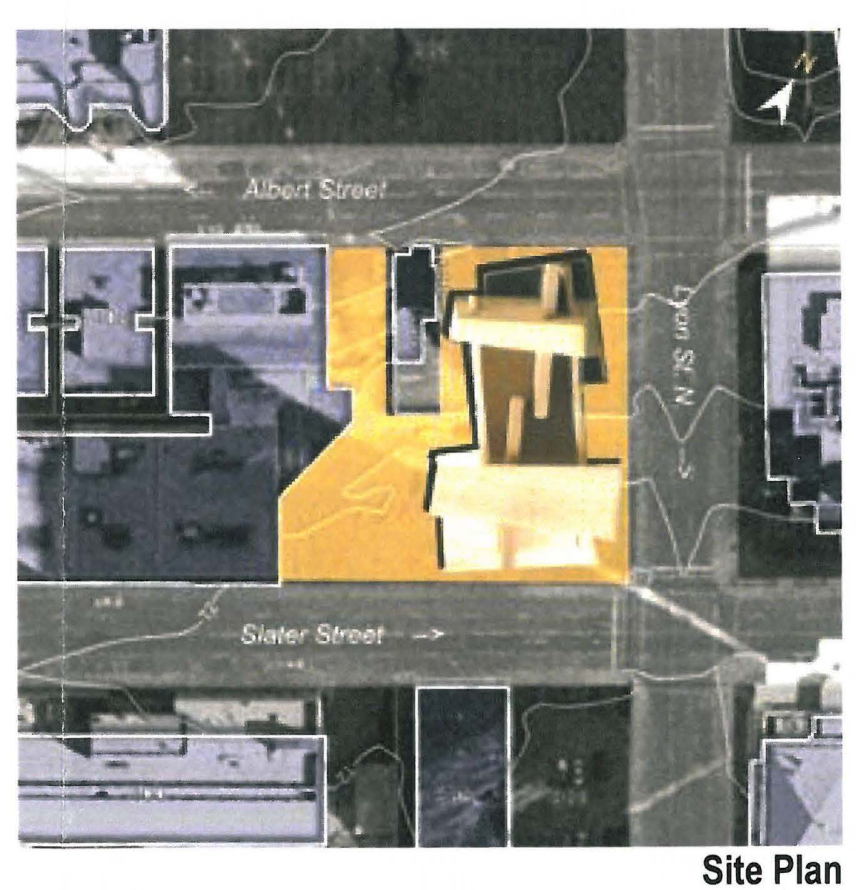

Digitally Manipulated Image from various photographs. $16^{\prime \prime} \times 16^{\prime \prime}$ 
Elevations:

1 of 2

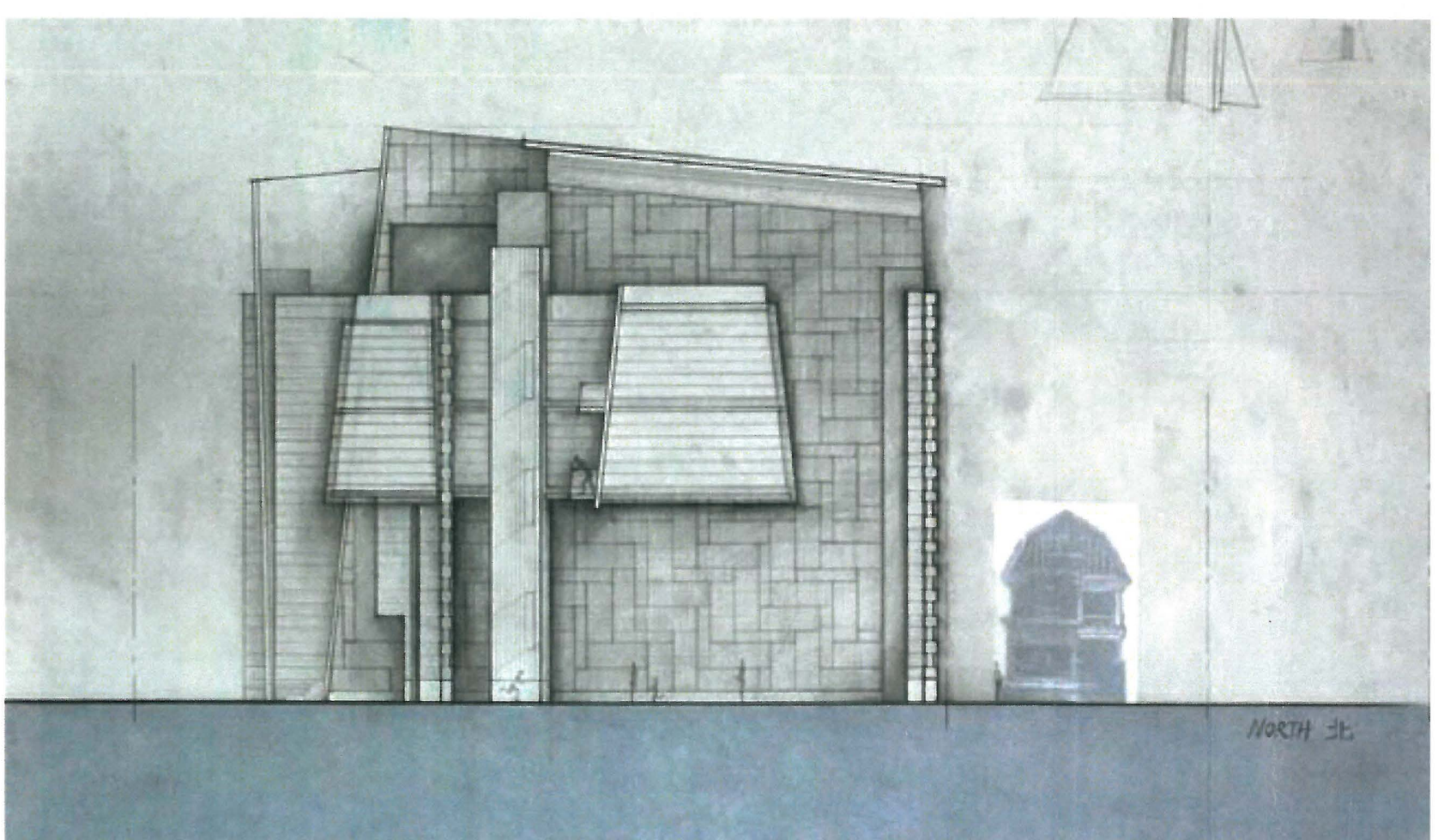

North Elevation Enlargement from elevation panel on the right.

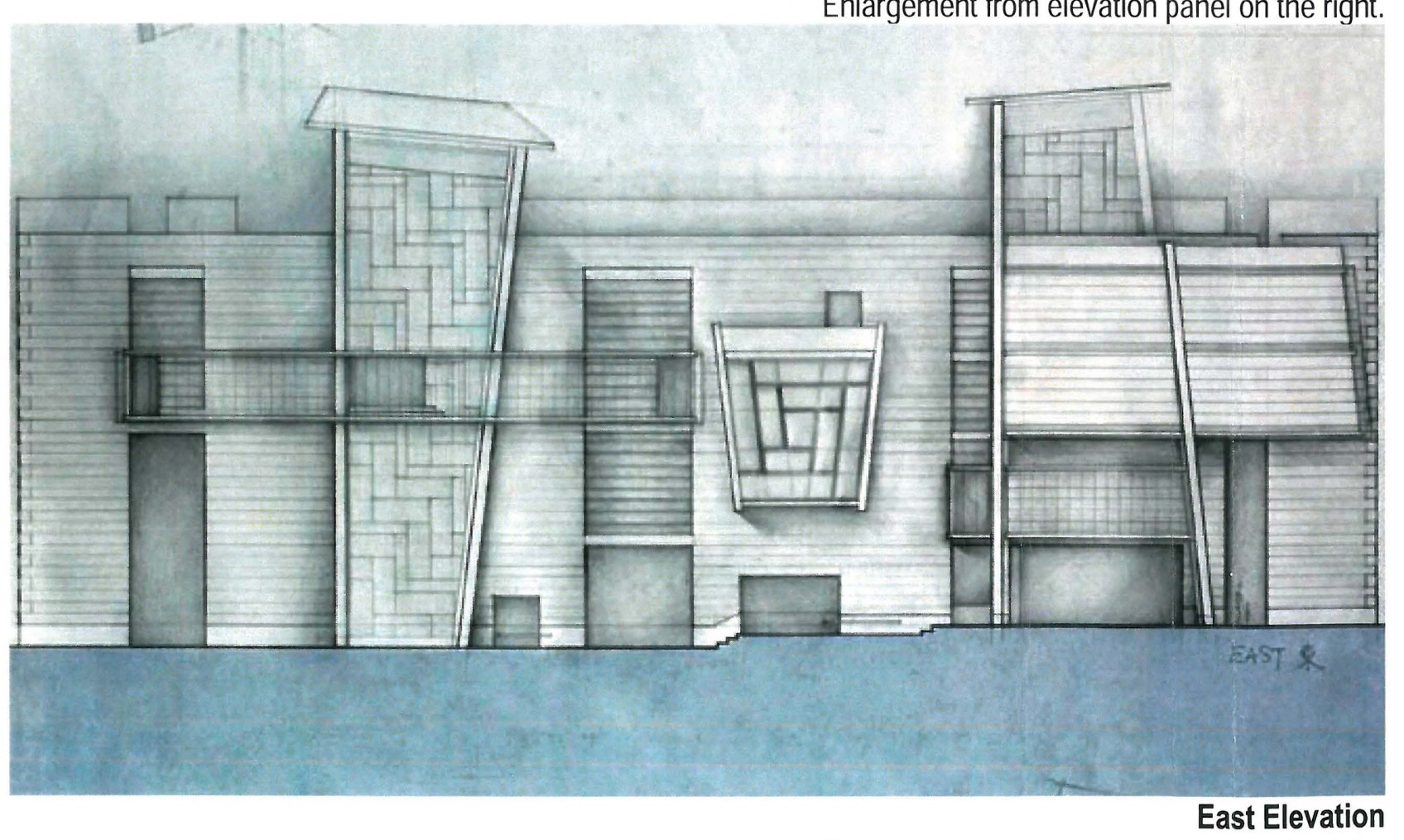

Enlargement from elevation panel on the right.
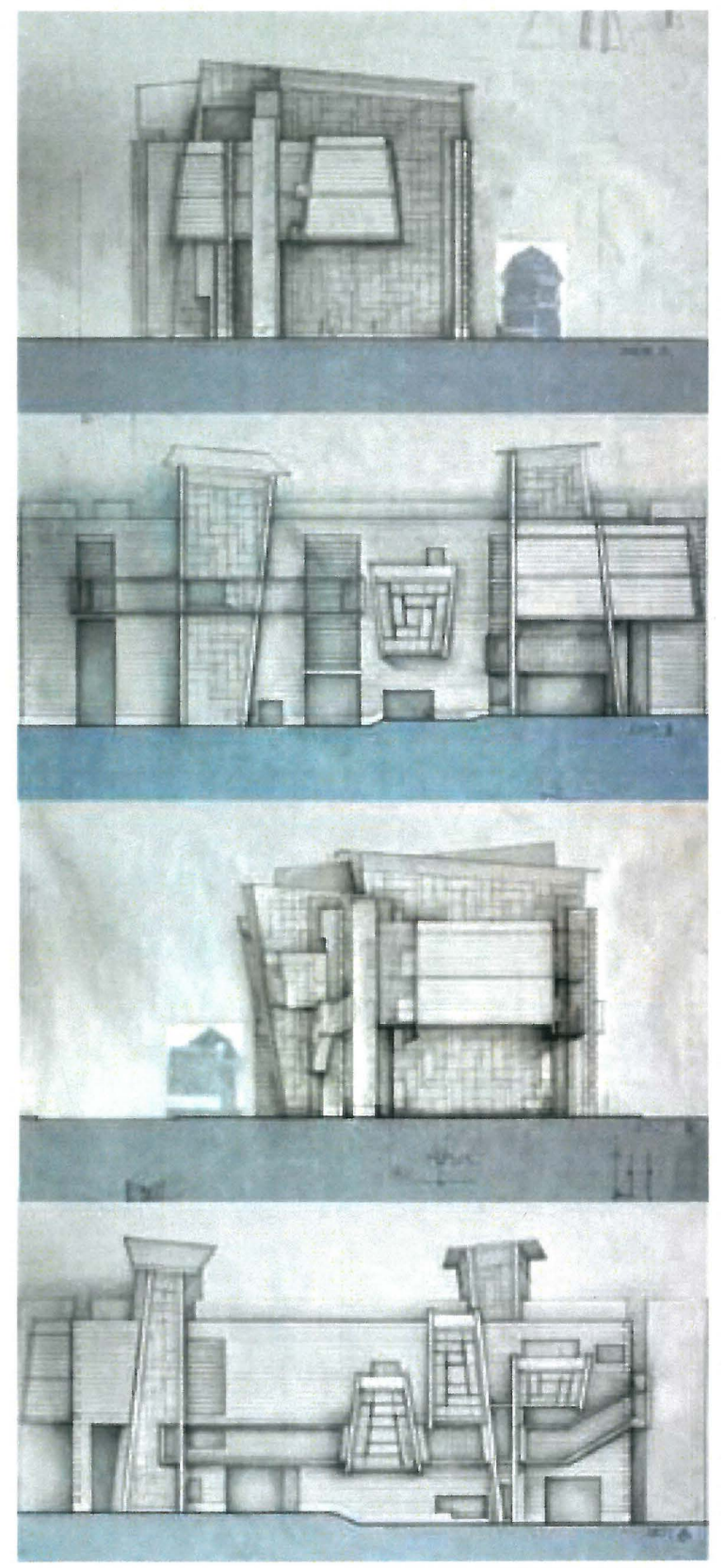

Elevation Panel Graphite on vellum. 60" x 24" 
Elevations:

2 of 2
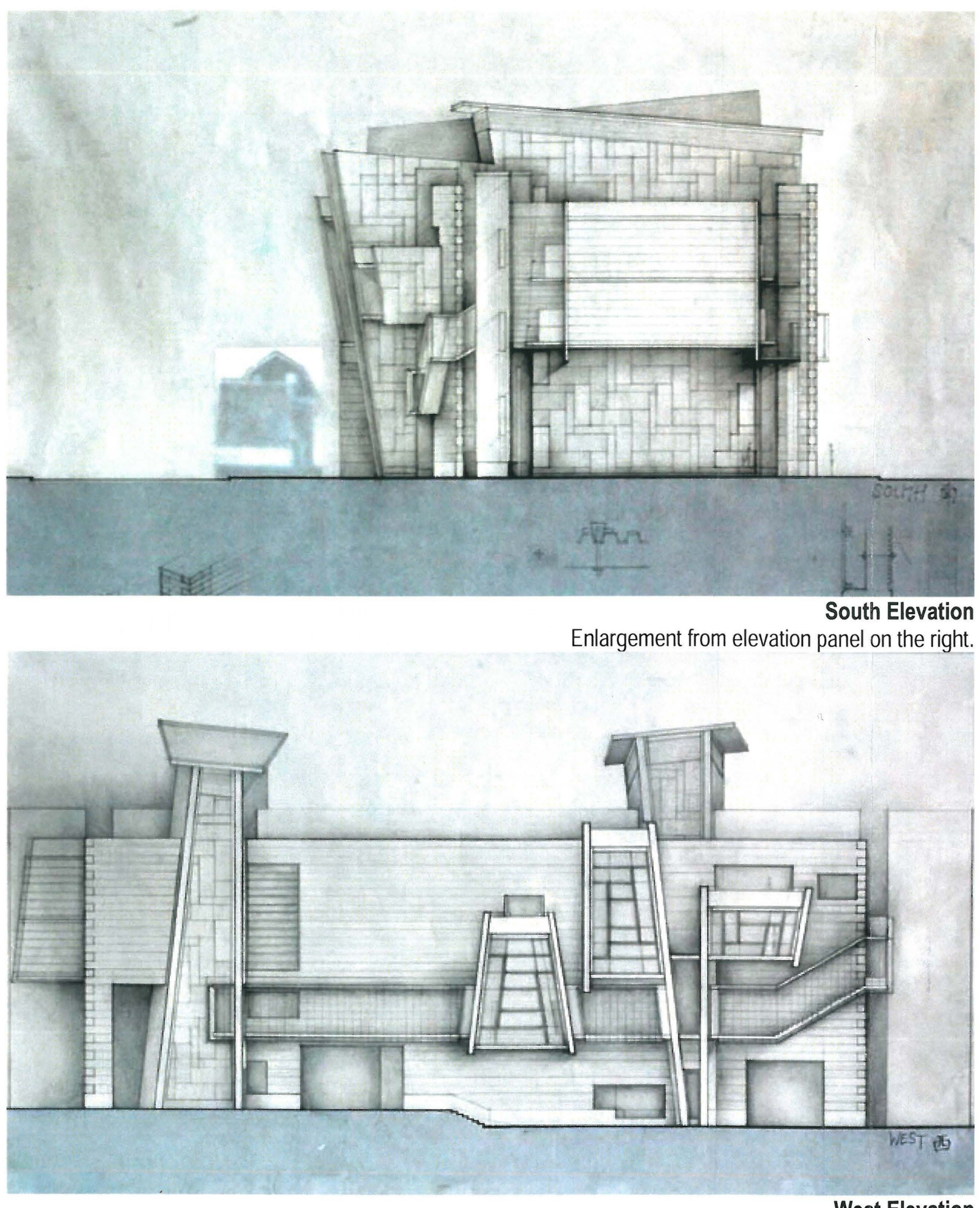

Enlargement from elevation panel on the right.
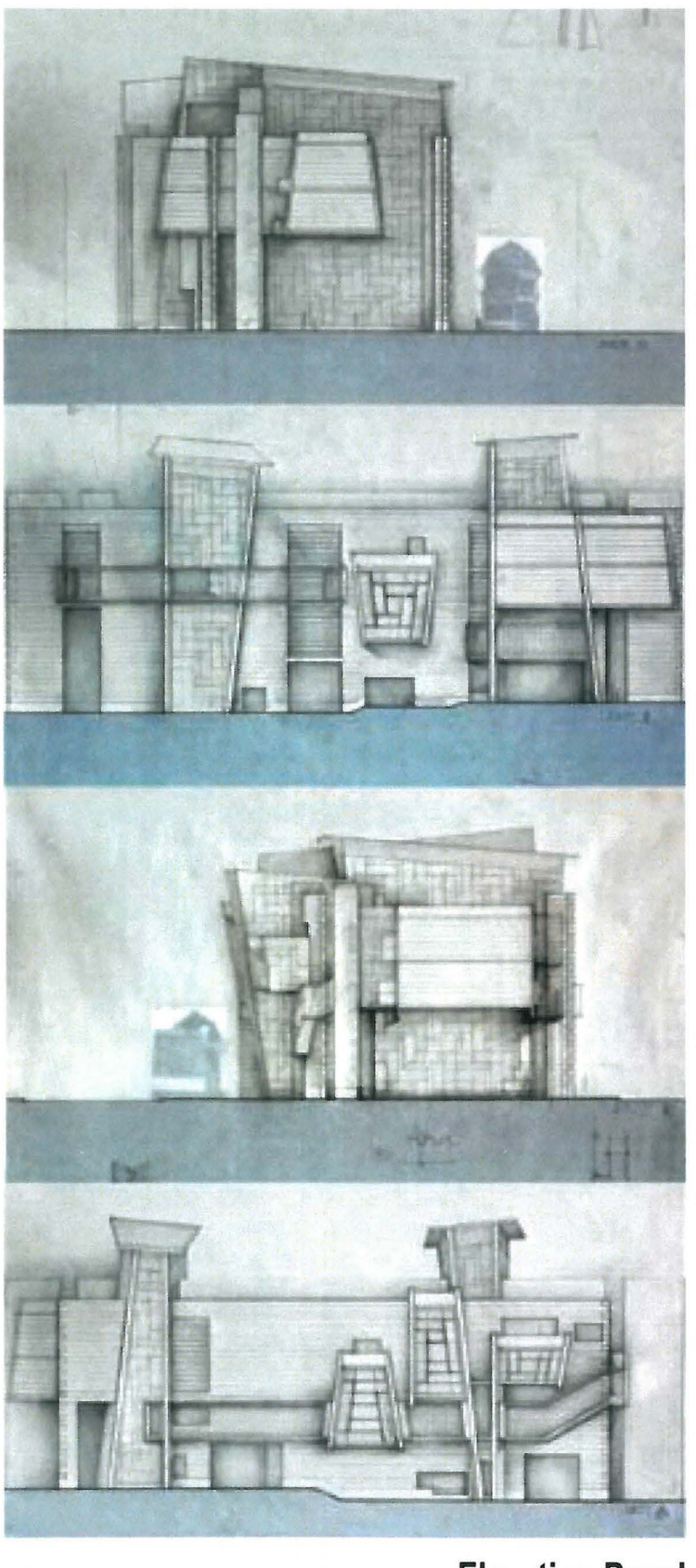

Elevation Panel Graphite on vellum. $60 "$ x 24" 
Sections:

1 of 2

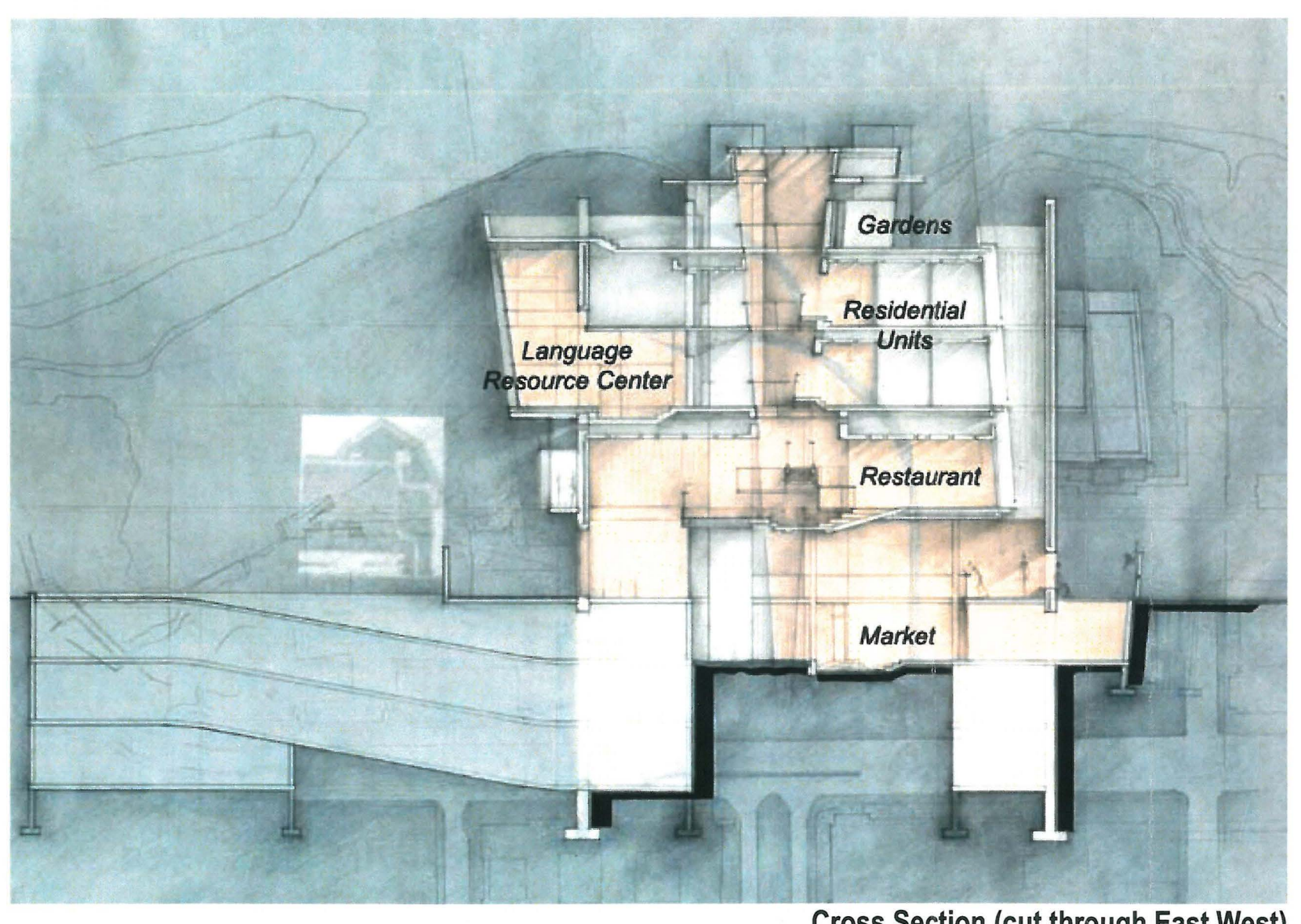

Cross Section (cut through East West)

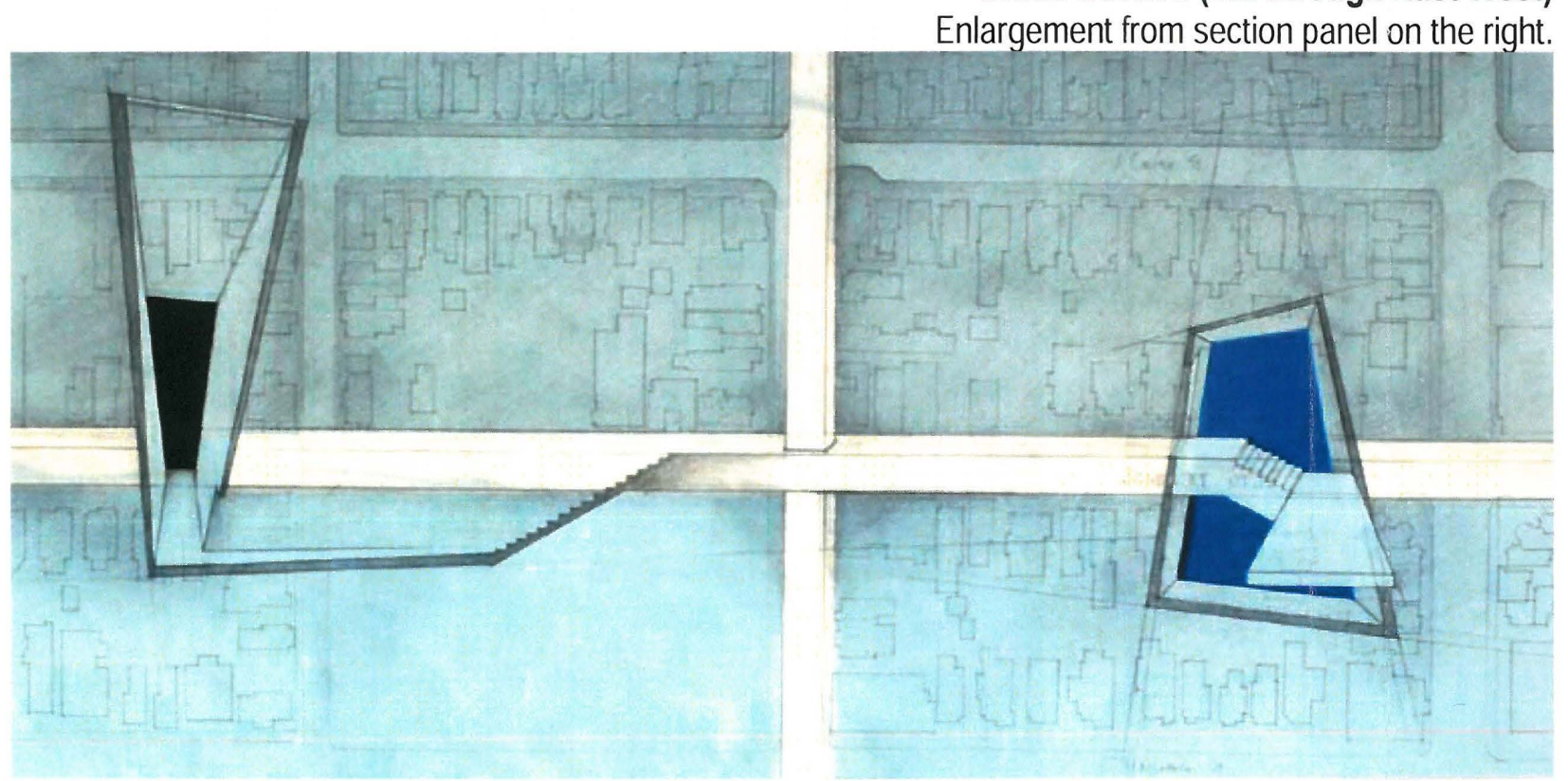

Conceptual Section Through Entrances Enlargement from elevation panel on the right.

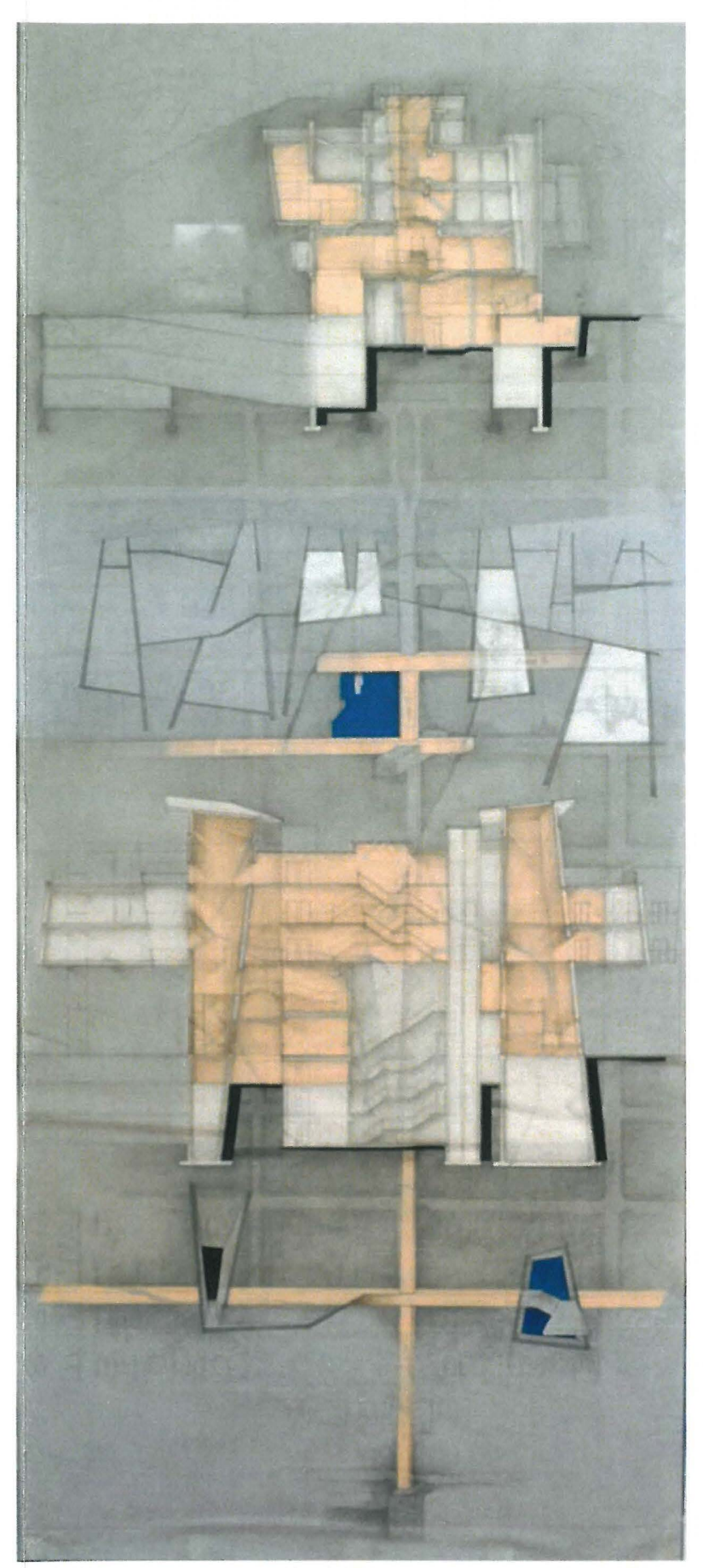

Section Panel Graphite on vellum, with Canson coloured paper layered behind. $60^{\prime \prime} \times 24 "$ 


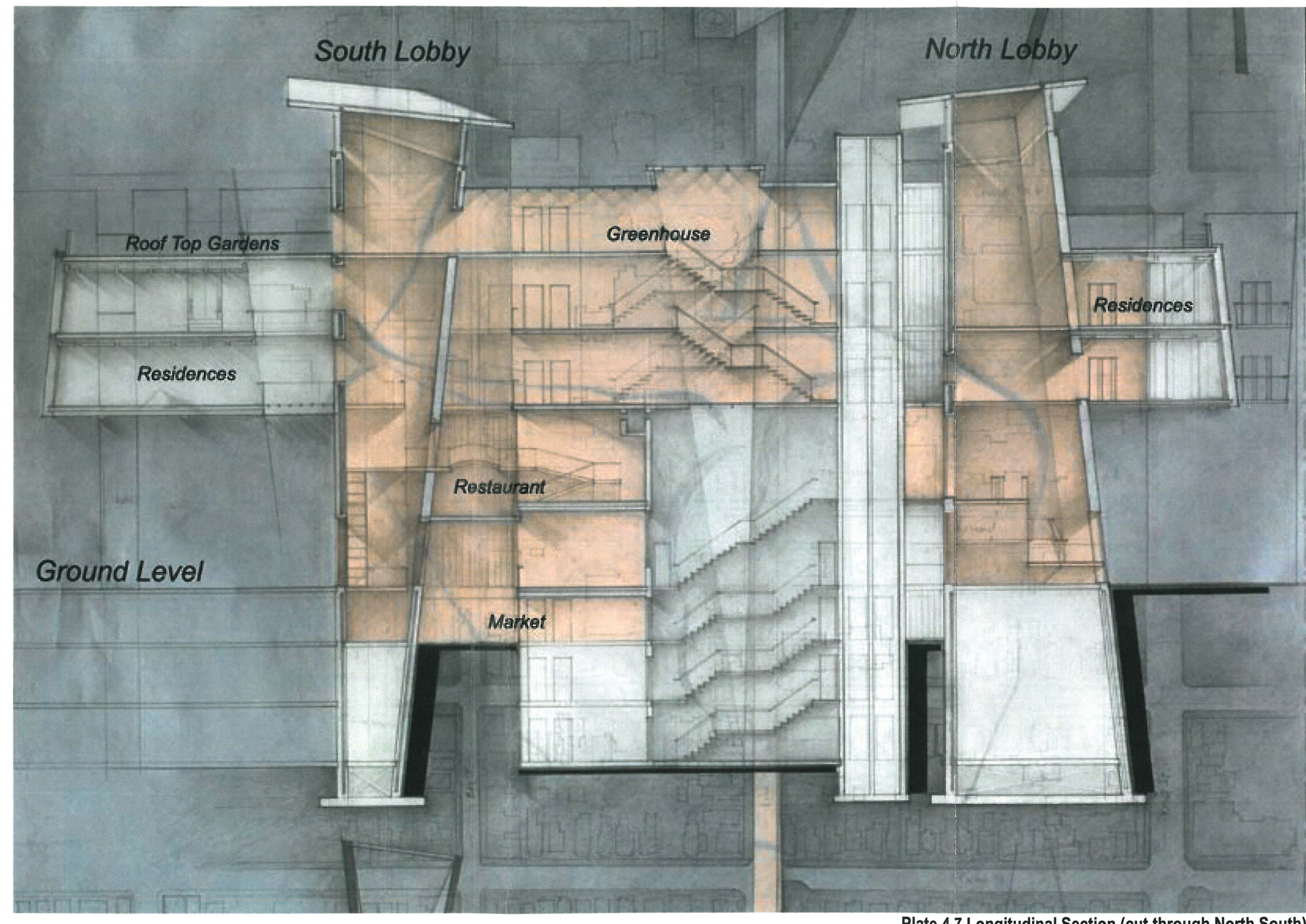




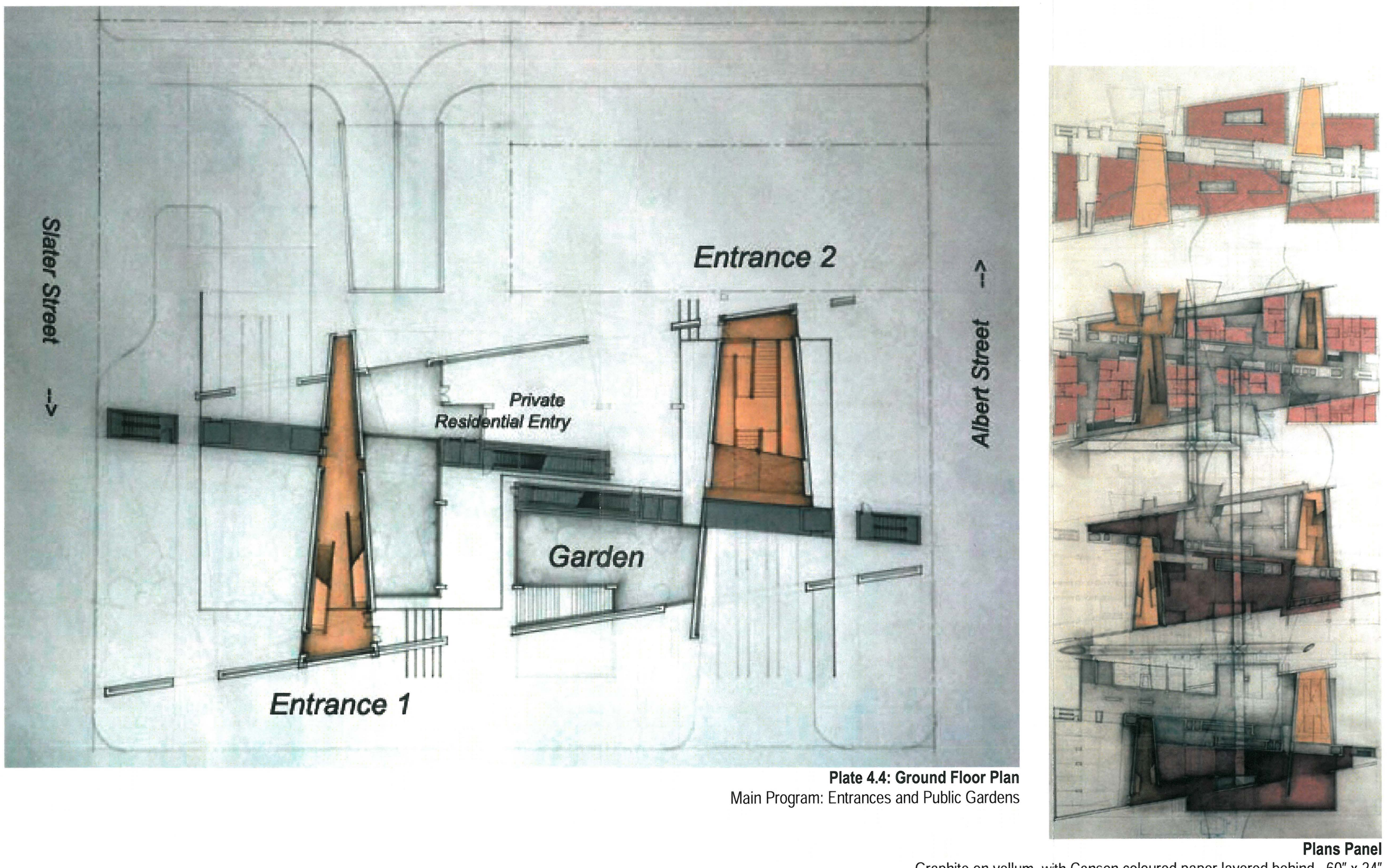




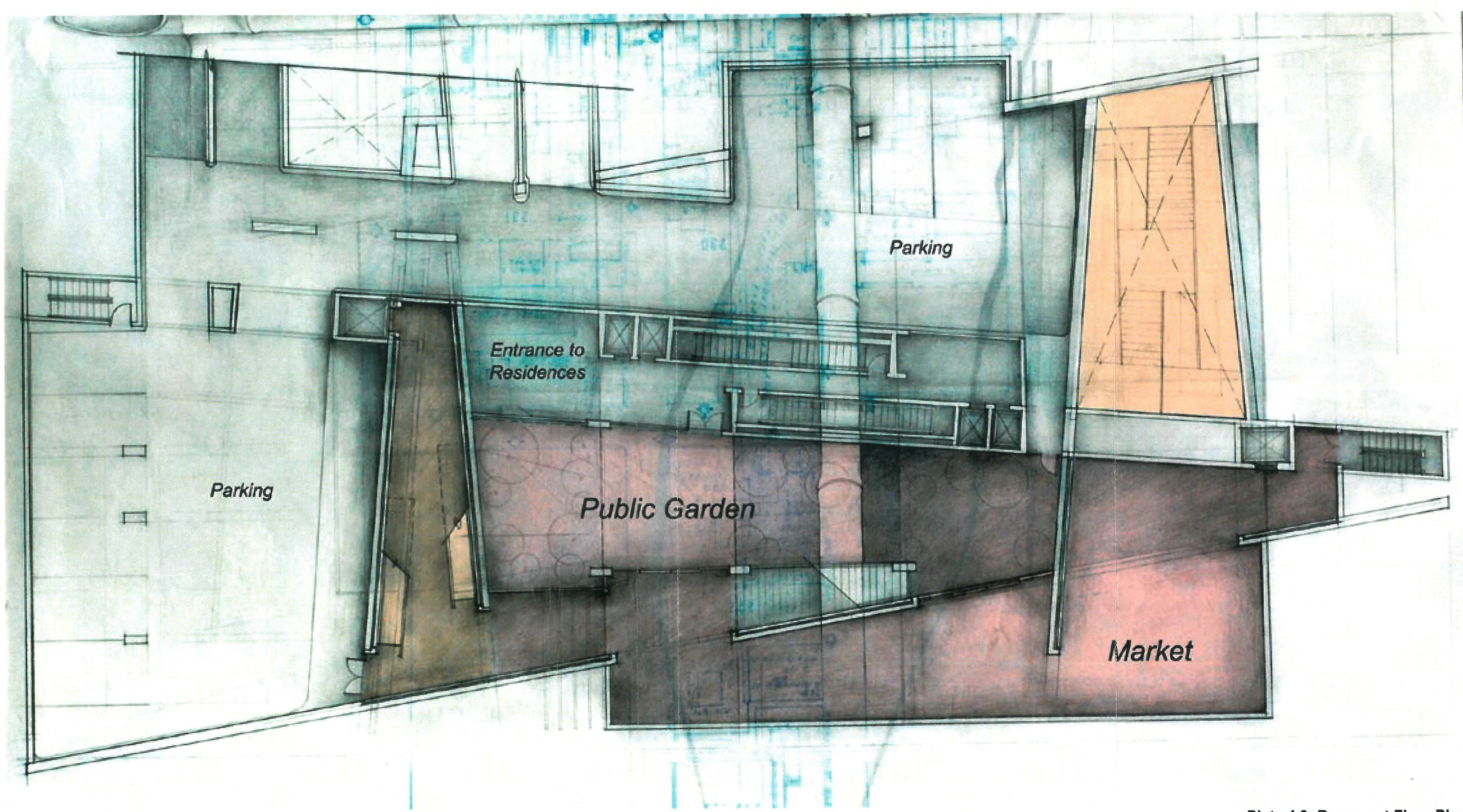




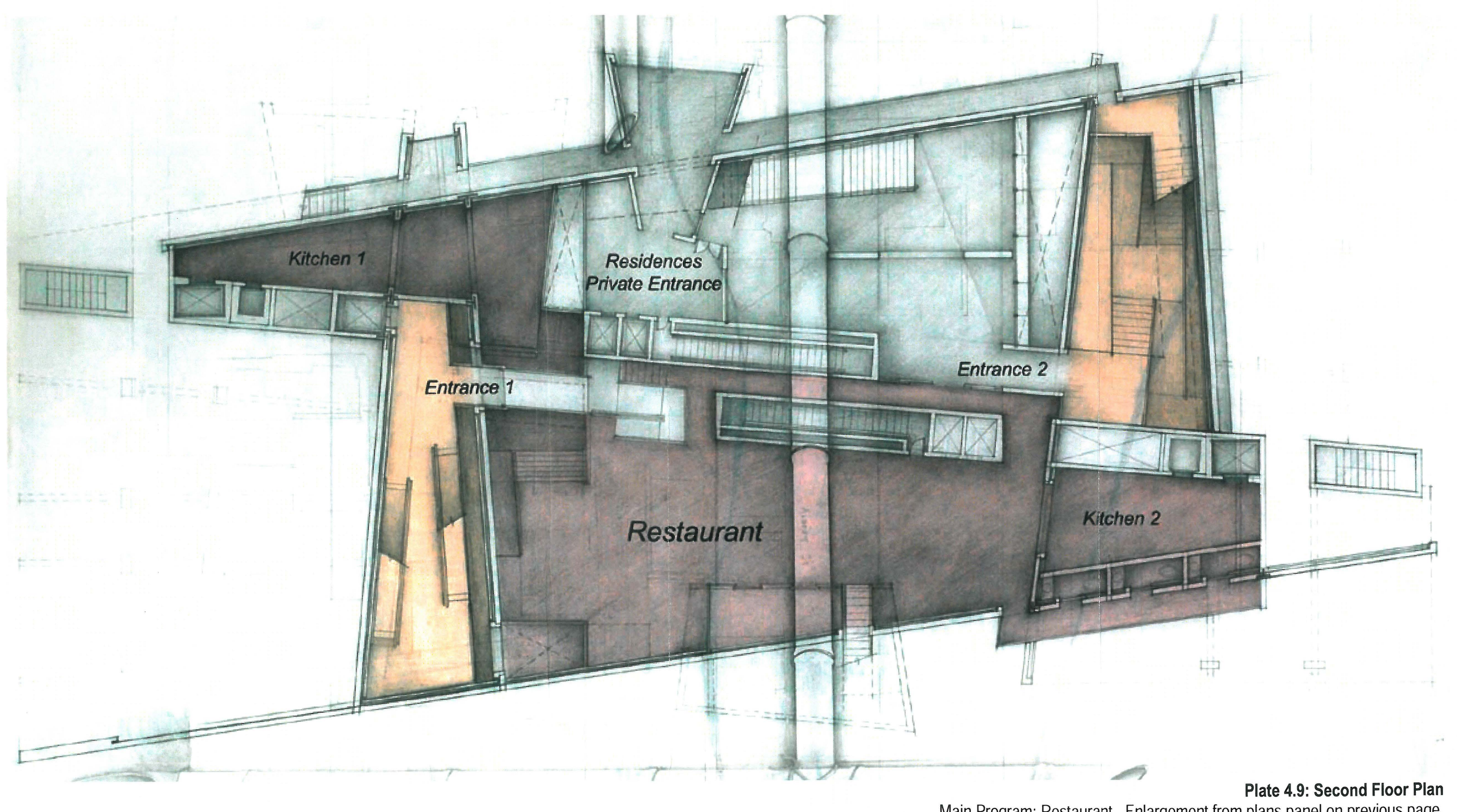


Plans:

4 of 6

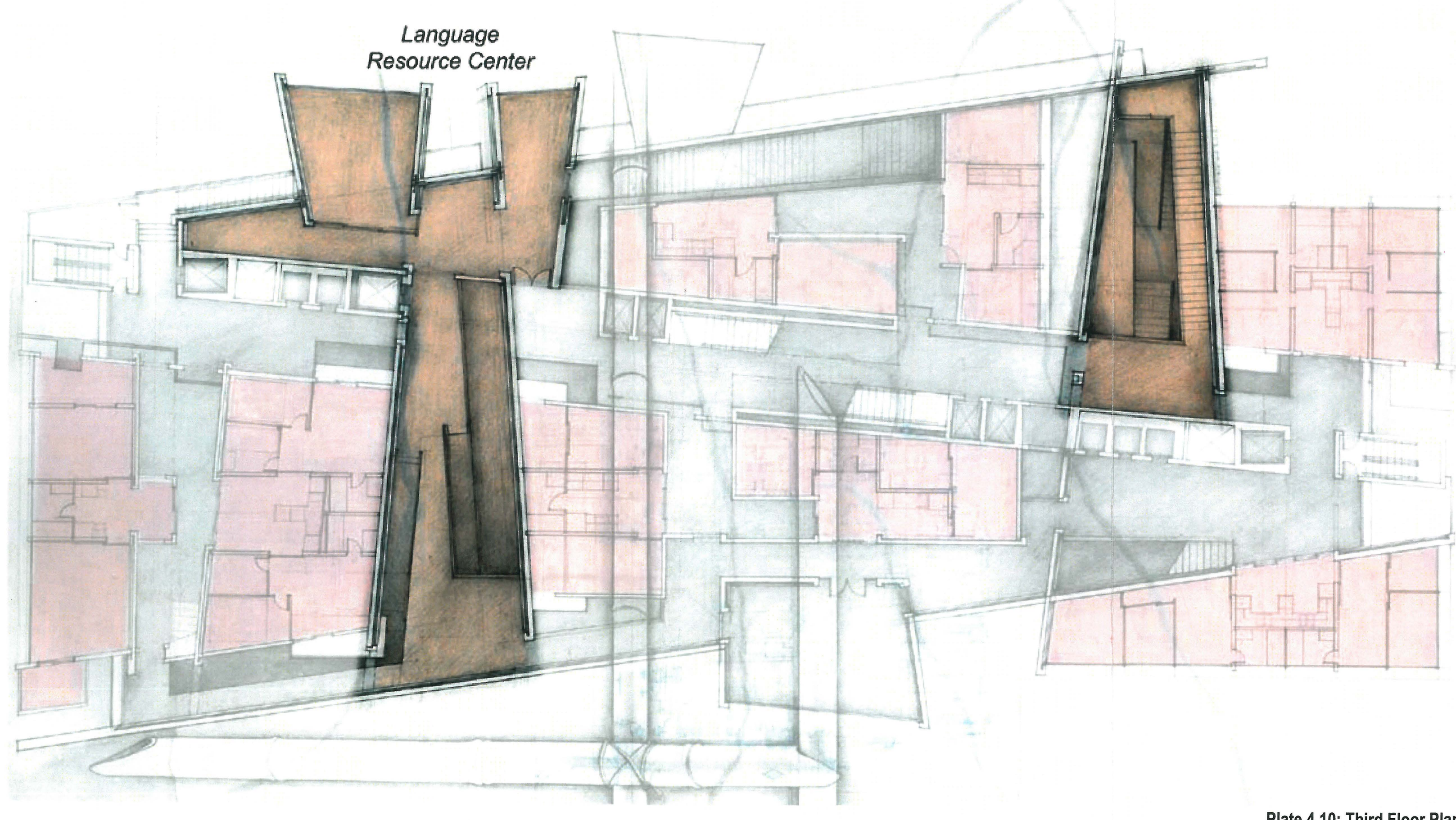

Main Program: Language Resource Centre and Residential Apartments. Enlargement from plate 4.10: Third Floor Plan 


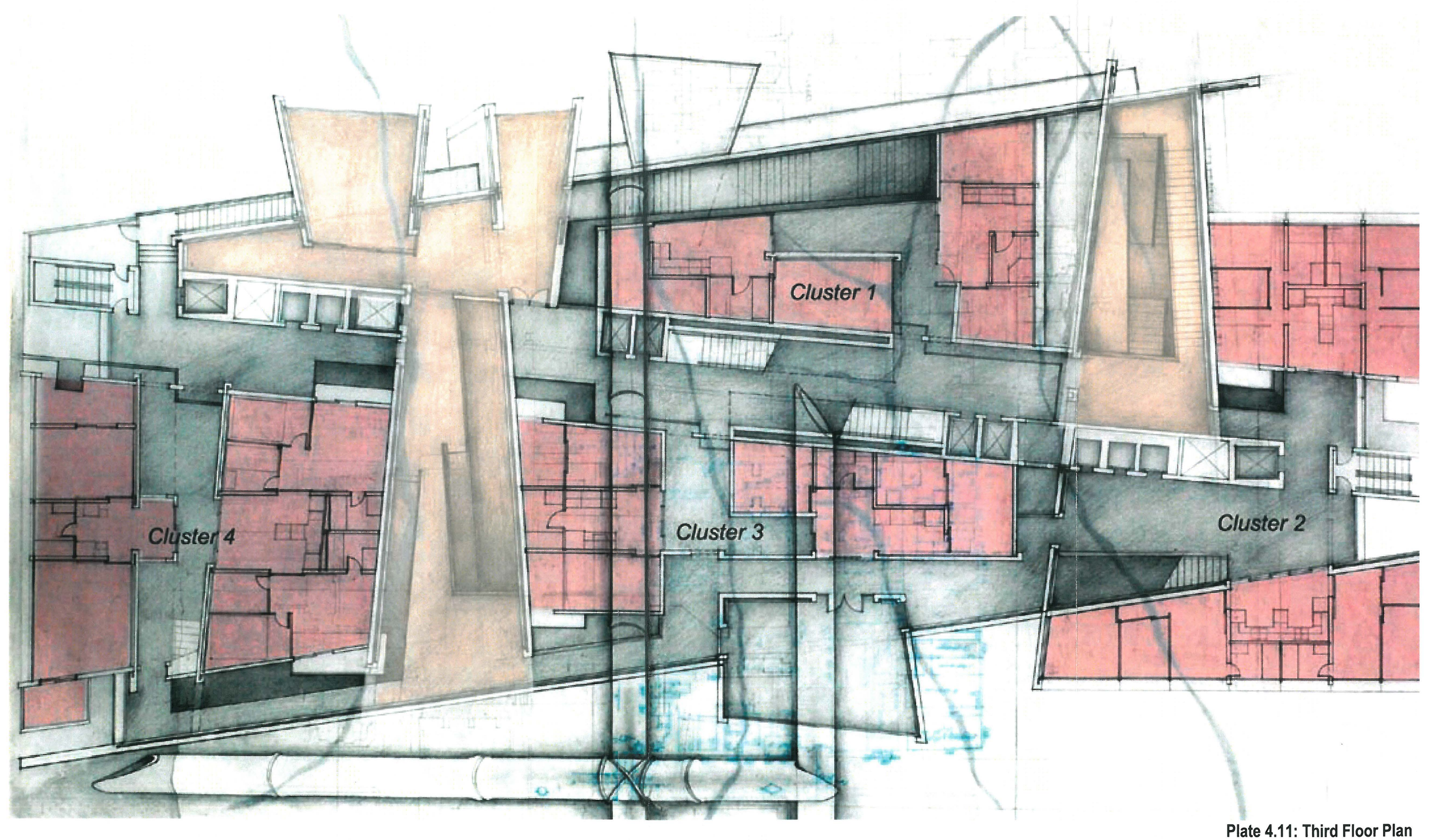




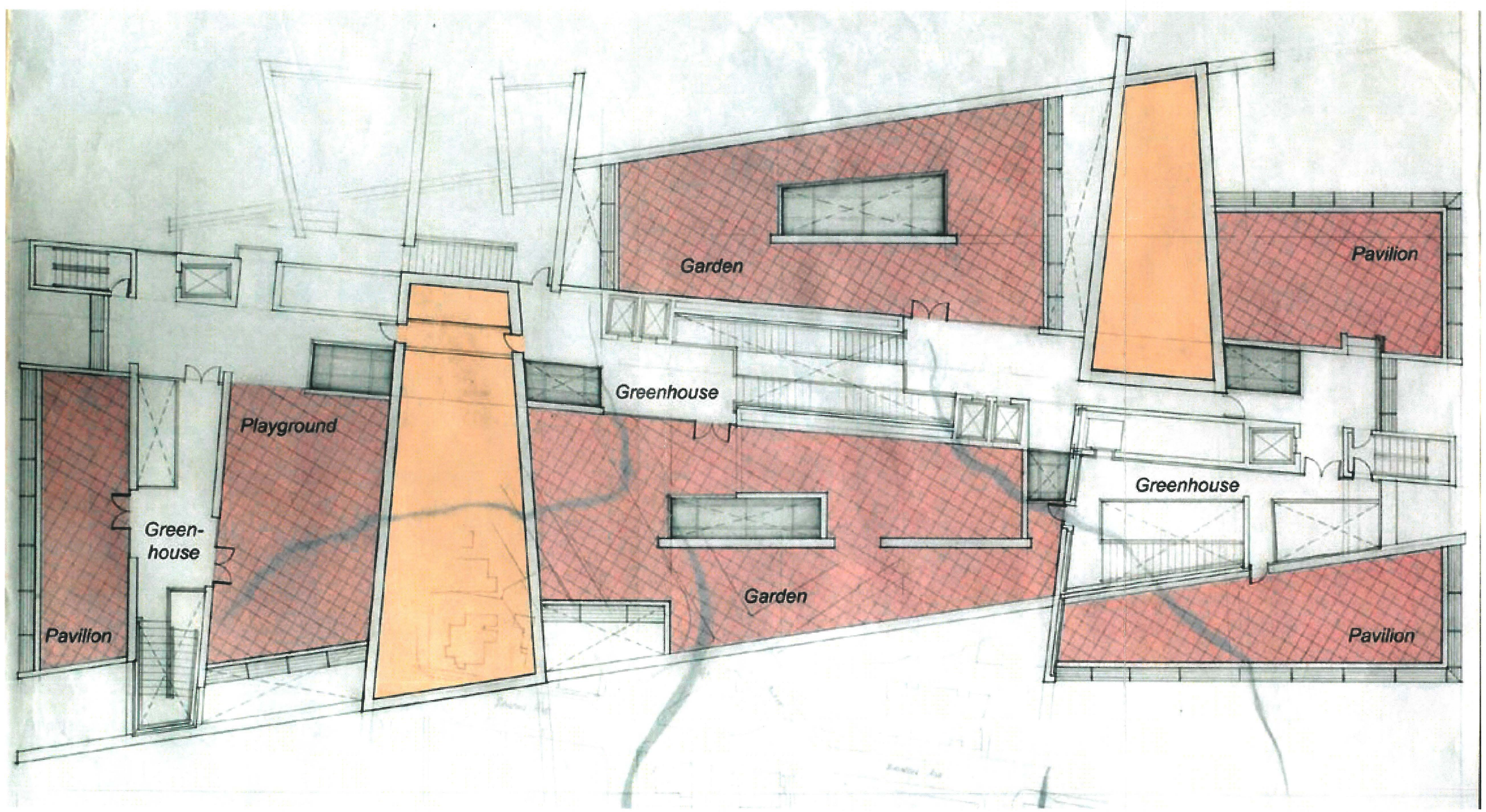




\section{Axonometric:}

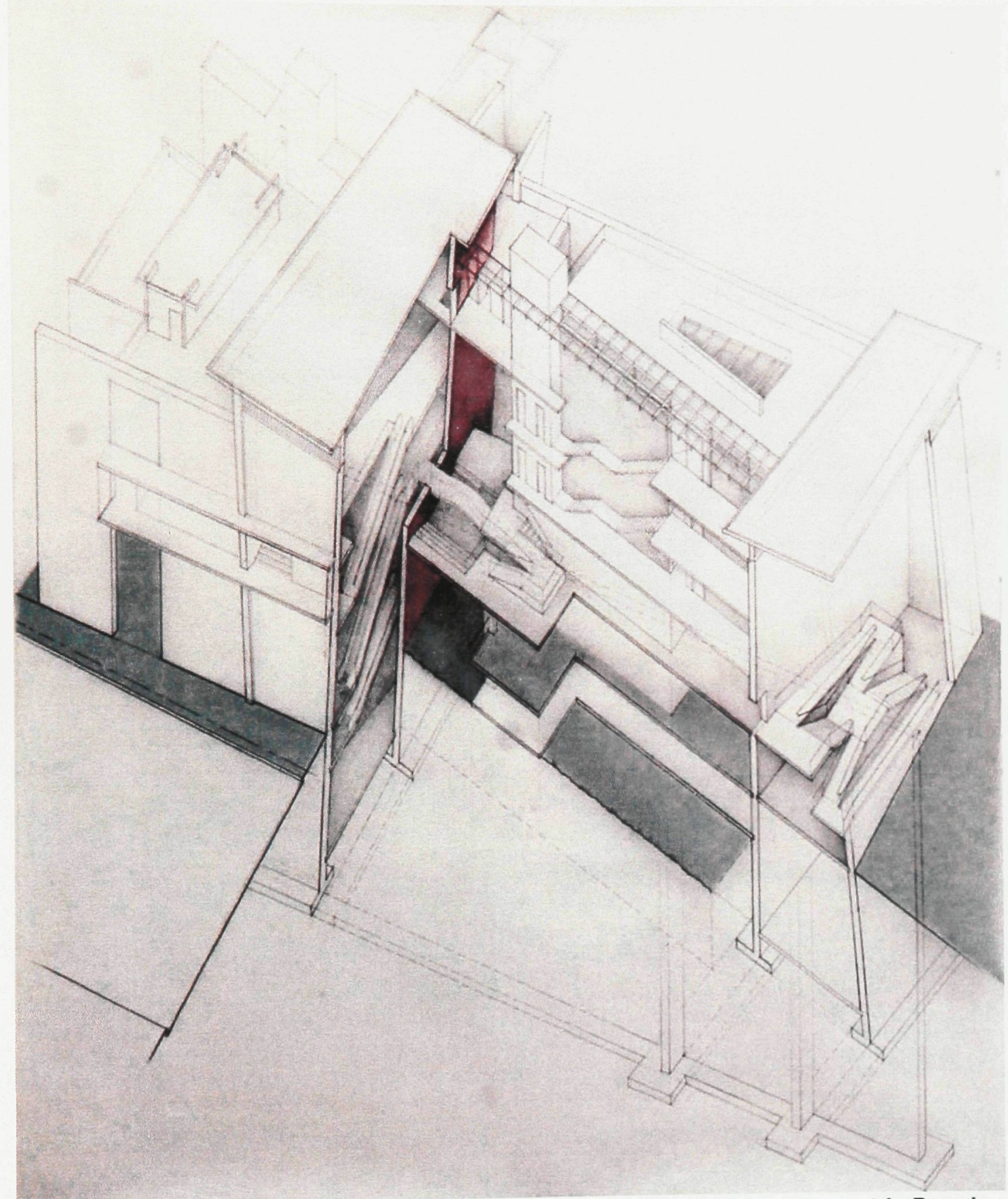

Plate 4.2: Axonometric Drawing

Graphite on vellum, with Canson coloured paper layered behind. $28^{\prime \prime} \times 24^{\prime \prime}$ 


\section{Perspective:}

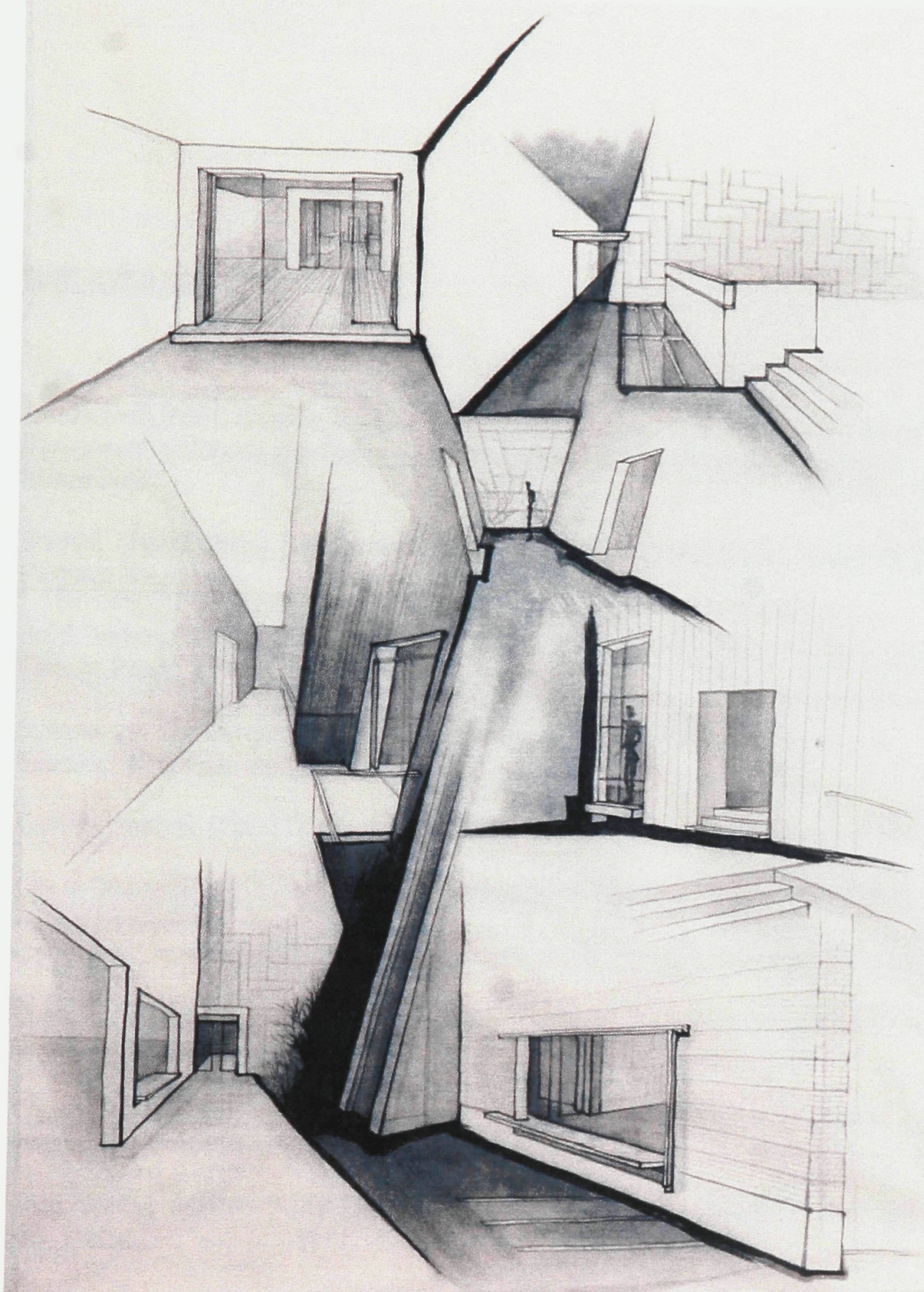

Plate 4.3: Perspective Drawing Chinese ink on rice paper. $32 "$ × $24^{\prime \prime}$ 


\section{七 BIBLIOGRAPHY:}

1. Bodde, Derk (1991) Chinese Thought, Society, and Science: The Intellectual and Social Background of Science and Technology in Pre-modern China. Honolulu: University of Hawaii Press.

2. Bonnett, Alastair (2004) The Idea of the West: Culture, Politics and History. New York: Palgrave Macmillan.

3. Boyd, Andrew (1962) Chinese Architecture 1500B.C. - A.D. 1911. Illinios: University of Chicago Press.

4. Buruma, lan, and Margalit, Avishai (2004) Occidentalism: The West in the Eyes of its Enemies. New York: Penguin Press.

5. Carrier, James G. (1995) Occidentalism: Images of the West. Oxford: Clarendon Press.

6. City of Ottawa (2005) "Table 1: Population of Canada's Six Largest Metropolitan Areas". Annual Development Report. 2005. <http://www.ottawa.ca/city_services/statistics/dev_report_2005/pdf/table_1_to_30_en.pdf>

7. Chen, XiaoMei (1995) Occidentalism: A Theory of Counter-Discourse in Post-Mao China. New York: Oxford University Press.

8. Cheng, François, and Jerome P. Seaton (1982) Chinese Poetic Writing. Bloomington: Indiana University Press.

9. Feng, Youlan, and Derk Bodde (1967) A Short History of Chinese Philosophy. New York: Free Press.

10. Fenollosa, Ernest Francisco, and Ezra Pound (1936) The Chinese Written Character as a Medium for Poetry. Edited by Ezra Pound. San Francisco: City Lights Books. 
11. Frascari, Marco (1982) "Professional Use of Signs in Architecture". JAE, Vol. 36, No. 2. (Winter, 1982): 16-23

12. Geertz, Clifford (1973) The Interpretation of Cultures. New York: Harper Collins/Basic Books.

13. Ginzburg, Carlo (1990) Myths, Emblems, Clues. Translated by John and Anne C. Tedeschi. UK: Hutchinson Radius.

14. Hall, Edward T (1990) The Hidden Dimension. New York: Anchor Books.

15. Hisamatsu, Shin'ichi (1971) Zen and the Fine Arts. Translated by Gishin Tokiwa. Japan: Kodansha International Ltd.

16. Hoizey, Dominique and Marie-Joseph (1993) A History of Chinese Medicine. Translated by Paul Bailey. Vancouver: UBC Press.

17. Huang, Evelyn (1992) Chinese Canadians: Voices from A Community. Vancouver: Douglas \& McIntyre Ltd.

18. James, Cary (1968) The Imperial Hotel: Frank Lloyd Wright and the Architecture of Unity. Japan: Charles E. Tuttle Company, Inc.

19. Jullien, Francois (2004) A Treatise on Efficacy: Between Western and Chinese Thinking, translated by Janet Lloyd. Honolulu: University of Hawaii Press.

20. Koolhass, Rem/OMA (2004) Content. Germany: Taschen.

21. Kuriyama, Shigehisa (1999) The Expressiveness of the Body and the Divergence of Greek and Chinese Medicine. New York: Zone Books.

22. Kuriyama, Shigehisa (2001) "The Case of Chinese Views of the Viscera". The Imagination of the Body and the History of Bodily Experience. Japan: International Research Center for Japanese Studies.

23. Leach, Neil (1997) Rethinking Architecture: a reader in cultural theory. New York: Routledge.

24. Lewellen, Ted (2002) The Anthropology of Globalization: Cultural Anthropology enters the $21^{\text {st }}$ Century. Connecticut: Bergin \& Harvey.

25. Lloyd, G.E.R. (1996) Adversaries and Authorities: Investigations into ancient Greek and Chinese science. Great Britain: Cambridge University Press.

26. Lloyd, G.E.R. and Sivin, Nathan (2002) The Way and the Word: Science and Medicine in early China and Greece. New Haven: Yale University Press. 
27. Li, Peter S. (1988) The Chinese in Canada. Canada: Oxford University Press

28. Lu, Gwei-Djen, and Needham, Joseph (1980) Celestial Lancets: A History and Rationale of Acupuncture and Moxa. New York: Cambridge University Press.

29. Nakayama, Shigeru, and Sivin, Nathan (1973) Chinese Science: Explorations of an Ancient Tradition. Cambridge, Massachusetts: The MIT Press.

30. Needham, Joseph (1971) Science and Civilisation in China (series). London: Cambridge University Press. Vol.3 - Cartography and Geography, Vol.4 - Civil Engineering and Building

31. Nitschke, Gunter (1993) From Shinto to Ando: Studies in Architectural Anthropology in Japan. Great Britain: Academy Editions.

32. Said, Edward (1979) Orientalism. New York: Vintage Books.

33. Said, Edward (1993) Culture and Imperialism. New York: Alfred A. Knopf.

34. Statistics Canada (2007) "2006 Census: Immigration, citizenship, language, mobility and migration". The Daily, 2007. Statistics Canada.

<htip://mm.statcan.ca/Daily/English/071204/d071204a.htm >

35. Tanizaki, Junichiro (1977) In Praise of Shadows. London: St. Edmundsbury Press.

36. Watts, Alan, and Al Chung-liang Huang (1977) Tao: The Watercourse Way. New York: Pantheon Books.

37. Wright, Frank Lloyd (1969) Frank Lloyd Wright: Writings and Buildings, selected by Edgar Kaufmann and Ben Raeburn. New York: Meridian Books.

38. Xue, Charlie Q. L. (2006) Building a Revolution: Chinese Architecture Since 1980. Hong Kong: Hong Kong University Press.

39. Zha, JianYing (1995) China pop: how soap operas, tabloids, and bestsellers are transforming a culture. New York: New Press.

40. Zhu, Jian Fei (1994) "A Celestrial BattleField: the Forbidden City and Beijing in late imperial China". AA Files, No. 28, (1994): 48-60.

41. Zhu, Jian Fei (2005) "Critically in between China and the West". The Journal of Architecture, Volume 10, Number 5, (2005): 479-498.

Chinese Sources:

42. Chinese Etymology. 2008, Richard Sears. < http://www internationalscientific org/ > 
43. Lao-tzu, Tao De Ching, translated by J.Legge (1891). Sacred Books of the East, Vol 39, 1891

44. Sunzi, The Art of War, translated by Giles, Lionel. M.A. 1910

45. 说文解字注. 2008, Gg-Art.Com NET TECH CO.LTD. < hittp:/Wwww.ggart.com/imgbook/index.php?bookid $=53$ >

... END 完 